
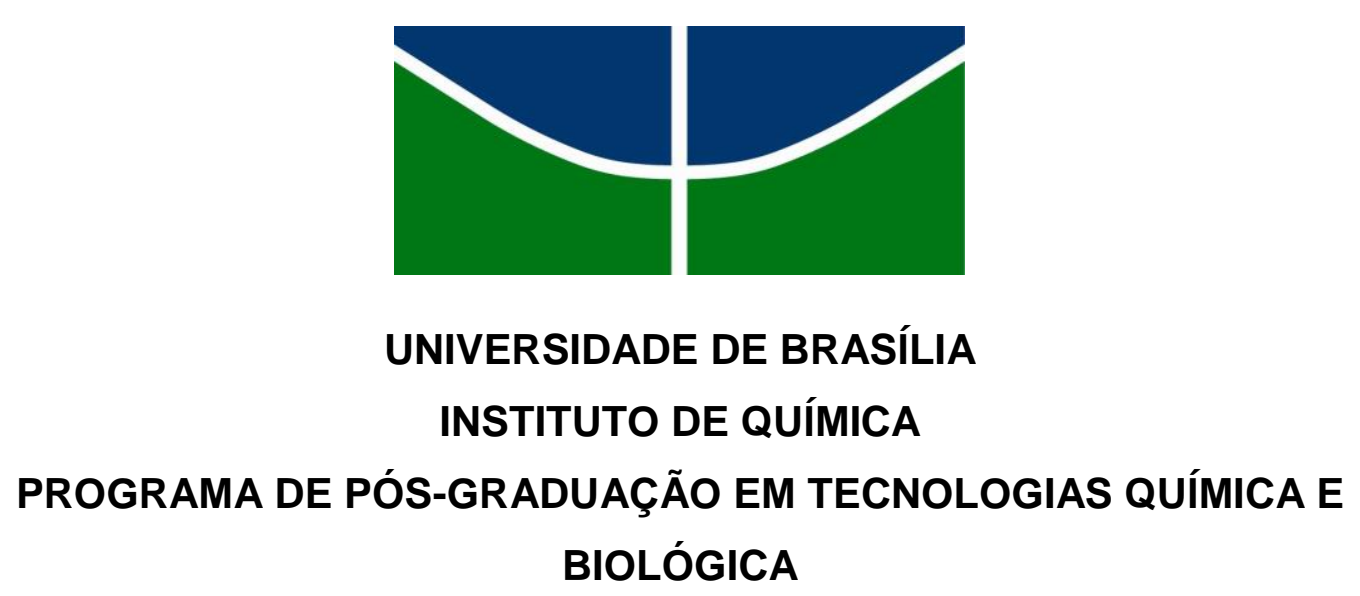

Camila de Lima Ribeiro

\title{
DETERMINAÇÃO ELETROANALÍTICA DE ÁCIDO SALICÍLICO EM PRODUTO DERMATOLÓGICO COM ELETRODOS DE NANOTUBOS DE CARBONO E NANOPARTÍCULAS DE ÓXIDO DE FERRO
}


Camila de Lima Ribeiro

\title{
DETERMINAÇÃO ELETROANALÍTICA DE ÁCIDO SALICÍLICO EM PRODUTO DERMATOLÓGICO COM ELETRODOS DE NANOTUBOS DE CARBONO E NANOPARTÍCULAS DE ÓXIDO DE FERRO
}

\begin{abstract}
Dissertação de Mestrado apresentada ao Programa de Pós-Graduação em Tecnologias Química e Biológica do Instituto de Química da Universidade de Brasília, na área de concentração Tecnologias Química, como requisito parcial para obtenção do título de Mestre em Tecnologias Química e Biológica.
\end{abstract}

Orientador: Prof. Dr. Jurandir Rodrigues de Souza Coorientador: Prof. Dr. Leonardo Giordano Paterno 


\section{FOLHA DE APROVAÇÃO}

Comunicamos a aprovação da Defesa de Dissertação de Mestrado

do (a) aluno (a) Camila de Lima Ribeiro, matrícula no 14/0115269, intitulada "Determinação Eletroanalítica de Ácido Salicílico em Produto Dermatológico com Eletrodos de Nanotubos de Carbono e Nanopartículas de Óxido de Ferro", apresentada no (a) Auditório Azul do Instituto de Química (IQ) da Universidade de Brasília (UnB) em 19 de fevereiro de 2016.

Prof. Dr. Jurandir Rodrigues de Souza Presidente de Banca (IQ/UnB)

Prof. Dr. Alexandre Fonseca Membro Titular (IO/UnB)

Prof. Dr. José Joaquin Linares Leon Membro Titular (IQ/UnB)

Profa Dra Marly Eiko Osugi Membro Suplente (IQ/UnB)

Em 19 de fevereiro de 2016. 


\section{Agradecimentos}

A Deus, razão de todas as coisas e a luz que nos faz vencer diante dos obstáculos. Sem a sua presença na minha vida, nada disso teria sentido.

Aos meus pais, Noeme de Lima e José de Sousa meus exemplos de vida, pelo apoio, compreensão, carinho, incentivo a nunca desistir dos meus sonhos e pelos esforços feitos para que eu tivesse uma educação de qualidade.

Ao meu querido companheiro Rubens Moreira pelo amor, carinho, paciência, incentivo e colaboração durante a realização deste trabalho.

À toda minha família que me orgulho de fazer parte, em especial meu irmão Roberval Ribeiro pelo apoio, ajuda e total disposição em contribuir sempre que precisei nessa trajetória e meu primo Antonio Filgueira pelo incentivo e palavras de apoio nos momentos difíceis que não me deixaram desistir desse objetivo.

À minhas amigas Tádila Alves, Elienay Cavalcante, Maryanne Barbosa, Josiene Silva, Euzedith Sousa, Djany Sousa, Prof. ${ }^{\underline{a}}$ Dr. ${ }^{\text {a }}$ Marta Célia Dantas, Fernanda Sodré, Nádia Alves e Mismeble Santos pelo incentivo e torcida para que conseguisse alcançar esse sonho. Esta caminhada não seria a mesma sem vocês.

Aos meus orientadores Prof. Dr. Jurandir Rodrigues de Souza e Prof. Dr. Leonardo Giordano Paterno, pela paciência, ensinamentos, incentivo, ideias e disposição em contribuir sempre que solicitados no desenvolvimento deste trabalho.

A todos os amigos do Laboratório de Química Analítica e Ambiental (LQAA) em especial Lourdes, Ariadna, Joelma, Naamã e João Guilherme pelos conhecimentos compartilhados e colaborações na realização deste trabalho.

Aos colegas do Laboratório de Polímeros (Labpol) em especial Amanda Costa e Priscila Rios por todas as contribuições.

Ao Prof. Dr. Jose Joaquin Linares por todas as colaborações quanto ao uso do potenciostato e por aceitar participar da banca examinadora, todas as suas dicas foram de fundamental importância.

Ao Prof. Dr. Alexandre Fonseca e à Prof..$^{a}$ Dr..$^{\underline{a}}$ Marly Osugi por aceitarem participar da banca examinadora dando suas contribuições para a melhoria da dissertação.

À CAPES pelo apoio financeiro com a bolsa de mestrado e ao Instituto de Química (IQ-UnB) por todos os serviços prestados. 


\section{Resumo}

Neste trabalho é descrito o desenvolvimento de uma metodologia eletroanalítica para determinação de ácido salicílico em produto dermatológico. Foram utilizados eletrodos preparados com automontagem camada por camada ou LbL, do inglês layer-by-layer, com a deposição de hidrocloreto de poli(dialildimetil amônio) (PDAC), nanotubos de carbono funcionalizados com ácido poliaminobenzeno sulfônico (NT-PABS) e nanopartículas de óxido de ferro (np-MAG) sobre o substrato ITO (do inglês, indium tin oxide) na sequência PDAC/NT-PABS/np-MAG/NT-PABS. O monitoramento da deposição foi controlada por espectros de absorção UV-vis, que demonstrou aumento linear da absorbância em função do número de tetracamadas depositadas ( $n$ ) em comprimentos de onda característicos das nanoestruturas utilizadas e imagens de microscopia de força atômica, que evidenciaram a presença de np-MAG nos eletrodos e aumento da espessura do filme com o aumento de $n$. Experimentos para caracterização eletroquímica dos eletrodos modificados foram realizados com ferricianeto de potássio $\left(\mathrm{K}_{3} \mathrm{Fe}(\mathrm{CN})_{6}\right)$ em $\mathrm{KCl}$ com as técnicas de voltametria cíclica e impedância eletroquímica, demonstrando principalmente que a presença de np-MAG nos eletrodos torna a transferência de elétrons mais rápida. $A$ Voltametria cíclica do ácido salicílico mostrou que na superfície do eletrodo ocorre principalmente um processo irreversível, com potencial de pico de oxidação em torno de 1,19 V. Esse pico foi utilizado para a quantificação do ácido salicílico com voltametria de pulso diferencial (DPV). Devida a contaminação do eletrodo com produtos formados na oxidação do ácido salicílico foi necessário condicionamento antes das leituras com metanol: água (1:10) e potencial de $-1 \mathrm{~V}$ por 60 segundos. Desta forma, 7 medidas consecutivas de ácido salicílico $5,8 \mu \mathrm{mol} \mathrm{L}{ }^{-1}$ em ácido acético $0,1 \mathrm{~mol} \mathrm{~L}^{-1}$, apresentou coeficiente de variação de $3 \%$. O método proposto apresentou faixa linear de trabalho de 0,6 a 46,3 $\mu_{\mathrm{mol} \mathrm{L}}^{-1}$ e limite de detecção e quantificação de $0,02 \mu \mathrm{mol} \mathrm{L}{ }^{-1}$ e $0,07 \mu \mathrm{mol} \mathrm{L}{ }^{-1}$ respectivamente. Os resultados obtidos na determinação de ácido salicílico em produto dermatológico comercial por cromatografia e DPV não apresentaram diferenças significativas a um nível de confiança de 95\%, esses resultados satisfatórios demonstram que o método desenvolvido é adequado para esse propósito. Palavras-chave: ácido salićlico, nanotubos de carbono, nanopartículas de óxido de ferro, voltametria. 


\begin{abstract}
This work describes the development of an electroanalytical methodology for determination of salicylic acid in dermatological product, electrodes were prepared with self-assembly layer by layer or LbL, with the deposition of poly(diallyldimethylammonium chloride) (PDAC), functionalized carbon nanotubes with poliaminobenzeno sulfonic acid (NT-PABS) and iron oxide nanoparticles (NP-MAG) on the ITO (indium tin oxide) substrate in the sequence PDAC / NT- PABS / np-MAG / NT-PABS. The monitoring of deposition was controlled by UV-vis absorption spectra, which showed linear increase in absorbance due to the number of deposited tetralayers ( $n$ ) at characteristic wavelengths of used nanostructures and images of atomic force microscopy, which showed the presence of np-MAG on the electrodes and increase of film thickness with increasing $\mathrm{n}$. Experiments for electrochemical characterization of modified electrodes were conducted with potassium ferricyanide $\left(\mathrm{K}_{3} \mathrm{Fe}(\mathrm{CN})_{6}\right)$ in $\mathrm{KCl}$ with cyclic voltammetry and electrochemical impedance, showing mainly the presence of np-MAG at the electrodes makes fast transfer of electrons. Cyclic voltammetry of salicylic acid showed that the electrode surface occurs mainly an irreversible oxidation process with a peak at around $1.19 \mathrm{~V}$. This peak was used to quantify the salicylic acid by differential pulse voltammetry (DPV). Due to contamination of electrode with products formed in the oxidation of salicylic acid conditioning it was necessary before the readings with methanol: water (1:10) and the potential of $-1 \mathrm{~V}$ for 60 seconds. The coefficient of variation for 7 consecutive measurements of salicylic acid $5.8 \mu \mathrm{mol} \mathrm{L}^{-1}$ in acetic acid $0.1 \mathrm{~mol} \mathrm{~L}^{-1}$ was $3 \%$. The proposed method showed a linear response range of the 0.6 to $46.3 \mu \mathrm{mol} \mathrm{L}^{-1}$ and

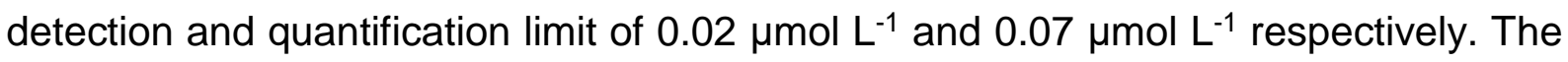
results obtained in the determination of salicylic acid in commercial dermatological product by chromatography and DPV showed no significant differences at a confidence level of $95 \%$, these satisfactory results show that the developed method is appropriate for this purpose.
\end{abstract}

Keywords: salicylic acid, carbon nanotubes, iron oxide nanoparticles, voltammetry. 


\section{Lista de Figuras}

Figura 1- Estrutura química do ácido salicílico.

Figura 2- Representação da cela eletroquímica utilizada nas medidas de voltametria.

Figura 3- (a) Sinal de excitação em voltametria cíclica. (b) Voltamograma cíclico de um processo reversível.

Figura 4 - Voltamogramas de um processo redox quasi-reversível (a) irreversível (b).

Figura 5- (a) Sinal de excitação em voltametria de pulso diferencial; (b) Voltamograma de pulso diferencial. 11

Figura 6- Esquema do método de automontagem via adsorção eletrostática. 13

Figura 7-Representação da estrutura de (a) Folha de grafeno, (b) SWCNT e (c) MWCNT

Figura 8- Estrutura da magnetita (a) Linha tracejada representa a cela unitária; (b) Modelo dos arranjos octaédricos e tetraédricos.

Figura 9- Preparo das nanopartículas de magnetita, (a) Gotejamento em $\mathrm{NaOH}$ da solução aquosa contendo íons de ferro; (b) Decantação das nanopartículas de magnetita; (c) Solução coloidal de nanopartículas de óxido de ferro. 21

Figura 10- (a) Estrutura do nanotubo de carbono funcionalizado com PABS. Fonte: site da Sigma Aldrich (2015). (b) Solução coloidal de nanotubos de carbono. .22

Figura 11- Esquema do preparo dos eletrodos por LbL. .....................................23 Figura 12 - (a) Substrato de ITO e eletrodos com (b) 1 (c) 3 (d) 5 (e) 7 e (f) 10 tetracamadas. .23

Figura 13- Sistema eletroquímico, (a) Potenciostato/Galvanostato; (b) Cela

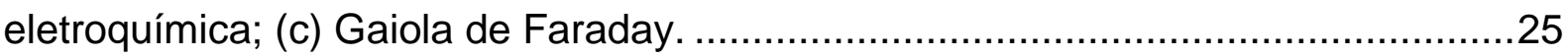

Figura 14- Cromatógrafo líquido com detecção UV-vis. .....................................26 Figura 15- Estrutura química, (a) ácido ascórbico; (b) ácido cinâmico; (c) ácido benzoico; (d) ácido p-hidroxibenzoico.

Figura 16- Fluxograma das metodologias comparadas na quantificação de ácido salicílico (AS) em produto dermatológico.

Figura 17- (a) Espectros de absorção Uv-vis das soluções de PDAC, np-MAG e NTPBAS; (b) e (c) Espectros de absorção Uv-vis dos eletrodos com 1, 3, 5, 7 e 10 
tetracamadas. Os gráficos inseridos mostram a relação linear entre absorbância e número de tetracamadas depositadas.

Figura 18- Imagens de AFM dos filmes com (a)1 (b) 3 (c) 5 (d) 7 (e)10 tetracamadas.

Figura 19- (a) Rugosidade e (b) espessura do filme em função do número de tetracamadas depositadas (n). 35

Figura 20- Voltamogramas cíclicos do ITO, eletrodos modificados com 1,3,5,7 e 10 tetracamadas (PDAC/NT-PABS/np-MAG/NT-PABS) e eletrodo com 5 bicamadas (PDAC/NT-PABS), na solução de $\mathrm{K}_{3} \mathrm{Fe}(\mathrm{CN})_{6} 1 \times 10^{-3} \mathrm{~mol} \mathrm{~L}^{-1} \mathrm{em} \mathrm{KCl} \mathrm{0,1} \mathrm{mol} \mathrm{L}^{-1}$, com velocidade de $25 \mathrm{mV} \mathrm{s}^{-1}$

Figura 21- Parâmetros eletroquímicos obtidos na voltametria cíclica de eletrodos com diferentes camadas na solução de $\mathrm{K}_{3} \mathrm{Fe}(\mathrm{CN})_{6} 1 \times 10^{-3} \mathrm{~mol} \mathrm{~L}^{-1} \mathrm{em} \mathrm{KCl} \mathrm{0,1} \mathrm{mol} \mathrm{L}^{-1}$, com velocidade de $25 \mathrm{mV} \mathrm{s}^{-1}$ (a) $\Delta \mathrm{E}$, (b) área eletroativa e (c) $\mathrm{ks}_{\mathrm{s}}$ 38

Figura 22- Voltamogramas cíclicos de $1 \times 10^{-3} \mathrm{~mol} \mathrm{~L}^{-1}$ de $\mathrm{K}_{3} \mathrm{Fe}(\mathrm{CN})_{6}$ em $0,1 \mathrm{~mol} \mathrm{~L}^{-1}$ de $\mathrm{KCl}$, nas velocidades de 25 a $200 \mathrm{mV} \mathrm{s}^{-1}$ com eletrodo de (a) ITO (b) 1 (c) 3 (d) 5 (e) 7 (f) 10 tetracamadas.

Figura 23- (a) Densidade de carga em função de $v^{1 / 2}$ (b) Diferença de potencial de picos anódicos e catódicos em função de log $v$.

Figura 24- Espectros de impedância eletroquímica, (a) $\mathrm{KCl}_{0,1} \mathrm{~mol} \mathrm{~L}^{-1}$; (b) $\mathrm{K} 3 \mathrm{Fe}(\mathrm{CN})_{6}$ $1 \times 10^{-3} \mathrm{~mol} \mathrm{~L}^{-1} \mathrm{em} \mathrm{KCl} \mathrm{0,1} \mathrm{mol} \mathrm{L}^{-1}$ 42

Figura 25- Circuito equivalente utilizado para ajuste dos dados de impedância. ....43 Figura 26- Voltamogramas cíclicos do ITO, eletrodos modificados com 1,3,5,7 e 10 tetracamadas (PDAC/NT-PABS/np-MAG/NT-PABS) e eletrodo com 5 bicamadas (PDAC/NT-PABS), na solução de ácido salićlico em concentração de $50 \mu \mathrm{mol} \mathrm{L}^{-1} \mathrm{em}$ ácido acético $0,1 \mathrm{~mol} \mathrm{~L}^{-1}$, com velocidade de $25 \mathrm{mV} \mathrm{s}^{-1}$ .45

Figura 27- Esquema de oxidação do ácido salicílico na superfície do eletrodo, (1) ácido 2,5-di-hidroxibenzoico; (2) ácido 2,3-di-hidroxibenzoico.

Figura 28- Voltamograma cíclico do ácido salicílico $2,5 \times 10^{-3} \mathrm{~mol} \mathrm{~L}^{-1} \mathrm{em}$ ácido acético $0,1 \mathrm{~mol} \mathrm{~L}^{-1}$ na velocidade de $25 \mathrm{mV} \mathrm{s}^{-1}$ (a) 1- primeira medida, 2- segunda medida; (b) Varredura de 0,3 a $0,8 \mathrm{~V}$ do primeiro ciclo.

Figura 29- Voltamograma cíclico do ácido acético $0,1 \mathrm{~mol} \mathrm{~L}^{-1}$ (branco) e do AS em ácido acético $0,1 \mathrm{~mol} \mathrm{~L}^{-1}$ em diferentes concentrações, na velocidade de $25 \mathrm{mV} \mathrm{s}^{-1} 49$ 
Figura 30- (a) Voltamograma de pulso diferencial na primeira leitura, segunda leitura e após realização de condicionamento por 120 segundos, (b) Densidades de corrente do pico de oxidação do ácido salićílico na concentração de $5,8 \mu \mathrm{mol} \mathrm{L}^{-1}$ em tampão acetato de amônio $0,1 \mathrm{~mol} \mathrm{~L}^{-1}, \mathrm{pH} 3,5 \mathrm{com}$ amplitude de pulso de $50 \mathrm{mV}$ e velocidade de $5 \mathrm{mV} \mathrm{s}^{-1}$ em função do tempo de condicionamento. 50

Figura 31- (a) Voltamograma de pulso diferencial do ácido salicílico $5,8 \mu \mathrm{mol} \mathrm{L}^{-1}$, em tampão RB $0,1 \mathrm{~mol} \mathrm{~L}^{-1}$ nos diferentes $\mathrm{pH}$ com amplitude de pulso de $25 \mathrm{mV}$ e velocidade de $5 \mathrm{mV} \mathrm{s}^{-1}$, (b) Densidades de corrente de pico em função do $\mathrm{pH}$.

Figura 32- Densidade de corrente de pico da oxidação de ácido salicílico $5,8 \mu \mathrm{mol} \mathrm{L}$ 1 nos eletrólitos: tampões citrato e RB com pH 2,5, ácido sulfúrico $\mathrm{pH} 1$, ácido acético pH 2,9, tampões acetato de amônio e de sódio pH 3,5, todos na concentração de 0,1 mol L-1 com amplitude de pulso de $25 \mathrm{mV}$ e velocidade de $5 \mathrm{mV} \mathrm{s}^{-1}$. .52

Figura 33- Voltamogramas de pulso diferencial de ácido salić́lico $5,8 \mu \mathrm{mol} \mathrm{\textrm {L } ^ { - 1 }} \mathrm{em}$ ácido acético nas diferentes concentrações com amplitude de pulso de $25 \mathrm{mV}$ e velocidade de varredura de $5 \mathrm{mV} \mathrm{s}^{-1}$. .53

Figura 34- Voltamograma de pulso diferencial de ácido salicílico $5,8 \mu \mathrm{mol} \mathrm{L}^{-1} \mathrm{em}$ ácido acético $0,1 \mathrm{~mol} \mathrm{~L}^{-1}$ com diferentes velocidades e amplitude de pulso de $25 \mathrm{mV}$.......54

Figura 35- (a) Densidade de corrente de pico em função da amplitude de pulso, (b) Voltamograma de pulso diferencial de ácido salićlico $5,8 \mu \mathrm{mol} \mathrm{L}^{-1} \mathrm{em}$ ácido acético $0,1 \mathrm{~mol} \mathrm{~L}^{-1} \mathrm{em}$ diferentes amplitudes de pulso e velocidade de varredura de $5 \mathrm{mV} \mathrm{s}^{-1}$.

Figura 36- Voltamogramas de pulso diferencial de 7 medidas consecutivas de ácido salić́lico $5,8 \mu \mathrm{mol} \mathrm{L}{ }^{-1} \mathrm{em}$ ácido acético $0,1 \mathrm{~mol} \mathrm{~L}^{-1}$ com amplitude de pulso de $50 \mathrm{mV}$ e velocidade de varredura $5 \mathrm{mV} \mathrm{s}^{-1}$ .56

Figura 37- Densidades de corrente de pico na oxidação do ácido salicílico na concentração de 5,8 $\mu \mathrm{mol} \mathrm{L}^{-1}$ em ácido acético $0,1 \mathrm{~mol} \mathrm{~L}^{-1}$ com amplitude de pulso de $50 \mathrm{mV}$ e velocidade de varredura $5 \mathrm{mV} \mathrm{s}^{-1}$ em função do número de leituras consecutivas.

Figura 38- Densidades de corrente de pico de oxidação em função das concentrações de ácido salicílico (a) 0,1 (b) 0,3 (c) 0,6 (d) 1,2 (e) 1,7 (f) 2,3 (g) 2,9 (h) 5,8 (i) 11,6 (j) 23,2 (k) 46,3 (I) 92,7 (m)185,3 $\mu \mathrm{mol} \mathrm{L}^{-1}$ em ácido acético 0,1 $\mathrm{mol} \mathrm{L}^{-1}$ (amplitude de pulso de $50 \mathrm{mV}$ e velocidade de varredura $5 \mathrm{mV} \mathrm{s}^{-1}$ ) .59 
Figura 39- Voltamograma de pulso diferencial do ácido salicílico nas concentrações de (a) 0,6 (b) 1,2 (c) 1,7 (d) 2,3 (e) 2,9 (f) 5,8 (g) 11,6 (h) 23,2 (i) 46,3 $\mu \mathrm{mol} \mathrm{L}^{-1} \mathrm{em}$ ácido acético $0,1 \mathrm{~mol} \mathrm{~L}^{-1}$, com amplitude de pulso de $50 \mathrm{mV}$ e velocidade de varredura $5 \mathrm{mV} \mathrm{s}^{-1}$. Inserido a curva analítica (densidade de corrente de pico versus concentração de ácido salicílico)

Figura 40- Espectros de UV-vis do ácido salicílico $8,7 \mu \mathrm{mol} \mathrm{L}^{-1} \mathrm{em}$ diferentes fases móveis. 61

Figura 41- Área do pico em função do padrão de ácido salicílico nas concentrações 0,7 a $868,8 \mu \mathrm{mol} \mathrm{L}-1$ 62

Figura 42- (a) Cromatogramas do ácido salicílico nas diferentes concentrações (inserido a curva analítica) (b) Cromatograma do ácido salicílico na amostra. 63 Figura 43- (a) Voltamograma de pulso diferencial (1) da amostra, (2) amostra + 2,9 $\mu \mathrm{mol} \mathrm{L}{ }^{-1}$, (3) amostra $+5,8 \mu \mathrm{mol} \mathrm{L}-1,(4)$ amostra $+8,7 \mu \mathrm{mol} \mathrm{L}^{-1}$ de ácido salicílico em ácido acético $0,1 \mathrm{~mol} \mathrm{~L}^{-1}$, com amplitude de pulso de $50 \mathrm{mV}$ e velocidade de varredura $5 \mathrm{mV} \mathrm{s}^{-1}$ 64 


\section{Lista de tabelas}

Tabela 1- Valores de parâmetros analíticos na detecção de ácido salicílico com

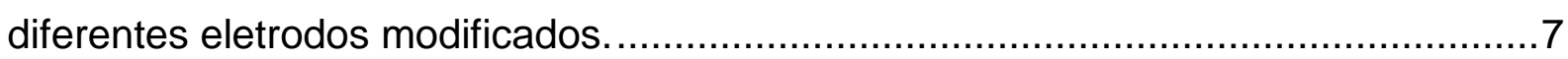

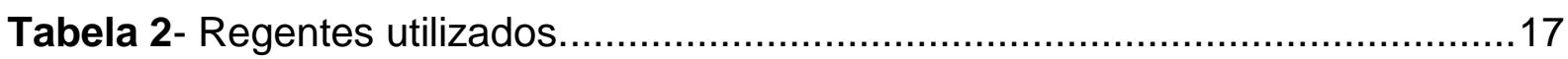

Tabela 3- Parâmetros de ajuste para a resposta de impedância dos eletrodos ITO, (1) PDAC/NT-PABS, (2) PDAC/NT-PABS/np-MAG/NT-PABS. ...............................44

Tabela 4- Densidade de pico de oxidação do ácido salicílico e tempo de preparo dos diferentes eletrodos............................................................................... 46

Tabela 5- Parâmetros de voltametria de pulso diferencial. .................................56

Tabela 6- Erro relativo entre as densidades de corrente da oxidação do ácido salicílico sem e com a presença dos interferentes nas diferentes concentrações. .58

Tabela 7- Área do pico e tempo de retenção dos cromatogramas de ácido salicílico na concentração de $87 \mu \mathrm{mol} \mathrm{L} \mathrm{L}^{-1}$ 62

Tabela 8- Valores da concentração de ácido salićlico encontrado no produto dermatológico por HPLC/UV-vis e DPV. .65 


\section{Lista de abreviaturas e siglas}

AFM

ANVISA

AS

CV

CPE

DAD

DPV

EIS

GCE

GC

HPLC

INMETRO

ITO

ks

LbL

LD

LQ

MS

MWCNT

np-MAG

NT-PABS

PDA

PDAC

RGO

RB

SWCNT

UV-vis
Microscopia de Força Atômica

Agência Nacional de Vigilância Sanitária

Ácido salicílico

Voltametria cíclica

Eletrodo de pasta de carbono

Detector com arranjo de diodos

Voltametria de pulso diferencial

Espectroscopia de impedância eletroquímica

Eletrodo de carbono vítreo

Cromatografia gasosa

Cromatografia líquida de alta eficiência

Instituto nacional de metrologia, qualidade e tecnologia

Óxido de estanho dopado com índio

Constante aparente de taxa de transferência de elétrons

Automontagem camada por camada

Limite de detecção

Limite de Quantificação

Espectrometria de massa

Nanotubos de carbono de parede múltiplas

Nanopartículas de óxido de ferro

Nanotubos de carbono funcionalizado com ácido

poliaminobenzeno sulfônico

Detector de arranjos de fotodiodos

Hidrocloreto de poli(dialildimetil amônio)

Óxido de grafeno reduzido

Tampão Robinson-Britton

Nanotubos de carbono de parede simples

Ultravioleta-visível 
1. INTRODUÇÃO

2. OBJETIVOS

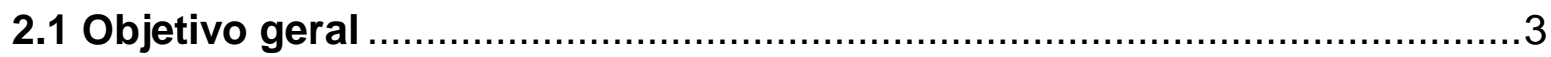

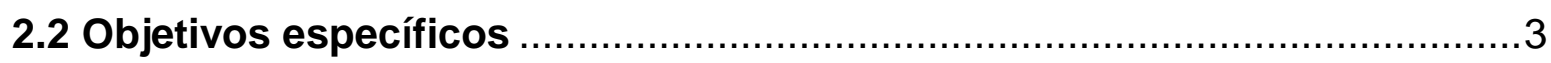

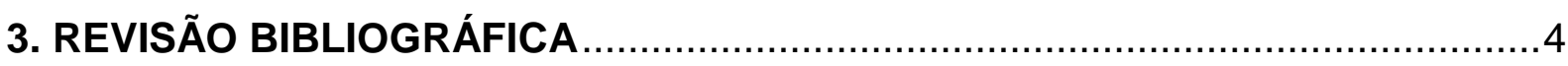

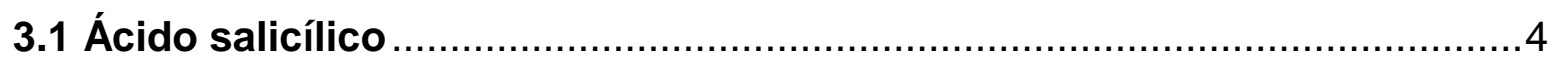

3.2 Métodos de determinação de ácido salicílico ….....................................

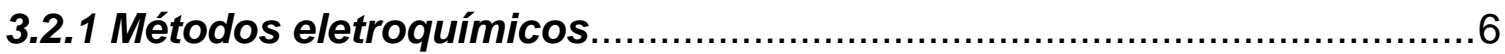

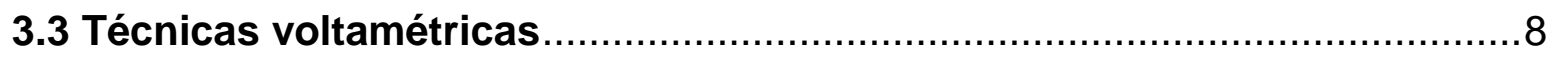

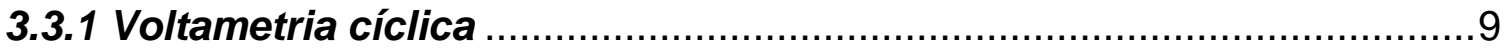

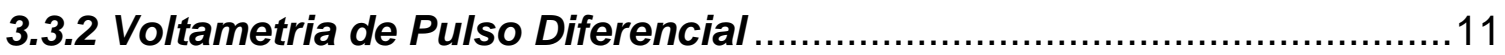

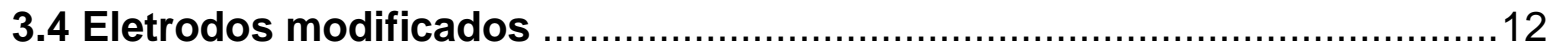

3.4.1 Deposição via Automontagem camada por camada (LbL) .................12

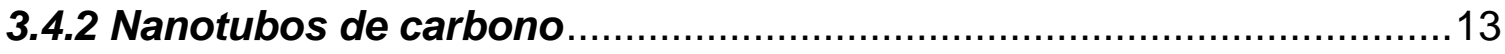

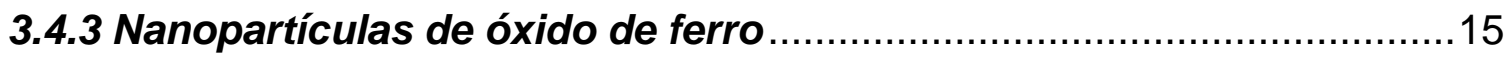

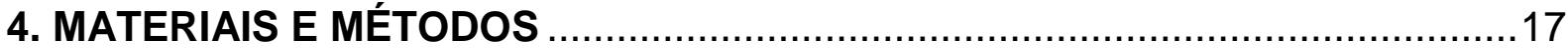

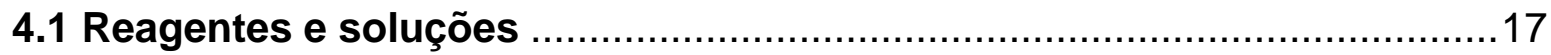

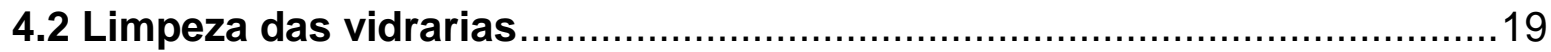

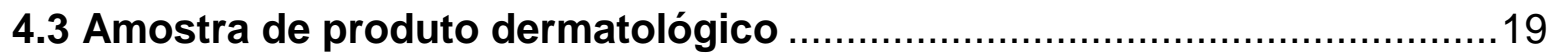

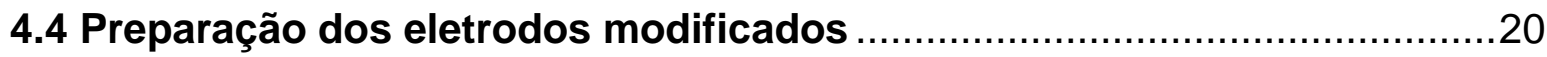

4.4.1 Limpeza do substrato de vidro condutor .........................................20

4.4.2 Preparo das nanopartículas de magnetita e dos nanotubos de carbono .

4.4.3 Deposição dos nanomateriais sobre vidro condutor via $L b L \ldots \ldots \ldots \ldots . . .22$

4.4 Estudos da deposição e estrutura dos eletrodos modificados .................23

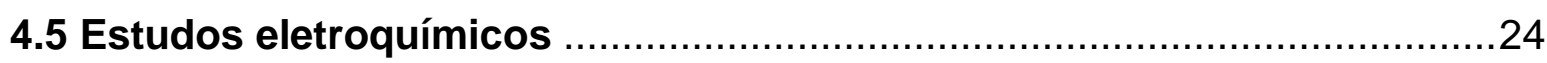

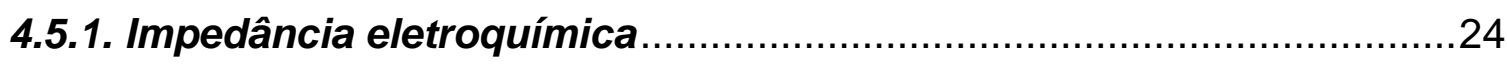

4.5.2 Voltametria cíclica e de pulso diferencial.........................................24

4.6 Cromatografia líquida de alta eficiência (HPLC) …................................26

4.7 Parâmetros de validação de metodologia ..............................................27

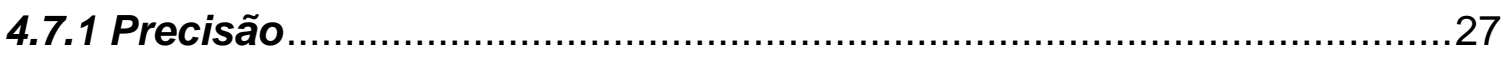

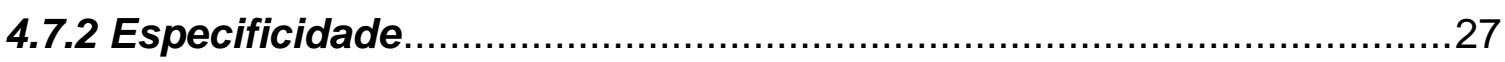

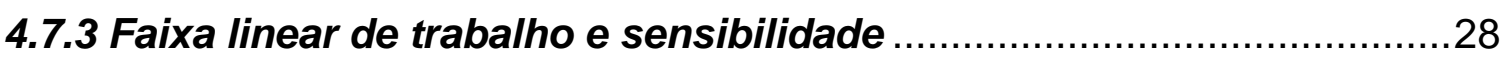




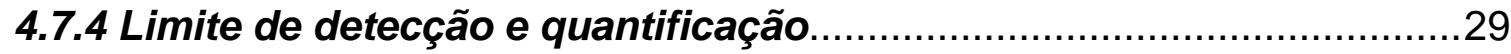

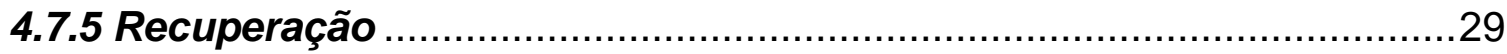

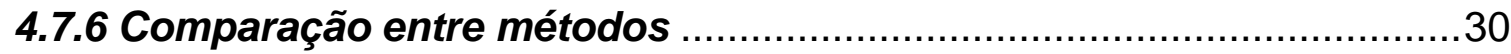

5. RESULTADOS E DISCUSSÃO

5.1 Modificação e caracterização estrutural dos eletrodos ...........................32

5.1.1 Monitoramento da adsorção dos Nanomateriais por Espectroscopia de

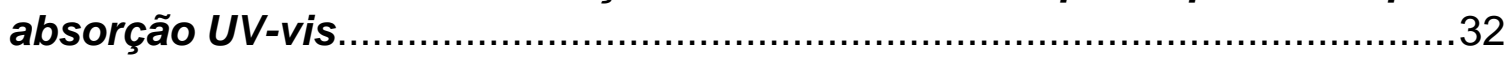

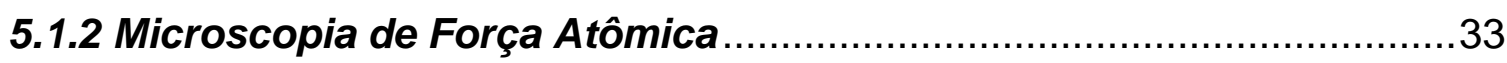

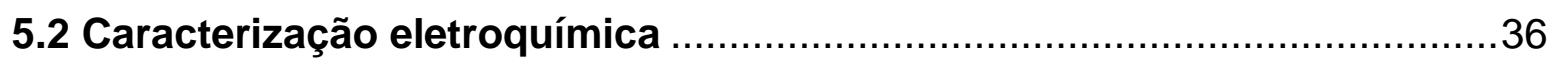

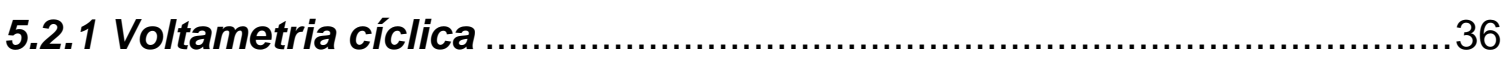

5.2.2 Impedância eletroquímica........................................................... 42

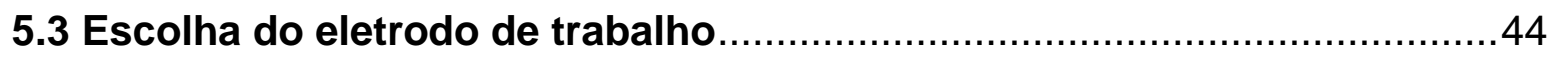

5.4 Comportamento eletroquímico do ácido salicílico na superfície do eletrodo .46

5.5 Otimização dos parâmetros na voltametria de pulso diferencial ..............49

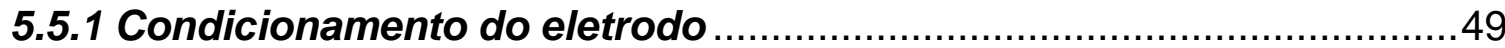

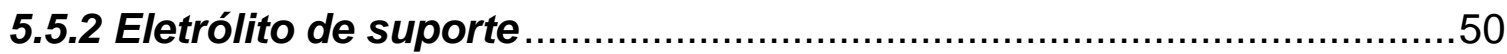

5.5.3 Velocidade de varredura e amplitude de pulso.....................................53

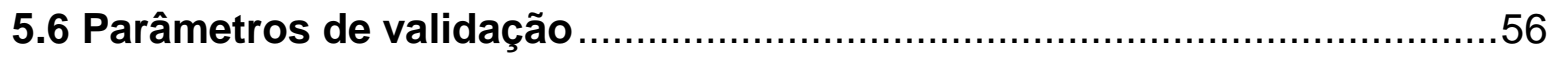

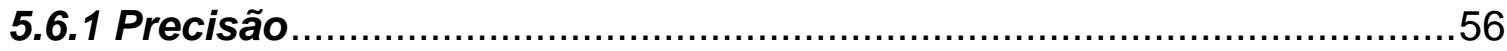

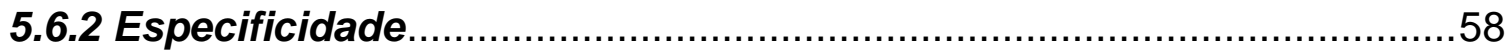

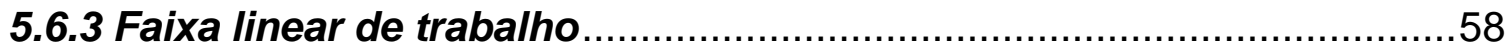

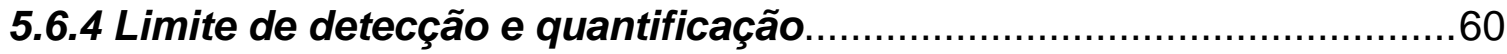

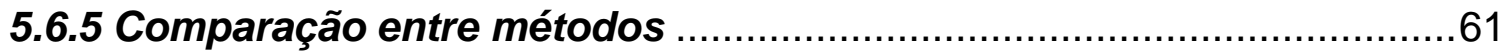

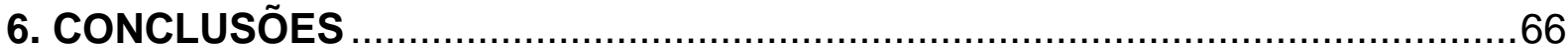

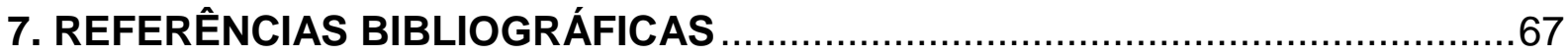




\section{INTRODUÇÃO}

Desde tempos antigos, são relatadas as prescrições de medicamentos derivados de plantas contendo salicilatos, sendo encontradas em documentos egípcios datados de cerca de 1500 anos antes de Cristo e vários anos mais tarde (cerca de 400 anos antes de Cristo) Hipócrates usou pó de casca de salgueiro para aliviar dores. $O$ ingrediente ativo da casca de salgueiro foi identificado por Leroux em 1829, que ele chamou de salicina, enquanto o ácido salićílico foi sintetizado em 1860. Anos depois, o ácido acetilsalicílico foi sintetizado por Hoffman e posteriormente recebeu o nome de marca, aspirina (CAZALS, 2000).

No início do século $X X$, a aspirina foi amplamente reconhecida por suas propriedades antipirética, analgésica e anti-inflamatória (CAZALS, 2000). A ingestão oral do ácido salicílico, princípio ativo da aspirina, gera irritação do estômago e muitos outros efeitos adversos gastrointestinais, que é a razão pela qual não pode ser usada diretamente como medicamento e a utilização de derivados é recomendada (PULGARÍN et al., 2011).

No entanto, o ácido salicílico é comumente utilizado como agente de terapia externa no tratamento de doenças da pele como acne, calos e psoríase (PULGARín et al., 2011). Porém, quando administrado em altas concentrações ele pode causar graves irritações na pele e ser absorvido pelo organismo provocando o salicilismo, síndrome de toxicidade que se desenvolve quando concentrações de salicilato no sangue são maiores que $0,35 \mathrm{mg} \mathrm{mL}^{-1}$. Os sintomas do salicilismo incluem náuseas, vómitos, tonturas, delírio, psicose, estupor podendo ocasionar até a morte do indivíduo contaminado (MADAN; LEVITT, 2014).

Devido a possibilidade de provocar essas reações adversas, a Resolução da ANVISA no 79 , de 28 de agosto de 2000 , delimita a concentração máxima permitida no produto final em $2 \%$ para produtos de tratamento de acne e $3 \%$ para produtos de combate a caspa.

Portanto, é importante o desenvolvimento de métodos confiáveis para o controle de qualidade desses produtos. O método para a determinação do ácido salicílico, disponível nas Farmacopeias Brasileira e Britânica é a volumetria de neutralização, método que tem como principal desvantagem a baixa precisão se comparado com os métodos instrumentais. Outros métodos são relatados na literatura 
como a espectrometria e a cromatografia (MEDINA et al., 2001; YOUSSEF et al., 2014).

O desenvolvimento de métodos eletroanalíticos para o controle de qualidade de produtos diversos (medicamentos, cosméticos, alimentos, bebidas) tem se intensificado nos últimos anos por causa de sua operação simples, resposta rápida, economia de tempo e baixo custo. A tendência atual nas pesquisas é a procura de eletrodos que confiram aos métodos melhor reprodutibilidade, sensibilidade e estabilidade (MORAES et al., 2011).

A modificação de eletrodos é uma prática já consagrada mas longe ainda da exaustão para aumentar o desempenho dos métodos eletroanalíticos. Em particular, nanotubos de carbono e nanopartículas de óxido de ferro por exemplo, têm sido referidos como materiais que aumentam a sensibilidade de eletrodos utilizados na quantificação de diversas espécies químicas. Essa melhora é principalmente atribuída ao aumento da área superficial que esses nanomateriais proporcionam aos eletrodos modificados e que, consequentemente, provoca o aumento da velocidade de transferência de elétrons, conferindo atividade catalítica em processos redox (LU et al., 2014; FERNANDES et al., 2014). Neste sentido, este trabalho propõe a modificação de eletrodos com esses nanomateriais para a determinação eletroquímica de ácido salicílico em produto dermatológico. 


\section{OBJETIVOS}

\subsection{Objetivo geral}

Este trabalho teve como objetivo geral, desenvolver e validar um método eletroanalítico, utilizando eletrodos modificados com nanotubos de carbono e nanopartículas de óxido de ferro, para a determinação de ácido salicílico em produto dermatológico.

\subsection{Objetivos específicos}

- Desenvolver metodologia para a modificação controlada dos eletrodos com nanotubos de carbono e nanopartículas de óxido de ferro;

$>$ Otimizar os parâmetros da voltametria de pulso diferencial para obtenção de melhor resposta do método;

> Validar a metodologia desenvolvida;

> Quantificar o ácido salicílico presente em uma amostra de produto dermatológico comercial. 


\section{REVISÃO BIBLIOGRÁFICA}

\section{1 Ácido salicílico}

O ácido salicílico (AS) ou ácido 2-hidroxibenzoico é um metabólito secundário de plantas com estrutura fenólica representada na Figura 1, sendo gerado principalmente a partir da via fenilpropanóide, por meio da oxidação do ácido cinâmico e a hidroxilação subsequente do ácido benzóico resultante (DUTHIE; WOOD, 2011).

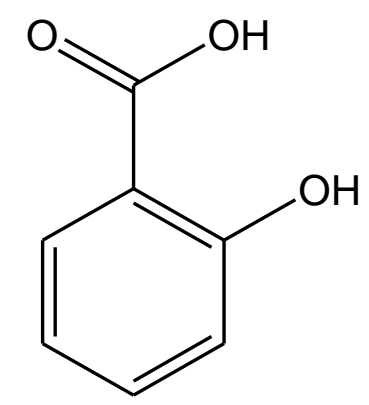

Figura 1- Estrutura química do ácido salicílico.

Nas plantas, esse composto atua como molécula de sinalização endógena, com papel importante na regulação de muitos processos fisiológicos como a floração, germinação de sementes e fechamento dos estômatos (WANG et al., 2010). Portanto, é encontrado em diversas espécies vegetais, inclusive de consumo humano.

A ingestão de AS em altas concentrações, pode causar graves irritações do estômago e, em consequência disso, desde o século passado ele é usado na síntese de ácido acetilsalicílico, que com menos efeitos adversos tem potencial analgésico e anti-inflamatório. Mais recentemente, estudos demonstraram sua eficiência para a prevenção de doenças cardiovasculares e de vários tipos de câncer (KAISER, 2012; RAJU et al., 2011).

Muito usado em produtos dermatológicos por sua ação queratolítica, bacteriostática, fungicida e propriedades fotoprotetoras, o ácido salicílico é um dos princípios ativos empregados em formulações de peelings químicos, tratamento de verrugas, calos, acne e psoríase, provocando principalmente o aumento da eliminação de células afetadas, na camada mais externa da pele (MADAN; LEVITT, 2014; PULGARÍN et al., 2011). 


\subsection{Métodos de determinação de ácido salicílico}

Diversas técnicas são propostas na literatura para a determinação de AS em diferentes amostras, como cromatografia líquida de alta eficiência (HPLC), espectrometria de absorção UV-vis, cromatografia gasosa com espectrometria de massa (GC-MS) e espectrometria de fluorescência. A cromatografia é umas das técnicas analíticas mais utilizadas na análise de ácido salicílico, por ter como principal vantagem a separação dos compostos interferentes, tornando a detecção mais específica e mais eficiente.

HPLC com detector de arranjo de diodos (DAD), foi utilizada na determinação de AS em pomada para tratamento de doenças da pele, com limite de deteç̧ão de $4 \times 10^{-3} \mathrm{mg} \mathrm{mL}^{-1}$ e faixa linear de trabalho de 0,012 a $0,75 \mathrm{mg} \mathrm{mL}^{-1}$, enquanto o tempo de retenção necessário foi de aproximadamente 1,7 minutos em coluna C8 $(150 \mathrm{~mm}$ x 4,6 mm, $5 \mu \mathrm{m}$ ) com metanol e tampão fosfato aquoso $0,02 \mathrm{~mol} \mathrm{~L}^{-1}, \mathrm{pH} 2,3$ (70:20) como fase móvel, o que mostra que a técnica é rápida. No entanto, a extração demandou mais tempo de análise, sendo realizada com solventes orgânicos para separação dos ácidos graxos da pomada (YOUSSEF et al., 2014).

Amostra de pomada farmacêutica também foi analisada por HPLC para quantificação de AS, porém com detector de arranjos de fotodiodos (PDA). O tempo de retenção requerido nesta técnica foi de 1,7 minutos utilizando uma coluna C18 (250 $\mathrm{mm} \times$ 4,6 mm, $5 \mu \mathrm{m}$ ) e acetonitrila:metanol:água (50:20:30 v/v/v) como fase móvel, porém a faixa linear de trabalho $\left(0,26\right.$ a $\left.0,38 \mathrm{mg} \mathrm{mL}^{-1}\right)$, apresentou o menor valor bem acima dos observados na técnica anterior, tornando assim o método limitado a amostras mais concentradas. O limite de detecção não é mencionado (SHEIKH et al., 2012).

Huang et al. (2015), realizaram a quantificação de AS em plantas para o estudo

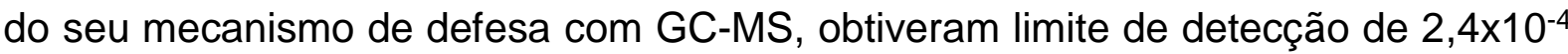
$\mathrm{mg} \mathrm{mL}^{-1}$ e tempo de retenção de 11,84 minutos e portanto, mais demorada que as técnicas de HPLC descritas anteriormente.

Espectrometria de absorção UV-vis foi utilizada na determinação de AS em produtos dermatológicos e comprimidos, obtendo-se uma faixa linear de trabalho de $1 \times 10^{-3}$ a $20 \times 10^{-3} \mathrm{mg} \mathrm{mL}^{-1}$ e limite de detecção de $6,4 \times 10^{-5} \mathrm{mg} \mathrm{mL}^{-1}$, valores esses suficientes para análise de fármacos. No entanto, esse método apresentou 
interferência significativa de ácido ascórbico, sacarina, paracetamol, Cu(II) e benzocaína, espécies que podem estar presentes em preparações farmacêuticas com ácido salicílico (MEDINA et al., 2001).

Pulgarín et al. (2011), desenvolveram um método de determinação de AS em fluídos biológicos (soro e urina humana), baseado em extração líquido-líquido com clorofórmio, após as amostras serem acidificadas com ácido clorídrico. A detecção foi realizada com a técnica de espectrometria de fluorescência. Nesse estudo os autores obtiveram resultados de $96,2 \%$ para a recuperação e $8,2 \times 10^{-6} \mathrm{mg} \mathrm{mL}^{-1}$ como limite de detecção. O método mostrou uma extração eficiente, e com limite de detecção abaixo dos outros métodos discutidos anteriormente.

De um modo geral, os métodos descritos são suficientemente eficientes para determinações realizadas em laboratório, apesar de exigirem o uso de equipamentos sofisticados e de alto custo, operados por usuários treinados. Na maioria dos casos, não podem ser fabricados em versões portáteis o que impossibilita a realização de medidas em campo. Além disso, técnicas como a cromatografia necessitam de gases de custo elevado ou grandes quantidades de solventes orgânicos, gerando resíduos nocivos ao meio ambiente.

\subsubsection{Métodos eletroquímicos}

Os métodos eletroquímicos têm mostrado ser uma alternativa interessante para os métodos apresentados no tópico anterior, com diversos trabalhos desenvolvidos usando eletrodos modificados com nanomateriais para a detecção de ácido salicílico.

Eletrodo de trabalho modificado com nanotubos de carbono e Nafion ${ }^{\circledR}$ (MWCNT/Nafion) e operado com voltametria de pulso diferencial, apresentou bom desempenho no monitoramento in situ da concentração de ácido salicílico, em folhas de tomate, com a finalidade de estudar o mecanismo de defesa das plantas. Os resultados foram validados pelos autores usando HPLC-MS/MS como método referência, apresentando valores consistentes em ambos os métodos (SUN et al., 2014).

Doulache et al. (2014), obtiveram boa resposta na detecção de ácido salicílico em comprimidos de aspirina utilizando a técnica de amperometria com eletrodo de carbono vítreo modificado eletroquimicamente com níquel por redução (Ni/GCE). O 
comprimido de aspirina foi submetido a um tratamento com hidróxido de sódio, para hidrolisar o ácido acetilsalicílico a ácido salicílico, sendo realizada portanto, a quantificação indireta de ácido acetilsalicílico nos comprimidos. O eletrodo utilizado nos experimentos mostrou estabilidade com coeficiente de variação de $3 \%$ entre as medidas.

Titanato de níquel foi utilizado por Ghoreishi et al. (2015) para modificação de eletrodo de pasta de carbono $\left(\mathrm{NiTiO}_{3} / \mathrm{CPE}\right)$, e mostrou resultados satisfatórios na quantificação de AS em plantas de aloe vera, com a técnica de voltametria de pulso diferencial. A repetitividade na preparação dos eletrodos foi assegurada na realização de experimentos com 5 eletrodos, obtendo coeficiente de variação de 1,3 a 4,5 \% na detecção de ácido salicílico.

Pomadas e comprimidos foram analisados para quantificar ácido salicílico com a técnica de amperometria, utilizando eletrodo de carbono vítreo modificado com hexacianoferrato de lutécio e óxido de grafeno reduzido (LuHCF/RGO). O coeficiente de variação para 5 medidas individuais foi de $4,5 \%$ e o método proposto pelos autores não teve interferências significativas na presença de ácido ascórbico, dopamina, ácido úrico, glicose e paracetamol (DEVADAS et al., 2014).

O limite de detecção e a faixa linear de trabalho para os métodos citados são apresentados na Tabela 1.

Tabela 1- Valores de parâmetros analíticos na detecção de ácido salicílico com diferentes eletrodos modificados.

\begin{tabular}{c|c|c}
\hline Eletrodos modificados & $\begin{array}{c}\text { Limite de detecção } \\
(\mu \mathrm{mol} \mathrm{L}-1)\end{array}$ & $\begin{array}{c}\text { Faixa linear de trabalho } \\
\left.(\mu \mathrm{mol} \mathrm{L})^{-1}\right)\end{array}$ \\
\hline \hline $\mathrm{MWCNT/Nafion}$ & 0,05 & 0,5 a 100 \\
\hline $\mathrm{Ni} / \mathrm{GCE}$ & 0,5 & 2 a 550 \\
\hline $\mathrm{NiTiO} / \mathrm{CPE}$ & 0,068 & 3 a 1000 \\
\hline $\mathrm{LuHCF} / \mathrm{RGO}$ & 0,49 & 5 a 1000 \\
\hline \hline
\end{tabular}

Portanto, fica evidente a versatilidade dos métodos eletroquímicos, com possibilidades de detecção do ácido salicílico em várias amostras, com eletrodos de diferentes nanoestruturas. Além disso, esses métodos apresentam boa repetitividade nos resultados, limite de detecção baixo e faixa linear de trabalho bastante ampla. 
Outras vantagens destas técnicas é a possibilidade de análises em campo, pouca geração de resíduos e custo menor.

Nos próximos tópicos, serão discutidas algumas características da voltametria, técnica eletroquímica utilizada no desenvolvimento deste trabalho.

\subsection{Técnicas voltamétricas}

A voltametria abrange um conjunto de técnicas, que dependem da medida da corrente em função do potencial aplicado. Este método é desenvolvido em uma cela eletroquímica, na qual a velocidade de oxidação ou redução do analito é limitada pela velocidade de transferência de massa do analito para a superfície do eletrodo de trabalho. No sistema apresentado na Figura 2, o potencial do eletrodo de trabalho é controlado em relação ao eletrodo de referência gerando o sinal de excitação e a corrente resultante passa do eletrodo de trabalho para o eletrodo auxiliar onde é então medida (SKOOG et al. 2006; BRETT; BRETT, 1993).

Todos os eletrodos devem estar imersos no eletrólito de suporte, e em alguns casos é necessário borbulhamento com nitrogênio para retirada de oxigênio, que dependendo do $\mathrm{pH}$, faixa de potencial aplicada e o material do eletrodo de trabalho pode interferir nas medidas (BRETT; BRETT, 1993).

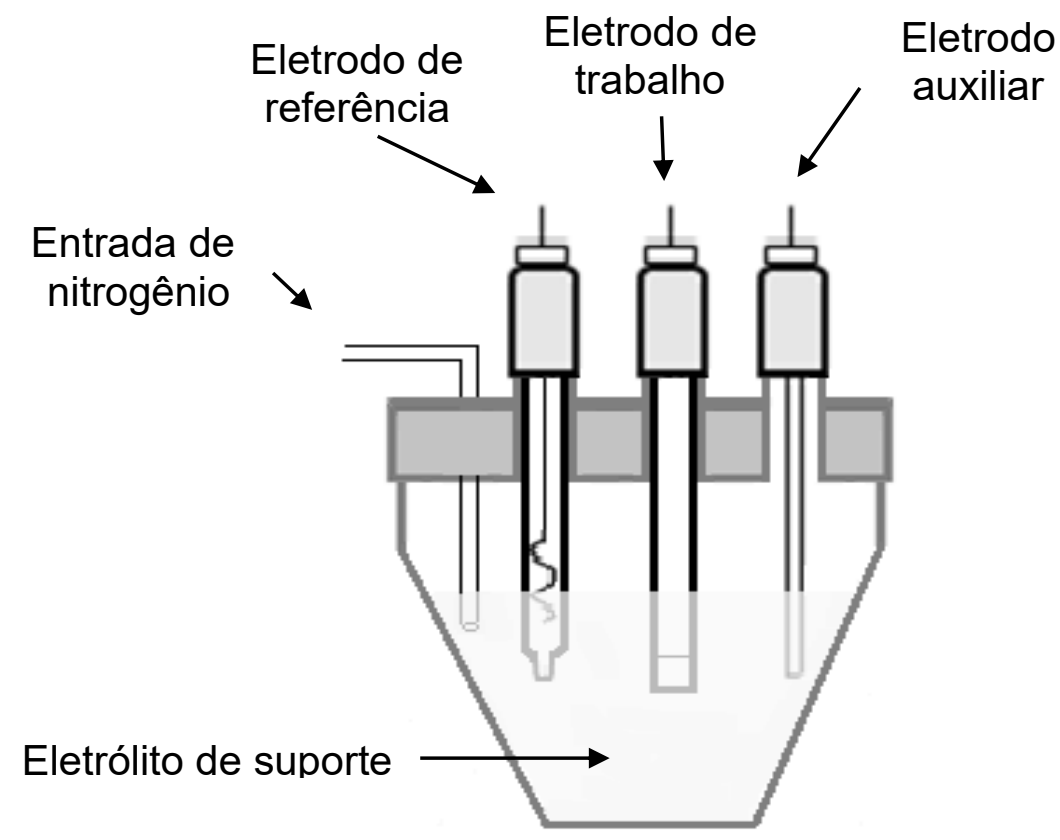

Figura 2- Representação da cela eletroquímica utilizada nas medidas de voltametria. 
Algumas características dos eletrodos e eletrólito de suporte, usados nas medidas voltamétricas são descritos a seguir:

$\checkmark$ Eletrodo de referência: eletrodo de referência precisa ter um potencial que é estável com o tempo, com a temperatura e que não é alterada por perturbações no sistema, como pela passagem de baixas correntes (BRETT; BRETT 1993).

$\checkmark$ Eletrodo auxiliar ou contra-eletrodo: eletrodo por onde passa a corrente que flui através da cela. Ele é geralmente um eletrodo que não produz substâncias por eletrólise, que podem atingir a superfície do eletrodo de trabalho e causar reações interferentes (BARD; FAULKNER, 2001).

$\checkmark$ Eletrodo de trabalho: é geralmente onde a reação de interesse ocorre, sua seleção depende de fatores como o comportamento redox do analito alvo, a corrente de fundo sobre a região de potencial necessária para a medição, janela de potencial, condutividade elétrica, reprodutibilidade da superfície, custo, disponibilidade e toxicidade (WANG, 2006).

$\checkmark$ Eletrólito de suporte: reações e fenômenos eletroquímicos ocorrem em um meio, geralmente um solvente que contenha íons dissolvidos e são necessários nos experimentos para diminuir a resistência da solução, eliminar os efeitos de eletromigração e manter uma força iónica constante. O eletrólito de suporte deve apresentar características como alta solubilidade, alto grau de ionização, não reagir com outras espécies presentes na solução (eletroativas ou não) e não ser oxidado nem reduzido eletroliticamente em toda a faixa de potencial de interesse a que as substâncias em estudo forem submetidas. (AGOSTINHO et al. 2004).

\subsubsection{Voltametria cíclica}

Embora não seja utilizada com frequência na análise quantitativa, a voltametria cíclica (CV) encontra ampla aplicabilidade no estudo de reações, com localização rápida de potenciais redox das espécies eletroativas, cinética de transferência de elétrons em reações heterogêneas, detecção de intermediários da reação e processos de adsorção de compostos nos eletrodos (SKOOG et al. 2006; WANG, 2006).

$\mathrm{Na}$ CV o sinal de excitação varia de forma linear em função do tempo, formando uma onda triangular, com varredura entre dois potenciais do eletrodo, chamados de 
potenciais de inversão, como mostrado na Figura 3(a) (KISSINGER; HEINEMAN, 1983). Um voltamograma cíclico é obtido através da medição da corrente no eletrodo de trabalho durante a aplicação do potencial.

Os parâmetros eletroquímicos mais importantes de um voltamograma cíclico, são os potenciais de pico catódico e anódico $\left(\mathrm{E}_{\mathrm{pc}}\right.$ e $\mathrm{E}_{\mathrm{pa}}$ ) e as correntes de pico catódico e anódico ( $l_{p c}$ e $\left.I_{p a}\right)$, essenciais para caracterizar os processos redox ocorridos (SKOOG et al. 2006). A partir desses parâmetros é possível definir se o processo é reversível, quasi-reversível ou irreversível. Para processos reversíveis, voltamograma apresentado na Figura 3(b) as principais características são: $E_{p a-} E_{p c} \approx 0,059 / n V$, onde $\mathrm{n}$ é o número de elétrons transferidos na reação no eletrodo e $\mathrm{I}_{\mathrm{pa}} / \mathrm{l}_{\mathrm{pc}}=1$ (KISSINGER; HEINEMAN, 1983).
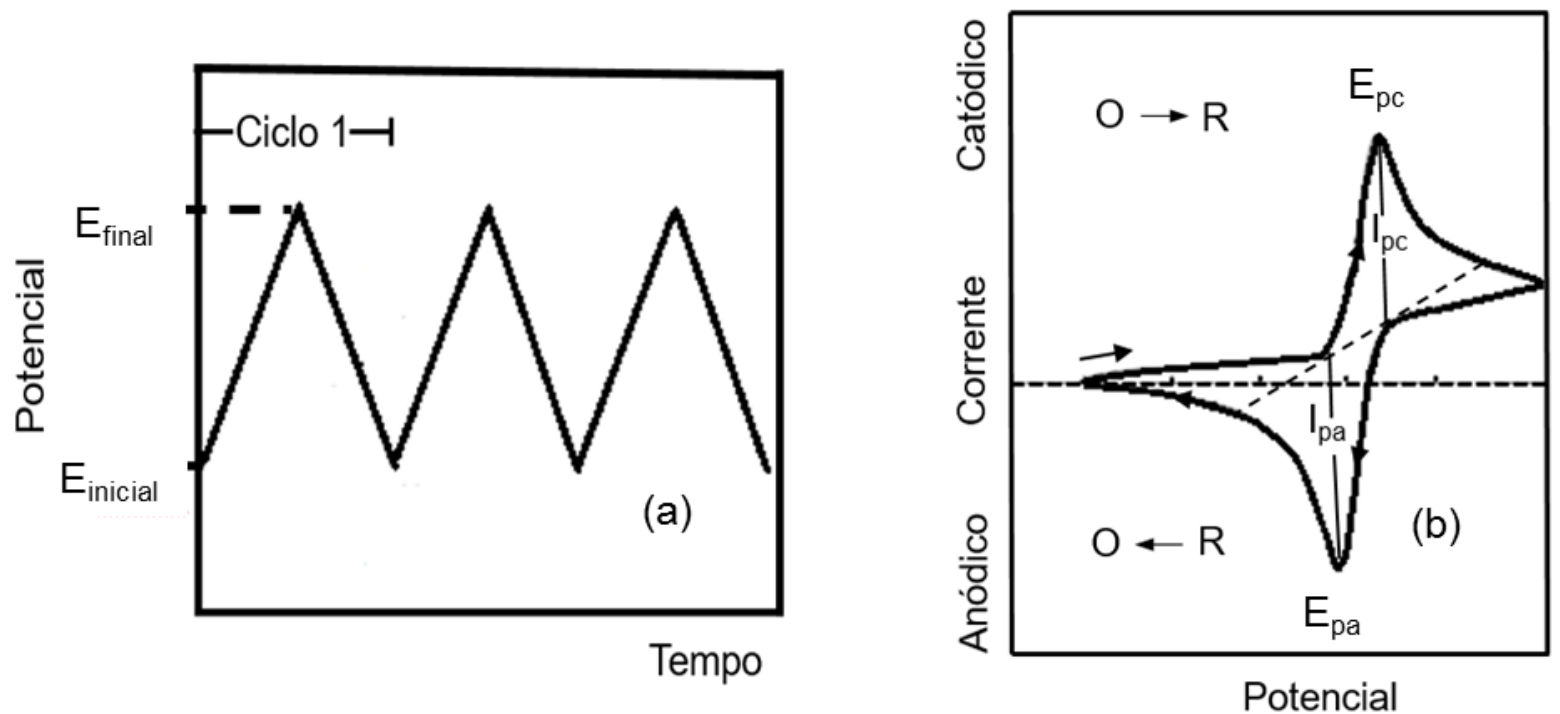

Figura 3- (a) Sinal de excitação em voltametria cíclica. (b) Voltamograma cíclico de um processo reversível.

Fonte: adaptada de Wang (2006).

No geral, os voltamogramas de um sistema quasi-reversíveis apresentado na Figura 4(a), exibem uma maior separação em potenciais de pico comparada com um sistema reversível, transferência de elétrons lenta na superfície do eletrodo (processos irreversíveis), ocasiona um aumento na separação de pico anódico e catódico e menores correntes de pico como pode ser observado no voltamograma da Figura 4(b) (KISSINGER; HEINEMAN, 1983; WANG, 2006). 


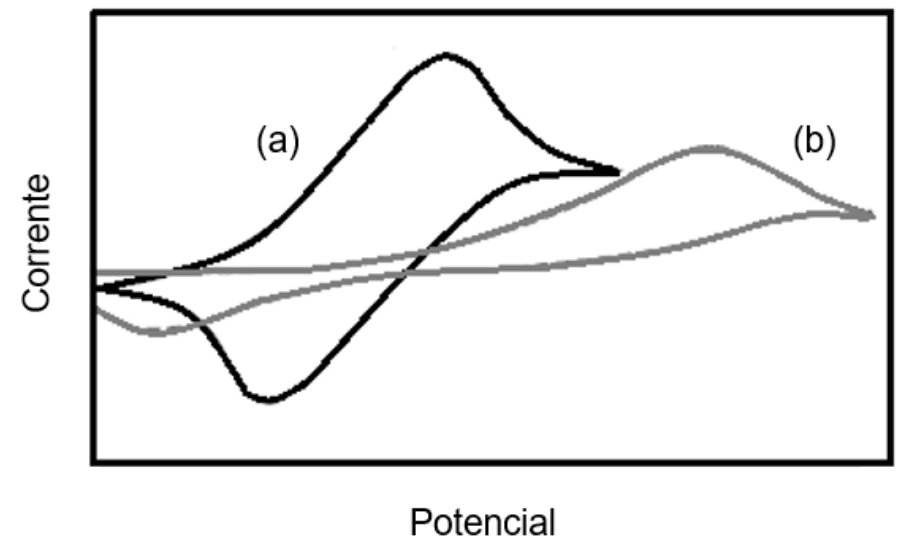

Figura 4 - Voltamogramas de um processo redox quasi-reversível (a) irreversível (b). Fonte: adaptada de Wang (2006).

\subsubsection{Voltametria de Pulso Diferencial}

Esta técnica apresenta maior sensibilidade que a voltametria cíclica, sendo mais utilizada na quantificação de componentes traços de uma amostra. A Figura 5 (a) mostra o sinal de excitação da voltametria de pulso diferencial (DPV), que envolve a combinação da aplicação de um pulso sobre uma varredura em forma de escada, onde um pequeno pulso, tipicamente de $50 \mathrm{mV}$, é aplicado durante os últimos $50 \mathrm{~ms}$. A corrente é medida imediatamente antes da aplicação do pulso $\left(S_{1}\right)$ e no fim do pulso $\left(\mathrm{S}_{2}\right)$, a diferença entre as duas correntes é registrada e como resultado se tem uma curva diferencial com um pico mostrado na Figura 5 (b), onde sua altura é diretamente proporcional a concentração do analito de interesse (SKOOG et al. 2006; BRETT; BRETT, 1993).
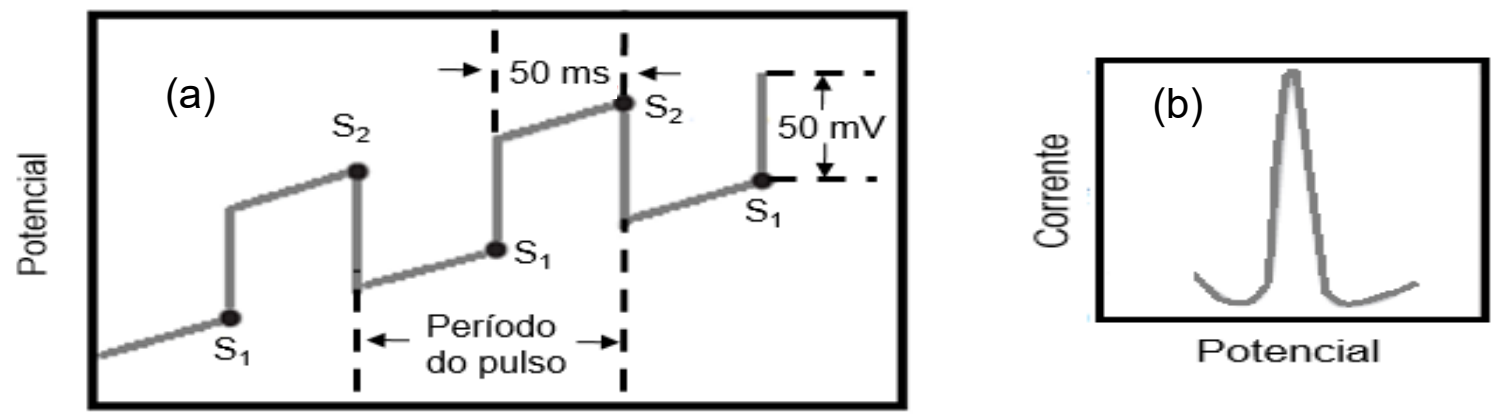

Tempo

Figura 5- (a) Sinal de excitação em voltametria de pulso diferencial; (b) Voltamograma de pulso diferencial.

Fonte: adaptada de Skoog et al. (2006). 


\subsection{Eletrodos modificados}

Os eletrodos quimicamente modificados podem ser definidos como superfícies eletroativas condutoras ou semicondutoras (substrato), que são revestidas com camadas monomoleculares, multimoleculares, iônica ou filme polimérico, a fim de gerar uma nova superfície com novas propriedades (ZOSKI, 2007).

A modificação de eletrodos pode resultar no aumento da cinética de transferência de elétrons, desempenhar um papel de catalisador e pequenos detalhes de morfologia da superfície, os quais determinam a sensibilidade da medição em aplicações eletroanalíticas. De forma geral, superfícies modificadas possuem os seguintes aspectos (SAJID et al., 2015):

- Transferência de propriedades físico-químicas do modificador para o eletrodo;

- Aumento da atividade eletrocatalítica, devido ao uso de materiais com grande área superficial que por sua vez permite uma melhor sensibilidade;

- Seletividade melhorada quando existe afinidade de substâncias de interesse com grupos funcionais imobilizados;

- Cinética rápida de difusão no caso de alguns materiais;

- Extração e acúmulo da substância analisada pelo eletrodo.

Modificações realizadas sobre um substrato podem envolver adsorção irreversível, camadas automontadas, ligação covalente, eletropolimerização dentre outros processos (SAJID et al., 2015). Neste trabalho destacaremos a técnica de automontagem camada por camada ou LbL, do inglês layer-by-layer que foi utilizada na preparação dos eletrodos de trabalho modificados.

\subsubsection{Deposição via Automontagem camada por camada (LbL)}

Esta técnica de preparo de eletrodos modificados é simples, não exige vidrarias ou equipamentos sofisticados, e a deposição pode ser realizada em diversos substratos de plástico, vidro e metais em qualquer formato, tais como lâminas planas, esferas e hastes (PATERNO; SOLER, 2013). A forma mais comum de realizar a deposição dos (nano)materiais via LbL é a utilização de interações eletrostáticas entre materiais iônicos de cargas opostas, conforme representado na Figura 6. 
A formação de filmes com camadas adsorvidas sequencialmente é realizada por imersão sucessiva de um substrato alternadamente nos reservatórios com soluções/suspensões de materiais catiônicos e aniônicos. Entre cada imersão, o conjunto substrato-camada é enxaguado e secado para remover o excesso de material. (PATERNO; SOLER, 2013).

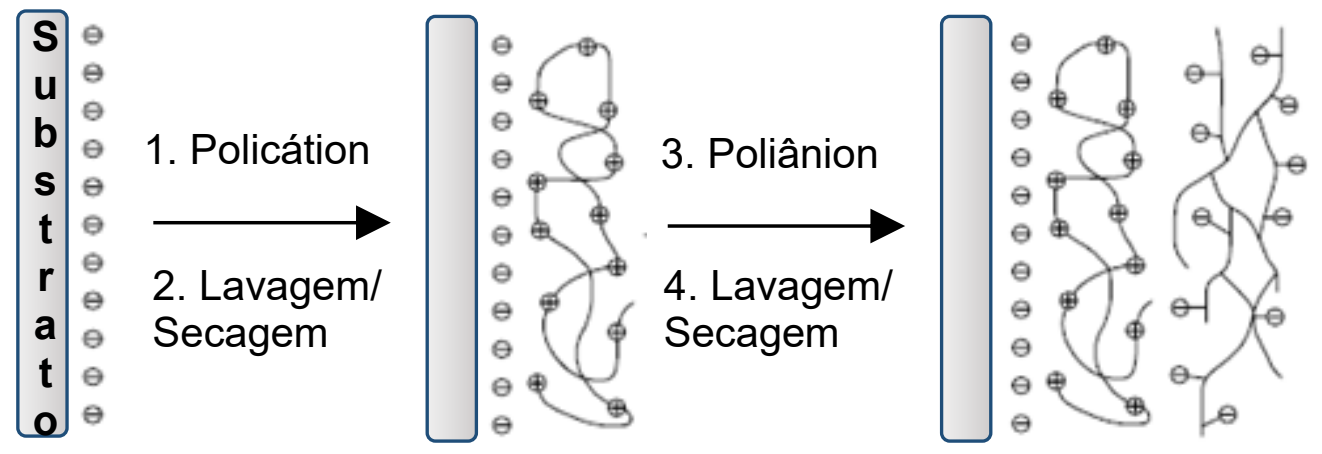

Figura 6- Esquema do método de automontagem via adsorção eletrostática. Fonte: adaptada de Paterno et al. (2001).

Diversos tipos de materiais podem ser utilizados para a preparação de filmes por LbL, dentre eles os nanotubos de carbono funcionalizados e nanopartículas de óxido de ferro. Alguns de seus aspectos teóricos serão discutidos a seguir.

\subsubsection{Nanotubos de carbono}

Os nanotubos de carbono (CNT) são constituídos de folhas de grafeno enroladas na forma de tubos, contendo quase que exclusivamente átomos de carbono dispostos em anéis aromáticos condensados. Eles são classificados principalmente em dois tipos: de parede simples ("single-walled carbon nanotubes"- SWCNT) com uma folha de grafeno enrolada ou de parede múltiplas ("multi-walled carbon nanotubes"-MWCNT) que são cilindros concêntricos formados com mais de uma folha de grafeno enrolada, apresentados na Figura 7 (BIANCO et al., 2011). 
(a)

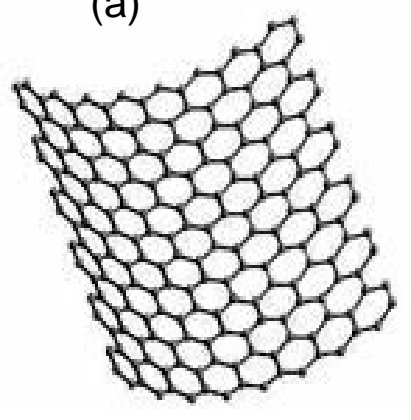

(b)

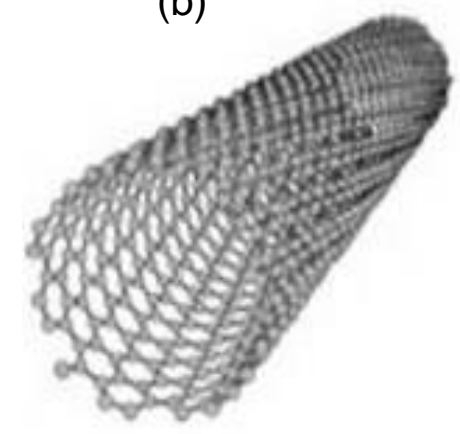

(c)

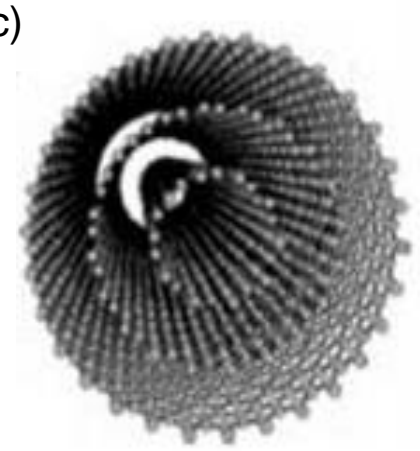

Figura 7-Representação da estrutura de (a) Folha de grafeno, (b) SWCNT e (c) MWCNT. Fonte: adaptada de Machado et al. (2014) e Muñoz (2011).

Devido a sua estrutura, os nanotubos de carbono possuem propriedades como a área de superfície elevada, estabilidade química e alta condutividade elétrica (GAO et al., 2012). Nas últimas décadas, tem aumentado o uso deste material na modificação de eletrodos com objetivo de aplicações eletroanalíticas.

O uso de nanotubos de carbono como modificador de eletrodos, foi essencialmente estabelecida, pela sua eficiente atividade catalítica, promovendo a transferência de elétrons em reações de sistemas redox. Além disso, sua compatibilidade com diferentes materiais permite preparação de eletrodos à base de diversas nanoestruturas associadas aos nanotubos de carbono (TSIERKEZOS et al.,2015; AJAYAN,1999).

Alguns estudos mostram o uso de eletrodos com nanotubos de carbono para a detecção eletroquímica de ácido salicílico. Zhang et al. (2010) desenvolveram eletrodos de carbono vítreo modificados com MWCNT que apresentaram atividade catalítica elevada e capacidade de transferência de elétrons para a oxidação eletroquímica do ácido salicílico muito maiores que as apresentadas pelo eletrodo não-modificado. Os voltamogramas obtidos por voltametria cíclica com tais eletrodos apresentaram picos muito mais definidos para o processo redox do ácido salicílico em comparação ao eletrodo não modificado.

Esta mesma constatação foi feita por Lu et al. (2014), que realizaram a modificação de eletrodo de carbono vítreo com óxido de grafeno e MWCNT. Apenas com o eletrodo modificado com MWCNT foi possível observar a oxidação do ácido salicílico. Tal resultado foi atribuído à grande área de superfície e condutividade elevada do MWCNT, como já mencionado. 
Eletrodo modificado com SWCNT também possui essas características, em um estudo comparativo a modificação de eletrodo de carbono vítreo com esse material, provocou o aparecimento do pico de oxidação de ácido salicílico, atribuído principalmente a excelente atividade eletrocatalítica de SWCNT (LU et al., 2015).

\subsubsection{Nanopartículas de óxido de ferro}

As nanopartículas de óxidos de ferro, em particular de magnetita ( $\mathrm{np}-\mathrm{Fe}_{3} \mathrm{O}_{4}$ ) e de maguemita (np- $\gamma-\mathrm{Fe}_{2} \mathrm{O}_{3}$ ), com diâmetros inferiores a $25 \mathrm{~nm}$ comportam-se como materiais superparamagnéticos, ou seja, sob temperatura ambiente e na ausência de um campo magnético externo não apresentam remanência nem magnetização líquida. Esse comportamento é consequência da redução do tamanho, bem como da estrutura cristalina de espinélio, em que os íons $\mathrm{O}^{2-}$ e $\mathrm{Fe}^{3+}$ e $\mathrm{Fe}^{2+}$ (apenas na magnetita) formam uma rede cúbica de face centrada, conforme apresentado na Figura 8. A alta estabilidade química, compatibilidade biológica, baixa toxicidade e propriedades magnéticas são características que tem atraído atenção de pesquisadores no uso desse material para diversas finalidades como tratamento de câncer por hipertermia, entrega de fármacos em alvo específico no organismo, degradação de pesticida em água, imunossensor para a detecção de bactéria e catálise (SOLER et al., 2012; NIGAM et al., 2011; YU et al., 2015; SHARMA et al., 2015; GAWANDE et al., 2013).

Em eletroquímica, nanopartículas de magnetita são utilizadas na modificação de eletrodos, melhorando o desempenho de processos de oxidação e redução de algumas moléculas orgânicas. Fernandes et al. (2014), realizaram a detecção de ácido ascórbico, dopamina e ácido úrico com eletrodos de nanotubos de carbono e nanopartículas de magnetita. Os eletrodos nanoestruturados com esses dois materiais apresentaram sensibilidade maior que a eletrodos modificados somente com nanotubos de carbono. Acredita-se que as $\mathrm{np}-\mathrm{Fe}_{3} \mathrm{O}_{4}$ aumentam ainda mais a área superficial do eletrodo, com consequente aumento sobre a taxa de transferência eletrônica e melhoria do desempenho. 


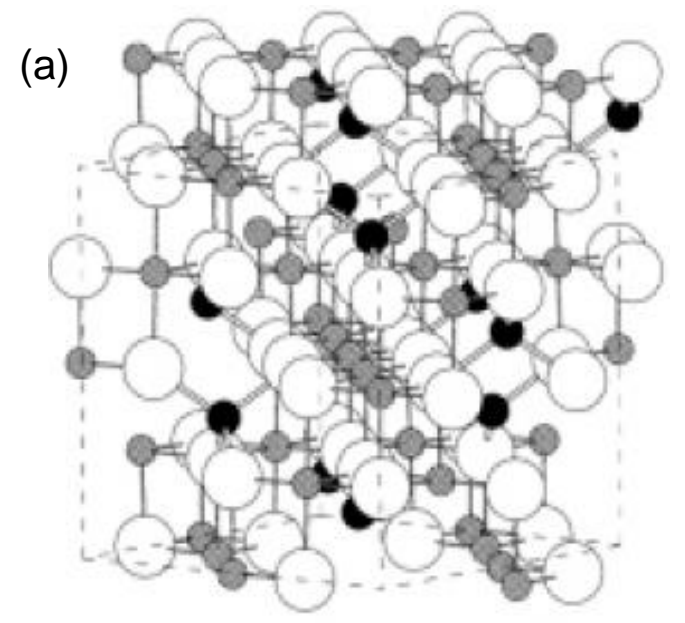

(b)

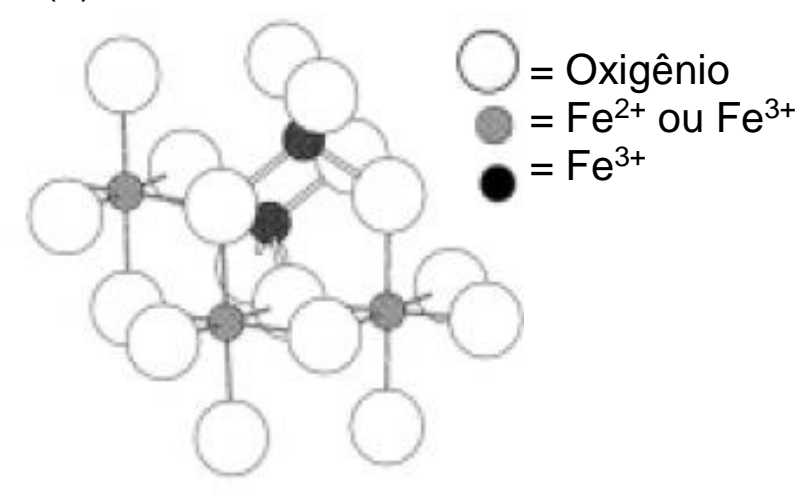

Figura 8- Estrutura da magnetita (a) Linha tracejada representa a cela unitária; (b) Modelo dos arranjos octaédricos e tetraédricos. Fonte: adaptada de Cornell (2014).

Sun et al. (2013), verificaram que um eletrodo de carbono vítreo modificado com quitosana e nanocompósito de nanopartículas de ouro com np- $\mathrm{Fe}_{3} \mathrm{O}_{4}$ foi mais eficaz que eletrodo não modificado na detecção e quantificação de ácido salicílico. Portanto, as nanopartículas de óxidos de ferro são nanomateriais interessantes para modificação de eletrodos com propósito analítico.

A determinação eletroanalítica de ácido salicílico com eletrodos modificados por LbL e nanoestruturados com nanotubos de carbono e nanopartículas de óxido de ferro ainda não foi relatada na literatura. Portanto, esta dissertação descreve o desenvolvimento e uso desses dois nanomateriais como elemento ativo de sensores eletroquímicos de alta sensibilidade ao processo de oxidação do ácido salicílico. 


\section{MATERIAIS E MÉTODOS}

\subsection{Reagentes e soluções}

Os reagentes utilizados nos experimentos e suas respectivas marcas e pureza são apresentados na tabela 2.

Tabela 2- Regentes utilizados.

\begin{tabular}{|c|c|c|}
\hline Reagentes & Marca & Pureza \\
\hline Acetato de amônio & Vetec & $99 \%$ \\
\hline Acetato de sódio & Sigma-Aldrich & $99 \%$ \\
\hline Acetonitrila & J.T. Baker & $99,8 \%$ \\
\hline Ácido acético & Merck & $99,8 \%$ \\
\hline Ácido ascórbico & Merck & $99,7-100,5 \%$ \\
\hline Ácido benzoico & Vetec & $99,5 \%$ \\
\hline Ácido bórico & Vetec & $99,5 \%$ \\
\hline Ácido cítrico & Vetec & $99,5 \%$ \\
\hline Ácido cinâmico & $\mathrm{BDH}$ & $99 \%$ \\
\hline Ácido fosfórico & Merck & $85 \%$ \\
\hline Ácido perclórico & J.T. Baker & $71,3 \%$ \\
\hline Ácido p-hidroxibenzoico & $\mathrm{BDH}$ & $99 \%$ \\
\hline Ácido salicílico (padrão certificado) & Sigma-Aldrich & $99,8 \%$ \\
\hline Ácido sulfúrico & Quimex & 95 á $98 \%$ \\
\hline Citrato de sódio & Reagen & 99 á 100,3\% \\
\hline Sulfato de ferro (II) heptahidratado & Sigma-Aldrich & $99 \%$ \\
\hline Cloreto de ferro (III) hexahidratado & Sigma-Aldrich & $97 \%$ \\
\hline Cloreto de potássio & Vetec & 99 á $100,5 \%$ \\
\hline Ferricianeto de potássio & Vetec & $99 \%$ \\
\hline $\begin{array}{l}\text { Hidrocloreto de poli(dialildimetil amônio) } \\
\qquad \text { (PDAC) }\end{array}$ & Sigma-Aldrich & 20 \% em água \\
\hline Hidróxido de sódio & Vetec & $98 \%$ \\
\hline Metanol & J.T. Baker & $99,9 \%$ \\
\hline Nanotubos de carbono (NT-PABS) & Sigma-Aldrich & 75 á $85 \%$ \\
\hline
\end{tabular}


As soluções utilizadas são descritas a seguir:

> Solução $5 \% \mathrm{v} / \mathrm{v}$ de detergente alcalino Dertec $-25 \mathrm{~mL}$ de detergente em 500 $\mathrm{mL}$ de água ultrapura.

> Solução $5 \% \mathrm{v} / \mathrm{v}$ de $\mathrm{KOH}$ em álcool - $5 \mathrm{ml}$ de solução aquosa saturada de $\mathrm{KOH}$ em $100 \mathrm{ml}$ de álcool 95\%, agitado e filtrado em funil de vidro sinterizado após 24 horas de decantação.

> Sulfato de ferro (II) heptahidratado $0,1 \mathrm{~mol} \mathrm{~L}^{-1}-0,28 \mathrm{~g}$ de sulfato de ferro (II) heptahidratado em $10 \mathrm{~mL}$ de água ultrapura.

> Cloreto de ferro (III) hexahidratado $0,2 \mathrm{~mol} \mathrm{~L}^{-1}$ - 0,56 g de cloreto de ferro (III) hexahidratado em $10 \mathrm{~mL}$ de água ultrapura.

> PDAC $1 \mathrm{~g} \mathrm{~L}^{-1}-0,25 \mathrm{~g}$ de PDAC em $50 \mathrm{~mL}$ de água ultrapura.

> Ferricianeto de potássio $1 \times 10^{-3} \mathrm{~mol} \mathrm{~L}^{-1}-33,25 \mathrm{mg}$ de ferricianeto de potássio em $100 \mathrm{~mL}$ de $\mathrm{KCl} 0,1 \mathrm{~mol} \mathrm{~L}^{-1}$.

> Padrão de ácido salić́lico $7,2 \times 10^{-3} \mathrm{~mol} \mathrm{~L}^{-1}$ - $50 \mathrm{mg}$ de ácido salicílico em $50 \mathrm{~mL}$ de água ultrapura.

> Tampão RB (pH 2,5 a 7,5) - preparado com a mistura das soluções de $\mathrm{H}_{3} \mathrm{PO}_{4}$, $\mathrm{H}_{3} \mathrm{BO}_{3}$ e $\mathrm{CH}_{3} \mathrm{COOH}\left(0,04 \mathrm{~mol} \mathrm{~L}^{-1}\right)$ e solução de $\mathrm{NaOH} 0,2 \mathrm{~mol} \mathrm{~L}^{-1}$ para ajustar $\mathrm{opH}$.

> Tampão citrato $(\mathrm{pH} \mathrm{2,5)}-6,44 \mathrm{~g}$ de ácido cítrico e 0,78 g de citrato de sódio em $100 \mathrm{~mL}$ de água ultrapura.

> Tampão acetato de amônio (pH 3,5 e 4,5) - solução $0,1 \mathrm{~mol} \mathrm{~L}^{-1}$ de acetato de amônio e solução $0,2 \mathrm{~mol} \mathrm{~L}^{-1}$ de ácido acético para ajustar o pH.

> Tampão acetato de sódio $(\mathrm{pH} 3,5)$ - solução $0,1 \mathrm{~mol} \mathrm{~L}^{-1}$ de acetato de sódio e solução $0,2 \mathrm{~mol} \mathrm{~L}^{-1}$ de ácido acético para ajustar o pH.

> Ácido acético $0,1 \mathrm{~mol} \mathrm{~L}^{-1}-143 \mu \mathrm{L}$ de ácido acético em $25 \mathrm{~mL}$ de água ultrapura.

> Ácido sulfúrico $0,1 \mathrm{~mol} \mathrm{~L}^{-1}-133 \mu \mathrm{L}$ de ácido sulfúrico em $25 \mathrm{~mL}$ de água ultrapura.

> Ácido ascórbico 7,2×10-3 $\mathrm{mol} \mathrm{L}^{-1}$ - 63,76 mg de ácido ascórbico em $50 \mathrm{~mL}$ de água ultrapura.

> Ácido cinâmico $2,4 \times 10^{-3} \mathrm{~mol} \mathrm{~L}^{-1}$ - 17,90 mg de ácido cinâmico em $50 \mathrm{~mL}$ de água ultrapura.

> Ácido benzoico $7,2 \times 10^{-3} \mathrm{~mol} \mathrm{~L}^{-1}$ - 43,98 $\mathrm{mg}$ ácido benzoico em $50 \mathrm{~mL}$ de água ultrapura. 
$>$ Ácido p-hidroxibenzoico $7,2 \times 10^{-3} \mathrm{~mol} \mathrm{~L}^{-1}-50 \mathrm{mg}$ de ácido p-hidroxibenzoico em $50 \mathrm{~mL}$ de água ultrapura.

\subsection{Limpeza das vidrarias}

As vidrarias utilizadas neste trabalho, foram lavadas inicialmente com detergente neutro para retirar o excesso de resíduos, enxaguadas em água corrente e deixadas por 2 horas completamente imersas, em solução $5 \% \mathrm{v} / \mathrm{v}$ de detergente alcalino Dertec em água ultrapura (resistividade: $18 \mathrm{Mohm} . \mathrm{cm}$ ). Após este tempo, as vidrarias foram enxaguadas com água corrente e posteriormente com solução $5 \% \mathrm{v} / \mathrm{v}$ de $\mathrm{KOH}$ em álcool, para remoção de compostos orgânicos presentes. As vidrarias foram por fim lavadas abundantemente com água corrente e em seguida com água ultrapura.

Após a limpeza realizada, as vidrarias volumétricas foram secas a temperatura ambiente e as vidrarias não volumétricas, foram colocadas em forno mufla por 2 horas na temperatura de $450^{\circ} \mathrm{C}$. Todas elas foram guardadas em recipiente limpo e fechado evitando contaminação do ar.

\subsection{Amostra de produto dermatológico}

A amostra de produto dermatológico analisada foi uma solução que é utilizada no tratamento de dermatite seborreica e psoríase com a seguinte formulação:

$\checkmark$ Dipropionato de betametasona, (equivalente a $0,5 \mathrm{mg}(0,05 \%)$ de betametasona) - 0,64 $\mathrm{mg} \mathrm{mL}^{-1}$.

$\checkmark$ Ácido salicílico (equivalente a $2 \%$ de ácido salićlico) - $20 \mathrm{mg} \mathrm{mL}^{-1}$.

$\checkmark$ Excipientes q.s.p (edetato dissódico, hipromelose, hidróxido de sódio, álcool isopropílico e água) - $1 \mathrm{~mL}$.

Para realização dos experimentos não foi necessário procedimento de extração apenas diluição de $250 \mu \mathrm{L}$ da amostra em $10 \mathrm{~mL}$ de água ultrapura, realizou-se então a leitura de três alíquotas da amostra com o método eletroanalítico proposto (Voltametria de Pulso Diferencial-DPV) e cromatografia líquida de alta eficiência (HPLC) conforme é apresentado no tópico 4.7.6. 


\subsection{Preparação dos eletrodos modificados}

\subsubsection{Limpeza do substrato de vidro condutor}

Os eletrodos de trabalho foram preparados sobre substratos de vidro (1 $\mathrm{mm} x$ $10 \mathrm{~mm} \times 20 \mathrm{~mm}$ ) recobertos com um filme condutor de óxido de estanho dopado com índio $\left(\mathrm{SnO}_{2} . \mathrm{xIn}\right.$; resistividade: $15 \mathrm{ohm} \mathrm{cm}$ ), também conhecido como ITO (do inglês, indium tin oxide). Antes da deposição das nanoestruturas, foi realizada a limpeza desse substrato esfregando manualmente ambos os lados com detergente neutro e depois mantendo-os num béquer com água destilada por 20 minutos em banho ultrassom. Após esse período, os substratos foram enxaguados com água ultrapura por 5 vezes para a remoção do detergente e colocados num béquer, com água ultrapura apenas, e banho ultrassom por 20 minutos. Ao término das etapas, os substratos foram armazenados imersos em água ultrapura e em geladeira até a deposição dos nanomateriais.

\subsubsection{Preparo das nanopartículas de magnetita e dos nanotubos de carbono}

O preparo das nanopartículas de magnetita foi realizado por co-precipitação de íons $\mathrm{Fe}(\mathrm{II})$ e $\mathrm{Fe}(\mathrm{III})$ em $\mathrm{NaOH}$, segundo método descrito na literatura (Santos et al., 2014). Uma solução aquosa (20 mL) contendo íons de $\mathrm{Fe}(\mathrm{II}) 0,1 \mathrm{~mol} \mathrm{~L}^{-1}$ e $\mathrm{Fe}$ (III) na concentração de $0,2 \mathrm{~mol} \mathrm{~L}^{-1}$ foi adicionada gota a gota sobre $25 \mathrm{~mL}$ de solução de $\mathrm{NaOH}\left(0,4 \mathrm{~mol} \mathrm{~L}^{-1}\right)$ sob agitação magnética e a temperatura ambiente como mostrado na Figura 9 (a). Depois da completa adição da solução de íons de ferro, a mistura foi mantida em agitação por mais 30 minutos, também em temperatura ambiente. 0 precipitado preto de np- $\mathrm{Fe}_{3} \mathrm{O}_{4}$ foi isolado por decantação com o auxílio de um ímã (Figura 9 b) e lavado (3 vezes) com água ultrapura. A estequiometria da reação para a síntese por co-precipitação é como se segue (KANG, et al., 1996):

$$
\mathrm{Fe}^{2+}(\mathrm{aq})+2 \mathrm{Fe}^{3+}(\mathrm{aq})+8 \mathrm{OH}^{-}(\mathrm{aq}) \rightarrow \mathrm{Fe}_{3} \mathrm{O}_{4}(\mathrm{~s})+4 \mathrm{H}_{2} \mathrm{O}(\mathrm{l})
$$

As partículas isoladas foram dispersas em solução aquosa de $\mathrm{HClO}_{4}(\mathrm{pH} 4)$ com agitação magnética durante 18 horas. Após o passo de agitação, a dispersão 
coloidal obtida foi submetida a agitação ultrassônica pulsada (Branson 450; potência: $250 \mathrm{~W}$; tempo: 10 minutos; pulso: 5 s ligado, 5 s desligado) e, em seguida, centrifugada (4500 rpm por 10 minutos), para remover partículas e agregados insolúveis. Esta dispersão foi empregada como fonte de nanopartículas para deposição dos filmes. O meio ácido protona a superfície das nanopartículas e, portanto, garante a estabilidade coloidal por meio de forças de repulsão eletrostática. Outro detalhe importante se refere a conversão parcial e inevitável da fase magnetita à maguemita, de modo que as nanopartículas são melhor descritas como sendo constituídas de óxido de ferro. Portanto, serão abreviadas como np-MAG.
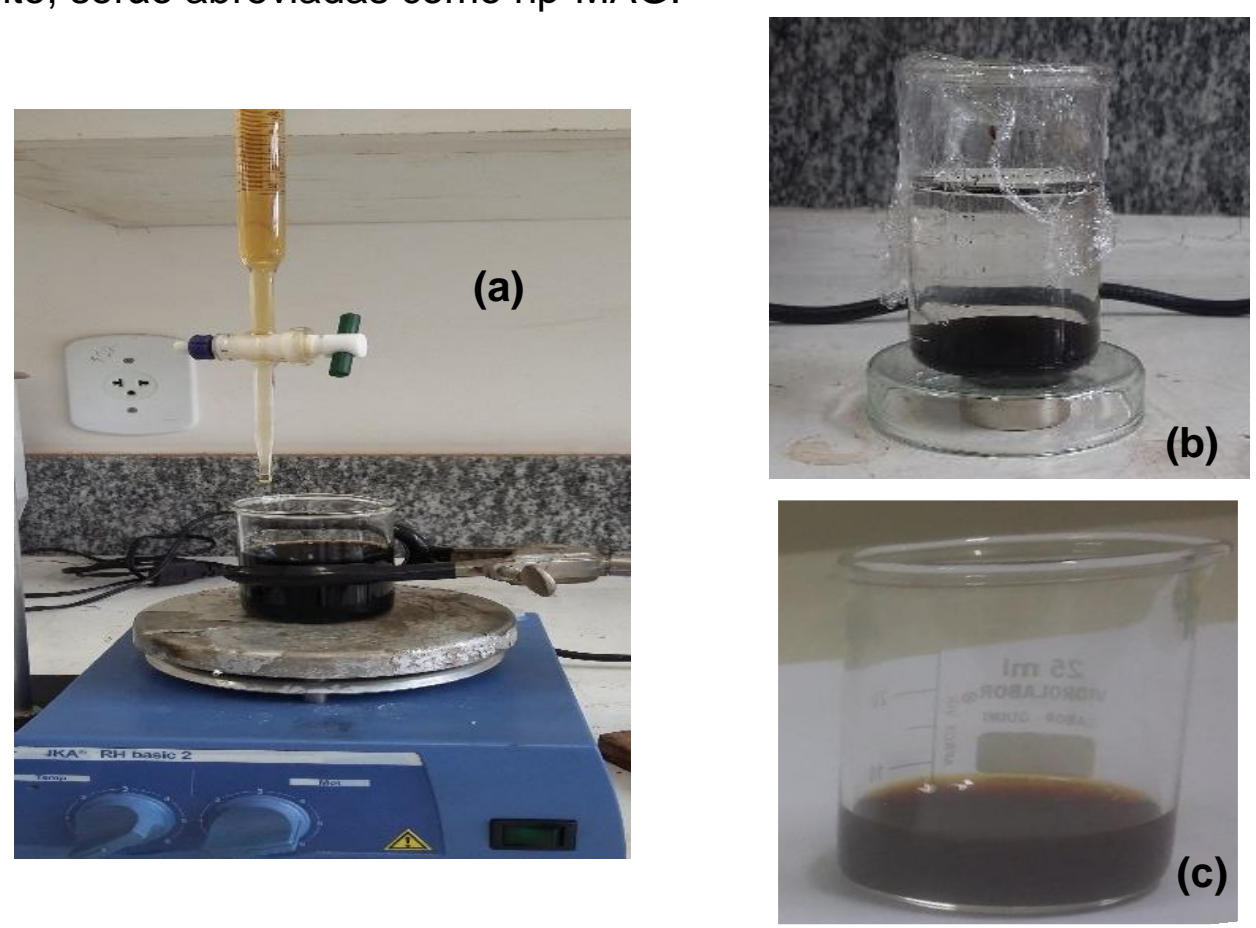

Figura 9- Preparo das nanopartículas de magnetita, (a) Gotejamento em $\mathrm{NaOH}$ da solução aquosa contendo íons de ferro; (b) Decantação das nanopartículas de magnetita; (c) Solução coloidal de nanopartículas de óxido de ferro.

Os nanotubos de carbono utilizados na preparação dos eletrodos foram do tipo de parede simples (SWNT), funcionalizados covalentemente com um oligômero condutor (ácido poliaminobenzeno sulfônico, PABS) solúvel em água e fornecidos pela Sigma-Aldrich, cuja estrutura é representada na Figura 10 (a). Devido à presença dos grupos sulfônicos, - $\mathrm{SO}_{3}$, os nanotubos modificados com PABS (NT-PABS) exibem comportamento aniônico e podem, portanto, ser depositados alternadamente com np-MAG, que são catiônicas, via LbL eletrostático. 

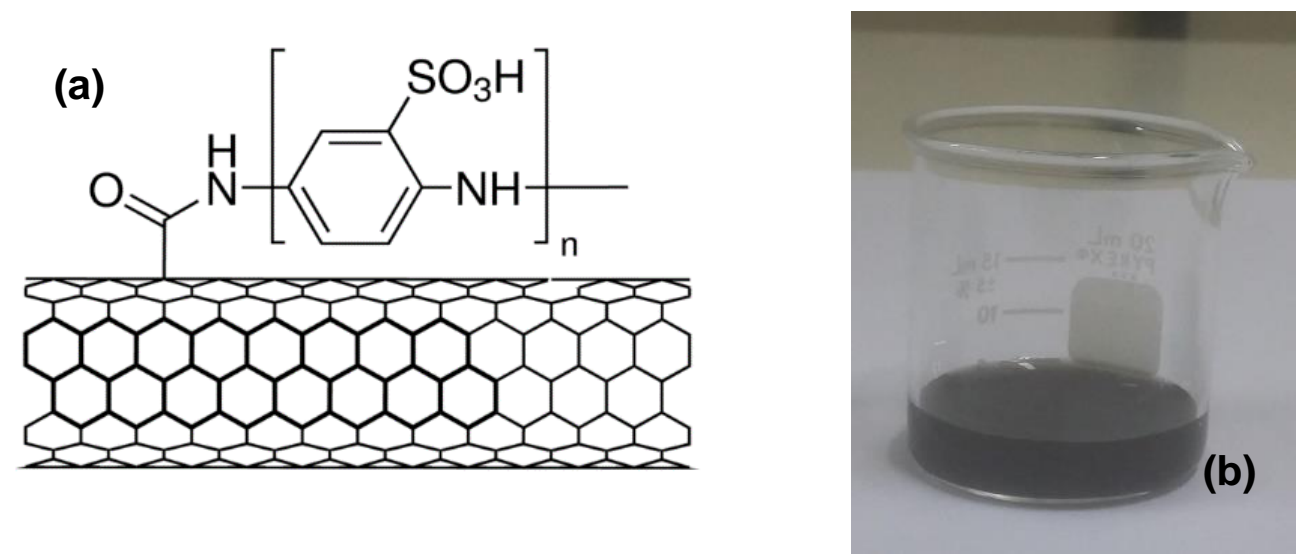

Figura 10- (a) Estrutura do nanotubo de carbono funcionalizado com PABS. Fonte: site da Sigma Aldrich (2015). (b) Solução coloidal de nanotubos de carbono.

Para o preparo de uma suspensão, $50 \mathrm{mg}$ de NT-PABS foram adicionados a $100 \mathrm{~mL}$ de água ultrapura e submetidos a agitação ultrassônica pulsada (potência: $250 \mathrm{~W}$; tempo: $1 \mathrm{~h}$; pulso: 1s ligado, 1s desligado). Após essa etapa, a amostra resultante foi centrifugada a $4500 \mathrm{rpm}$ por 10 minutos para remoção de material insolúvel. O sobrenadante, uma solução coloidal de nanotubos (Figura 10 b), foi obtida e armazenada em geladeira até a preparação dos filmes.

\subsubsection{Deposição dos nanomateriais sobre vidro condutor via $L b L$}

Os substratos de ITO foram modificados com filmes ultrafinos de np-MAG/NTPABS via técnica LbL. Como forma de garantir um número suficiente de sítios de adsorção para os nanomateriais e aumentar a resistência mecânica dos filmes, camadas do polieletrólito catiônico hidrocloreto de poli(dialildimetil amônio) (PDAC, $\mathrm{Mw} 450.000 \mathrm{~g} \mathrm{~mol}^{-1}$ ) foram introduzidas entre os nanomateriais. Uma ilustração esquemática do processo de modificação dos eletrodos é apresentada na Figura 11. Em essência, o substrato de ITO foi imerso, sequencialmente, na solução de PDAC $\left(1 \mathrm{~g} \mathrm{~L}^{-1}\right)$, seguido das suspensões de NT-PABS e np-MAG. O tempo de imersão em cada solução/suspensão foi de 3 minutos enquanto o tempo de enxágue foi de 20 segundos. Água ultrapura foi usada no enxágue após a deposição de PDAC e NTPABS enquanto uma solução $\mathrm{pH} 4$ de $\mathrm{HClO}_{4}$ foi empregada no enxágue após a camada de np-MAG. Ainda, após cada camada depositada e enxágue, o substrato modificado foi secado com jato de ar comprimido. 


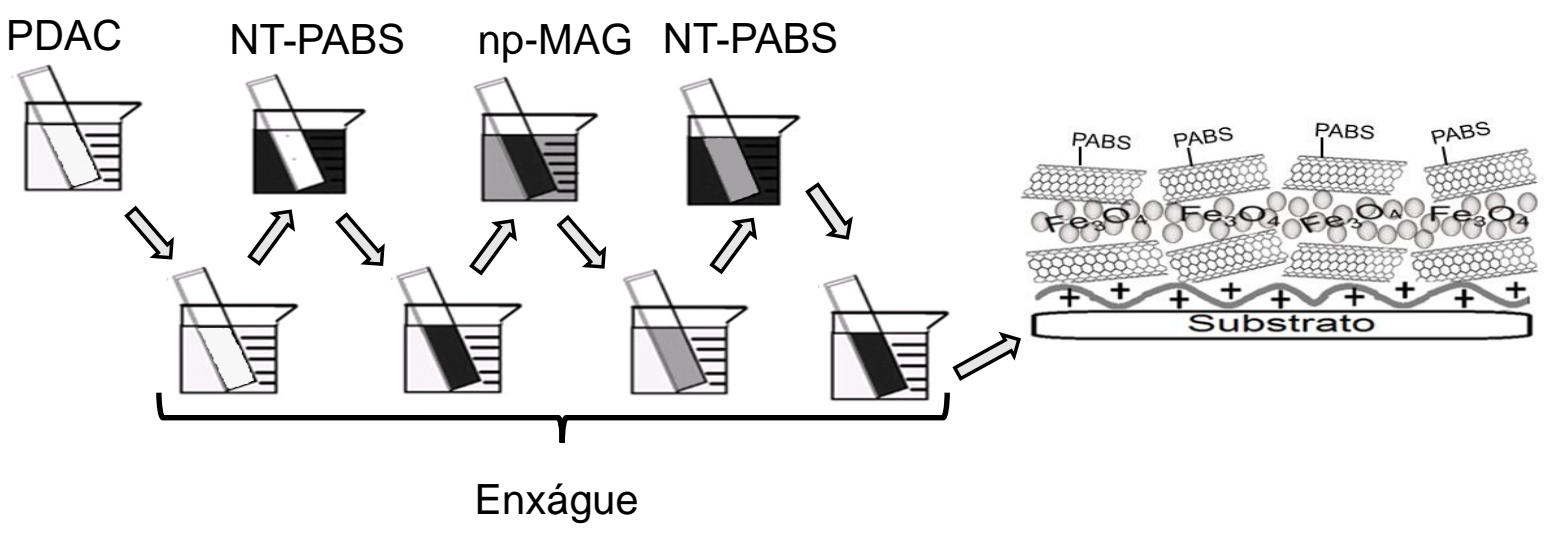

Figura 11- Esquema do preparo dos eletrodos por LbL.

Fonte: adaptado de Paterno; Soler, 2013.

Ao término de cada ciclo foi obtido um filme com estrutura de tetracamadas (PDAC/NT-PABS/np-MAG/NT-PABS) $n$ com $n=1,3,5,7$ e 10 como demonstrado na Figura 12. A área de modificação dos substratos de ITO foi delimitada com fita adesiva do tipo Scotch. Assim, os resultados são expressos em densidade de corrente (J), que é a razão entre a corrente e a área geométrica do eletrodo. Esse cuidado foi tomado devido ao fato da corrente ter dependência direta com a área do eletrodo conforme expresso pela equação de Randles-Sevick, descrita nos resultados (tópico 5.2.3).

(a)

(b)

(c)

(d)

(e)

(f)

Figura 12 - (a) Substrato de ITO e eletrodos com (b) 1 (c) 3 (d) 5 (e) 7 e (f) 10 tetracamadas

\subsection{Estudos da deposição e estrutura dos eletrodos modificados}

A deposição das nanoestruturas foi monitorada por espectroscopia de absorção UV-vis com um espectrofotômetro Varian Cary 5000. Os espectros foram obtidos com eletrodos contendo 1, 3, 5, 7 e 10 tetracamadas depositadas em lâmina de quartzo que não absorvem na região do UV-vis. 
A morfologia de nanomateriais depositados foi avaliada por Microscopia de força atômica ("Atomic Force Microscopy", AFM) em um equipamento Digital MultiModo Nanoscope IIla, modo "tapping"). Este experimento foi realizado na Universidade Federal de São Carlos (UFSCAR).

\subsection{Estudos eletroquímicos}

\subsubsection{Impedância eletroquímica}

Os experimentos de impedância eletroquímica foram realizados no potenciostato/galvanostato da AUTOLAB modelo PGSTAT204 da Metrohm, com amplitude de $0,01 \mathrm{~V}$ e frequência de 0 a $100 \mathrm{kHz}$. Os eletrodos utilizados foram os mesmos dos experimentos de voltametria que serão expostos a seguir, em $25 \mathrm{~mL}$ de solução de ferricianeto de potássio $\left(\mathrm{K}_{3} \mathrm{FeCN}_{6}\right) 1 \times 10^{-3} \mathrm{~mol} \mathrm{~L}^{-1} \mathrm{em} \mathrm{KCl} 0,1 \mathrm{~mol} \mathrm{~L}^{-1}$.

\subsubsection{Voltametria cíclica e de pulso diferencial}

Os experimentos de voltametria cíclica e pulso diferencial foram realizados em potenciostato Autolab modelo PGSTAT302N da Metrohm (Figura 13a). A cela eletroquímica utilizada, continha um eletrodo de referência de $\mathrm{Ag} / \mathrm{AgCl}(\mathrm{KCl}$ saturado), contra-eletrodo de platina e o eletrodo de trabalho proposto, como apresentado na Figura 13(b). Para os experimentos de voltametria de pulso diferencial, devido as correntes serem baixas e a sensibilidade maior, foi necessário o uso de uma gaiola de Faraday (Figura 13c), conectada no terra do equipamento para diminuir os ruídos.

A voltametria cíclica foi realizada em $25 \mathrm{~mL}$ de uma solução de $\mathrm{K}_{3} \mathrm{Fe}(\mathrm{CN})_{6}$ na concentração de $1 \times 10^{-3} \mathrm{~mol} \mathrm{~L}^{-1} \mathrm{em} \mathrm{KCl} 0,1 \mathrm{~mol} \mathrm{~L}^{-1}$ com potencial de $-0,1$ a $0,6 \mathrm{~V}$. Esses experimentos foram realizados, para determinar parâmetros cinéticos dos eletrodos preparados com diferentes camadas. Medidas de voltametria cíclica, também foram realizadas para analisar o comportamento do ácido salicílico na superfície do eletrodo de trabalho, sendo realizada em $25 \mathrm{~mL}$ de soluções de ácido salicílico nas concentrações de 2,5; 5 e $10 \times 10^{-3} \mathrm{~mol} \mathrm{~L}^{-1} \mathrm{em}$ ácido acético $0,1 \mathrm{~mol} \mathrm{~L}^{-1}$ com potencial de 0 a $1,5 \mathrm{~V}$. 

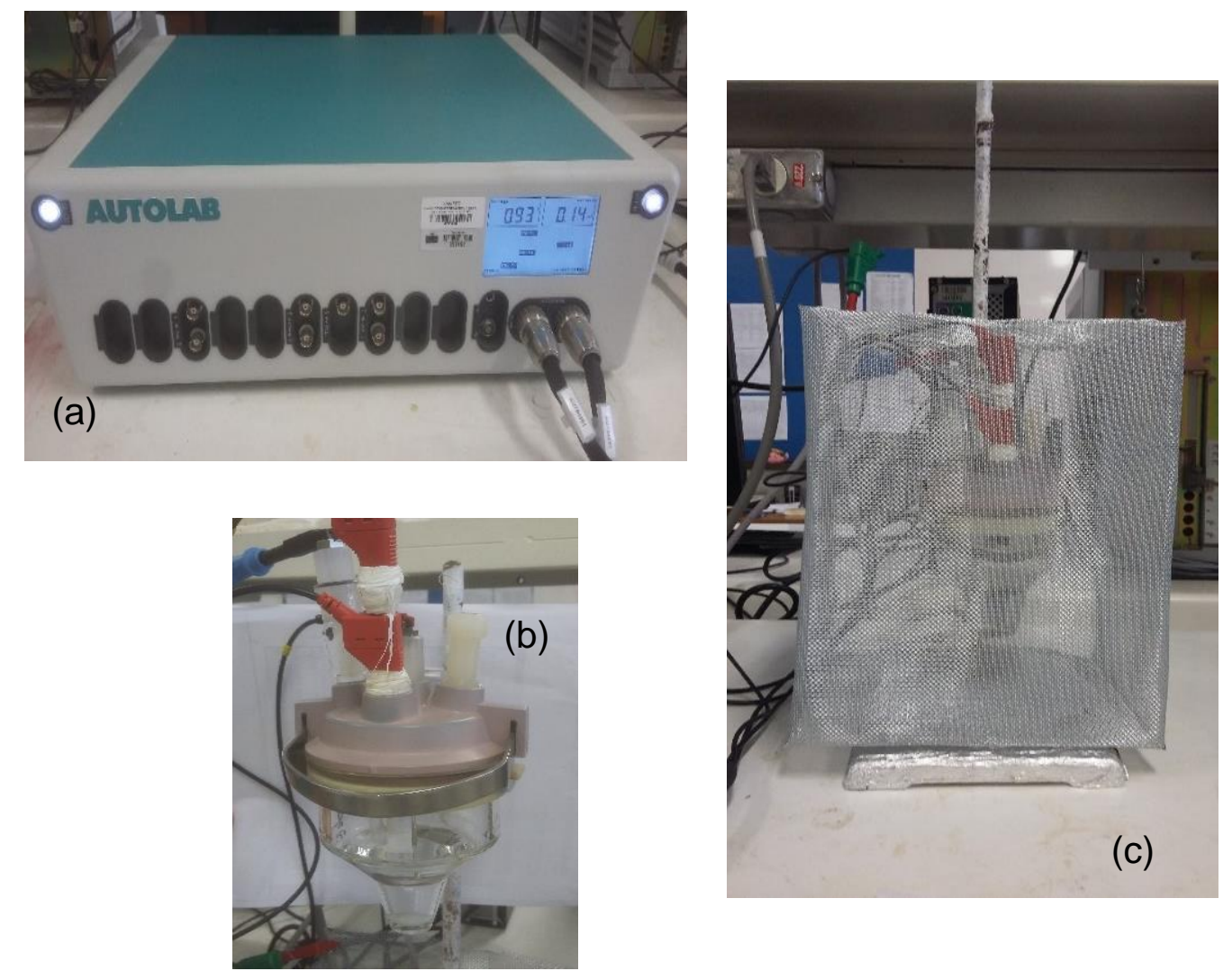

Figura 13- Sistema eletroquímico, (a) Potenciostato/Galvanostato; (b) Cela eletroquímica; (c) Gaiola de Faraday.

Para a voltametria de pulso diferencial, foi preparada uma solução padrão de ácido salicílico em água ultrapura $\left(7,2 \times 10^{-3} \mathrm{~mol} \mathrm{~L}^{-1}\right)$ e realizado adições com micropipeta diretamente sobre o eletrólito de suporte conforme a concentração requerida. A cada adição realizada a solução foi agitada por 60 segundos, simultaneamente neste mesmo período o condicionamento do eletrodo foi realizado, em solução de metanol:água (1:10), não foi necessário borbulhamento de nitrogênio, pois o oxigênio não apresentou interferência nas medidas realizadas. Os eletrólitos de suporte testados foram: tampão $\mathrm{RB}(\mathrm{pH} 2,5$ a 7,5), tampão citrato $(\mathrm{pH} 2,5)$, tampão acetato de amônio ( $\mathrm{pH} 3,5$ e 4,5), tampão acetato de sódio ( $\mathrm{pH} 3,5$ ), Ácido acético $0,1 \mathrm{~mol} \mathrm{~L}^{-1} \mathrm{e}$ Ácido sulfúrico $0,1 \mathrm{~mol} \mathrm{~L}^{-1}$.

Outros parâmetros da voltametria de pulso diferencial, foram testados para se obter melhor resolução e altura de pico, como a velocidade de varredura $(2,5,10 \mathrm{e}$ $20 \mathrm{mV} \mathrm{s}^{-1}$ ) e amplitude de pulso (5, 10, 25, 50, 100 e $150 \mathrm{mV}$ ), testadas em uma solução de $5,7 \mu \mathrm{mol} \mathrm{L} \mathrm{L}^{-1}$ de ácido salićlico em ácido acético $0,1 \mathrm{~mol} \mathrm{~L}^{-1}$. 


\subsection{Cromatografia líquida de alta eficiência (HPLC)}

A cromatografia líquida de alta eficiência foi utilizada como método de referência para validação da metodologia. Para estes experimentos foi utilizado um cromatógrafo líquido (Figura 14) com detecção UV-vis (Varian 920-LC), coluna phenomenex C18 (100x4,6 mm; 2,6 $\mu \mathrm{m})$ e fluxo de 0,4 $\mathrm{mL} \mathrm{min}^{-1}$.

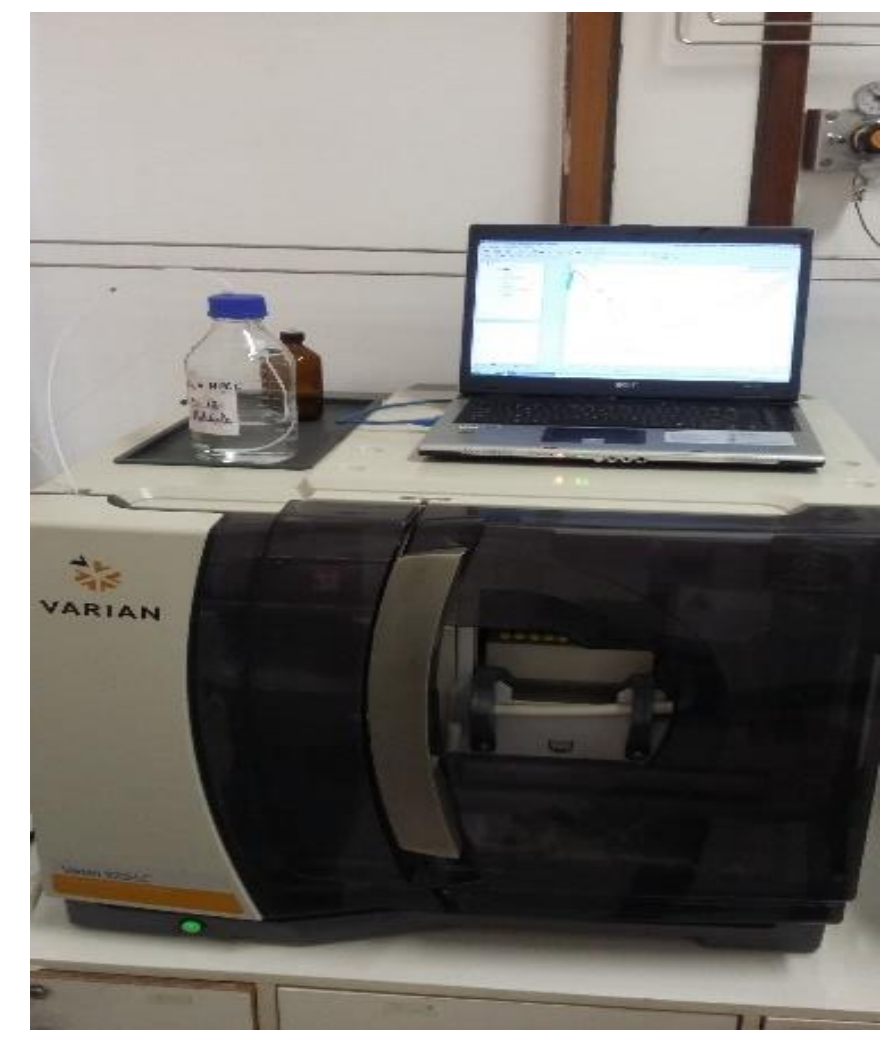

Figura 14- Cromatógrafo líquido com detecção UV-vis.

Diferentes fases móveis descritas na literatura foram testadas e são descritas a seguir:

- Tampão acetato de amônio (concentração $0,01 \mathrm{~mol} \mathrm{~L}^{-1}$ e pH 4,5): acetonitrila (80:20) (JANGBAl et al., 2012);

- Água: metanol: ácido acético (54:45:1) (TORRIERO et al., 2004);

- Água: acetonitrila: ácido acético (54:45:1) (adaptada de TORRIERO et al., 2004).

O melhor comprimento de onda foi escolhido a partir de experimentos com soluções de ácido salicílico $8,7 \mu \mathrm{mol} \mathrm{L}^{-1}$, nas fases móveis citadas acima, analisadas em espectrofotômetro UV-vis (Agilent Modelo 8453). 


\subsection{Parâmetros de validação de metodologia}

Para assegurar a confiabilidade do método desenvolvido, foram realizados experimentos padrões de validação de metodologia, descritos em documentos de orientação sobre validação de métodos de ensaios químicos (INMETRO, 2011; ANVISA, 2003; ICH, 1995).

\subsubsection{Precisão}

Precisão é avaliar a dispersão de resultados entre ensaios independentes, repetidos de uma mesma amostra ou padrões em condições definidas, podendo ser determinada realizando experimentos de repetitividade, onde o grau de concordância entre os resultados das medições sucessivas de um mesmo mensurando, efetuadas sob as mesmas condições, determina se o método utilizado é preciso (INMETRO, 2011).

Este parâmetro foi mensurável com 7 leituras de ácido salicílico na concentração de $5,7 \mu \mathrm{mol} \mathrm{L}-1$ em ácido acético $0,1 \mathrm{~mol} \mathrm{~L}^{-1}$, sendo realizado o condicionamento do eletrodo entre cada medida. Testes com três eletrodos diferentes também foram realizados nessas mesmas condições. Dessas medidas realizou-se o cálculo do desvio padrão relativo ou coeficiente de variação (CV), com a equação 1 .

$$
C V \%=\frac{D P}{C M D} \times 100
$$

Onde DP é o desvio padrão e CMD é a média do valor encontrado nas medidas.

\subsubsection{Especificidade}

Um método que produz resposta para apenas um analito é chamado específico. Portanto, para confirmar que o valor medido provém somente do ácido salicílico, foram realizadas medidas eletroquímicas deste composto na presença de possíveis interferentes. Foram escolhidos três ácidos fenólicos com moléculas que têm estrutura parecida com o analito de interesse além do ácido ascórbico, apresentadas na Figura 15 (WANG et al., 2010). 


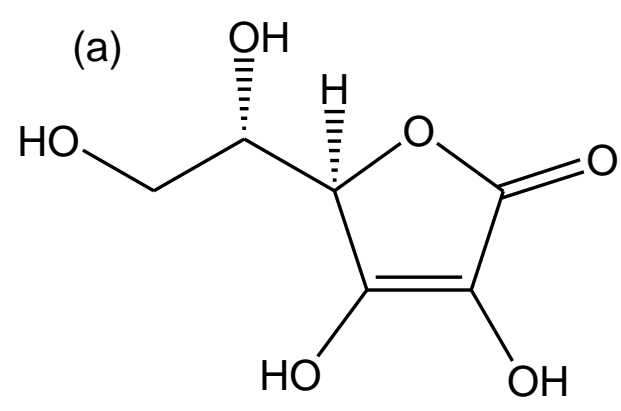

(c)

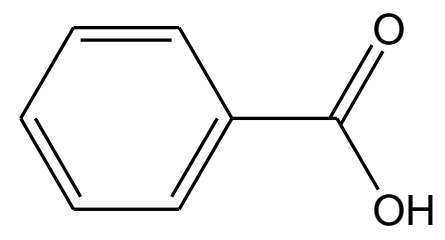<smiles>O=C(O)/C=C/c1ccccc1</smiles>

(d)<smiles>O=C(O)c1ccc(O)cc1</smiles>

Figura 15- Estrutura química, (a) ácido ascórbico; (b) ácido cinâmico; (c) ácido benzoico; (d) ácido p-hidroxibenzoico.

Soluções de cada composto apresentado foram preparadas na concentração de $7,2 \times 10^{-3} \mathrm{~mol} \mathrm{~L}^{-1}$ com exceção do ácido cinâmico que foi preparado na concentração de $2,4 \times 10^{-3} \mathrm{~mol} \mathrm{~L}^{-1}$ devido sua baixa solubilidade em água, e realizadas adições na cela eletroquímica em proporção igual, dez vezes maior e dez vezes menor de ácido salićlico $5,8 \mu \mathrm{mol} \mathrm{L}-1$ em ácido acético na concentração de $0,1 \mathrm{~mol} \mathrm{~L}^{-1}$. As leituras foram realizadas em triplicata e o erro relativo $\left(E_{r}\right)$ foi calculado com equação 2, em que $\bar{X}$ é a média dos valores encontrados e $\mu$ é o valor de referência.

$$
E_{r}=\frac{\bar{X}-\mu}{\mu} \times 100
$$

\subsubsection{Faixa linear de trabalho e sensibilidade}

A faixa linear de trabalho é o intervalo entre os níveis inferior e superior de concentração do analito no qual pode ser demonstrada possível a determinação com precisão, exatidão, linearidade e sensibilidade constante nas faixas de concentrações definidas (INMETRO, 2011).

Medidas do ácido salicílico em ácido acético $0,1 \mathrm{~mol} \mathrm{~L}^{-1}$, nas concentrações a partir do limite de quantificação, foram realizadas e por observação visual foi determinada a faixa linear de trabalho, confirmada através da linearidade calculada pela equação de regressão linear da reta (coeficiente de determinação ou $\mathrm{r}^{2}$ ), obtida 
da relação entre concentração do ácido salićlico e a densidade de corrente de pico resultante.

Sensibilidade é um parâmetro que demonstra a variação da resposta em função da concentração do analito, podendo ser expressa pela inclinação da reta de regressão da curva analítica e é determinada simultaneamente com os testes de linearidade (INMETRO, 2011).

\subsubsection{Limite de detecção e quantificação}

Limite de detecção é a menor quantidade do analito presente em uma amostra que pode ser detectado, porém não necessariamente quantificado, sob as condições experimentais estabelecidas e o limite de quantificação é a menor quantidade do analito em uma amostra que pode ser determinada com precisão e exatidão aceitáveis sob as condições experimentais estabelecidas (ANVISA, 2003).

O limite de detecção (LD) foi calculado através do desvio padrão (DP), das correntes medidas no mesmo potencial de oxidação do ácido salicílico em 7 leituras do branco (ácido acético 0,1 mol L-1), utilizando equação 3 (ANVISA, 2003; ICH, 1995).

$$
\mathrm{LD}=\frac{3,3 \mathrm{DP}}{\mathrm{b}}
$$

Onde b é o coeficiente angular da curva.

O limite de quantificação (LQ) foi calculado pelo mesmo experimento, porém com a equação 4.

$$
L Q=\frac{10 \mathrm{DP}}{b}
$$

\subsubsection{Recuperação}

A recuperação mede a eficiência do procedimento de extração de um método analítico dentro de um limite de variação de concentração (ANVISA, 2003). Como não foi necessária realização de extração, apenas a diluição da amostra o experimento de recuperação não foi realizado. 


\subsubsection{Comparação entre métodos}

Consiste na comparação dos resultados obtidos utilizando um método interno, com os resultados conseguidos por meio de um método de referência. O objetivo é estudar o grau de proximidade dos resultados obtidos pelos dois métodos de ensaio, ou seja, avaliar a exatidão do método desenvolvido com o de referência (INMETRO, 2011). Para isso, as análises foram efetuadas em três alíquotas da amostra, utilizando o método eletroquímico proposto (Voltametria de Pulso Diferencial-DPV) e HPLC como referência. A Figura 16 apresenta como foram realizados estes experimentos.

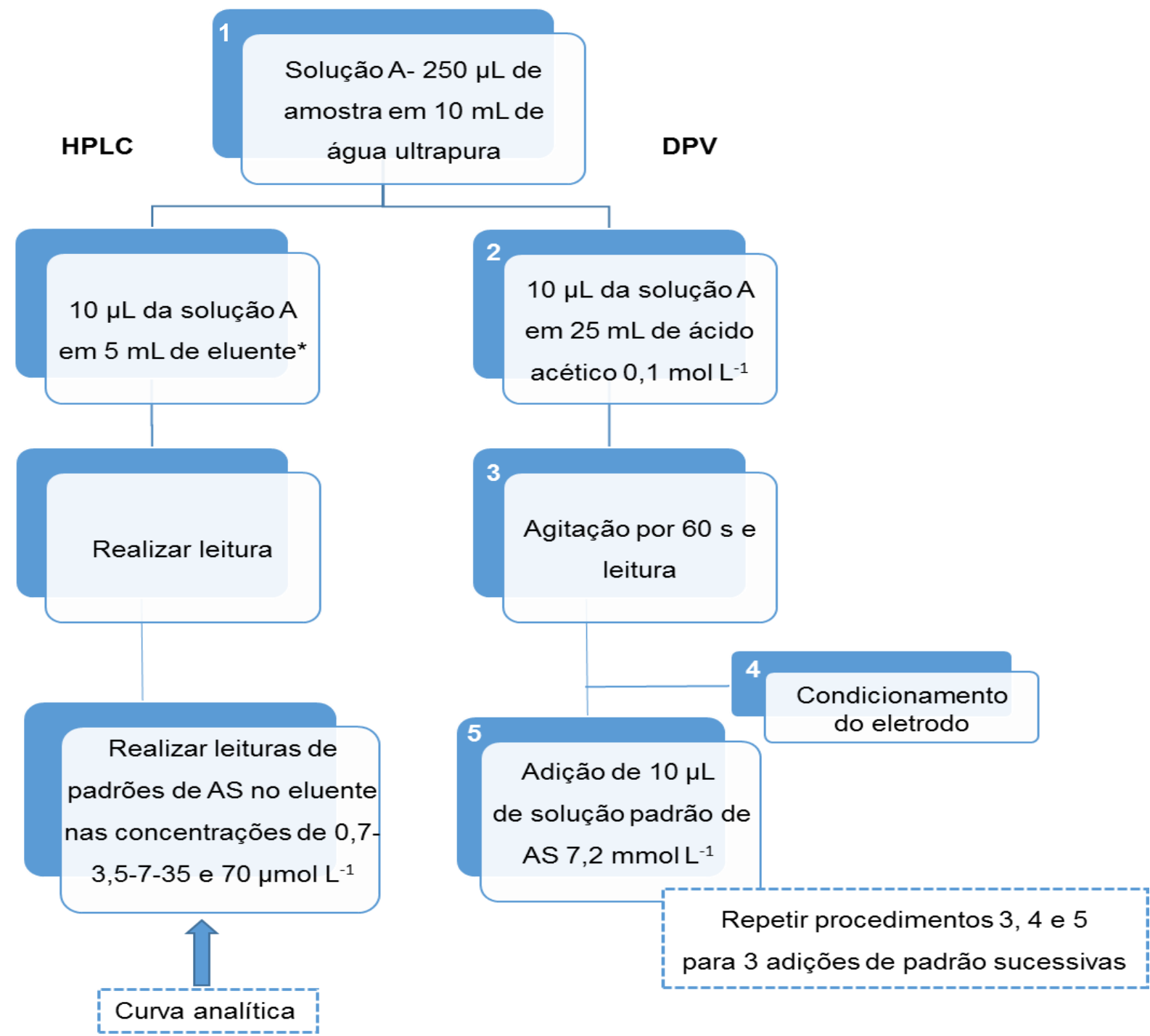

*Eluente utilizado foi a própria fase móvel escolhida

${ }^{* *}$ Condicionamento realizado em metanol:água em potencial de $-1 \mathrm{~V}$ por 60 segundos

Figura 16- Fluxograma das metodologias comparadas na quantificação de ácido salicílico (AS) em produto dermatológico. 
Como demonstrado no fluxograma a quantificação do ácido salicílico na amostra por HPLC, foi realizada através de equação da curva analítica obtida com relação área do pico e concentração medida, na DPV o método utilizado foi de adição de padrão, em que quantidade conhecida da solução padrão contendo o analito é adicionada na amostra. As respostas antes e depois da adição são medidas e posteriormente usadas para obter a concentração do analito (SKOOG, 2006). Essa concentração é o ponto de intersecção do eixo das concentrações, calculado pela equação da curva analítica.

$\mathrm{Na}$ comparação entre os resultados obtidos foi utilizado primeiramente o teste estatístico $F$ (Snedecor) para verificar se as variâncias das amostras podem ser consideradas iguais utilizando a equação 5 .

$$
F_{\text {calculado }}=\frac{s_{1}^{2}}{s_{2}^{2}}
$$

Onde, $s_{1}^{2}$ e $s_{2}^{2}$ são as variâncias de cada amostra, com a maior variância no

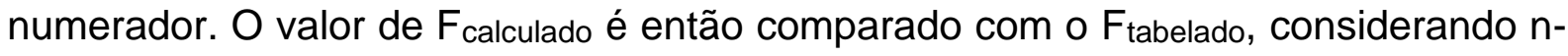
1 graus de liberdade e adotando-se um nível de confiança de 95\%. Para Fcalculado

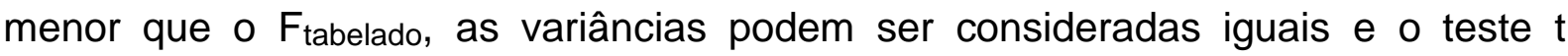
(Student) segue a equação 6 .

$$
t_{\text {Calculado }}=\frac{\left|\overline{x_{1}}-\overline{x_{2}}\right|}{\sqrt{s^{2}\left(\frac{1}{n_{1}}+\frac{1}{n_{2}}\right)}}
$$

Onde, $\bar{x}_{1}$ e $\bar{x}_{2}$ são as médias que serão comparadas, $s^{2}$ é calculado pela equação 7.

$$
s^{2}=\frac{\left(n_{1}-1\right) s_{1}^{2}+\left(n_{2}-1\right) s_{2}^{2}}{\left(n_{1}+n_{2}-2\right)}
$$

Em que $n_{1}$ e $n_{2}$ são os tamanhos das amostras, ou seja, quantidade de replicatas realizadas.

O valor de ttabelado é obtido a partir da tabela da distribuição de Student para ( $\mathrm{n}_{1}$ + $n_{2}$ - 2) graus de liberdade e nível de confiança de $95 \%$. Quando o valor de $t$ calculado for menor que o $t$ tabelado pode-se concluir que não há diferença significativa entre as médias (SKOOG, 2006; INMETRO, 2011). 


\section{RESULTADOS E DISCUSSÃO}

\subsection{Modificação e caracterização estrutural dos eletrodos}

Esse estudo foi realizado com o objetivo de verificar a modificação do eletrodo com as nanopartículas de óxido de ferro e os nanotubos de carbono depositados pela técnica de automontagem camada por camada (LbL).

\subsubsection{Monitoramento da adsorção dos Nanomateriais por Espectroscopia de absorção UV-vis}

Na Figura 17 são apresentados os espectros de absorção UV-vis da solução e dispersão dos nanomateriais e dos filmes depositados. Na Figura 17(a) estão os espectros das soluções de np-MAG, NT-PABS e polieletrólito PDAC. O espectro da solução de np-MAG apresenta um ombro com máximo em 360 nm atribuído à transição eletrônica $\mathrm{Fe}^{2+} \rightleftharpoons \mathrm{Fe}^{3+}$ (SCHWERTMANN;CORNELL, 1991). O espectro da solução de nanotubos apresenta uma absorção mais intensa, por volta de $260 \mathrm{~nm}$, a qual é atribuída aos plasmons $\pi$ (POPOV, 2004) e absorção em 990 nm referente a singularidades da densidade de estados dos nanotubos semicondutores (interbanda

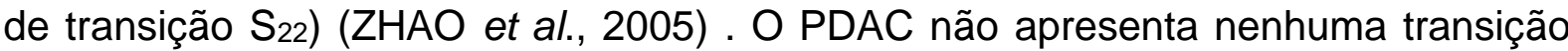
eletrônica na faixa UV-vis. Desse modo, é possível monitorar a adsorção dos nanomateriais por espectroscopia de absorção UV-vis.

Na Figura 17(b) e 17(c) são apresentados os espectros do substrato de quartzo com número variado de tetracamadas (PDAC/NT-PABS/np-MAG/NT-PABS) n, com $n$ $=1,3,5,7$ e 10. Primeiramente, nota-se grande semelhança entre os espectros do filme sobre quartzo (figura 16b) e o espectro da solução de np-MAG. Apesar da presença dos NT-PABS, evidenciado na Figura 17(c) com pico de absorção em 990 nm também presente na solução de nanotubos, o espectro de absorção dos filmes é dominado pelas transições referentes às np-MAG. Um efeito similar foi observado por Santos et al. (2014) em filmes de np-MAG com poli(estireno sulfonato de sódio). Este último apresenta uma banda característica em 270 nm e que não foi observada nos filmes. Uma segunda observação importante que pode ser feita é com respeito ao aumento linear da absorbância nos comprimentos de onda de 360 nm e 480 nm 
(gráfico inserido na figura 17b) com o número de tetracamadas depositadas. Esse aumento linear sugere que a quantidade de material adsorvido é sempre a mesma à cada tetracamada depositada. Mais do que isso, permite concluir que o processo LbL assegura o controle em escala nanométrica da arquitetura do filme.
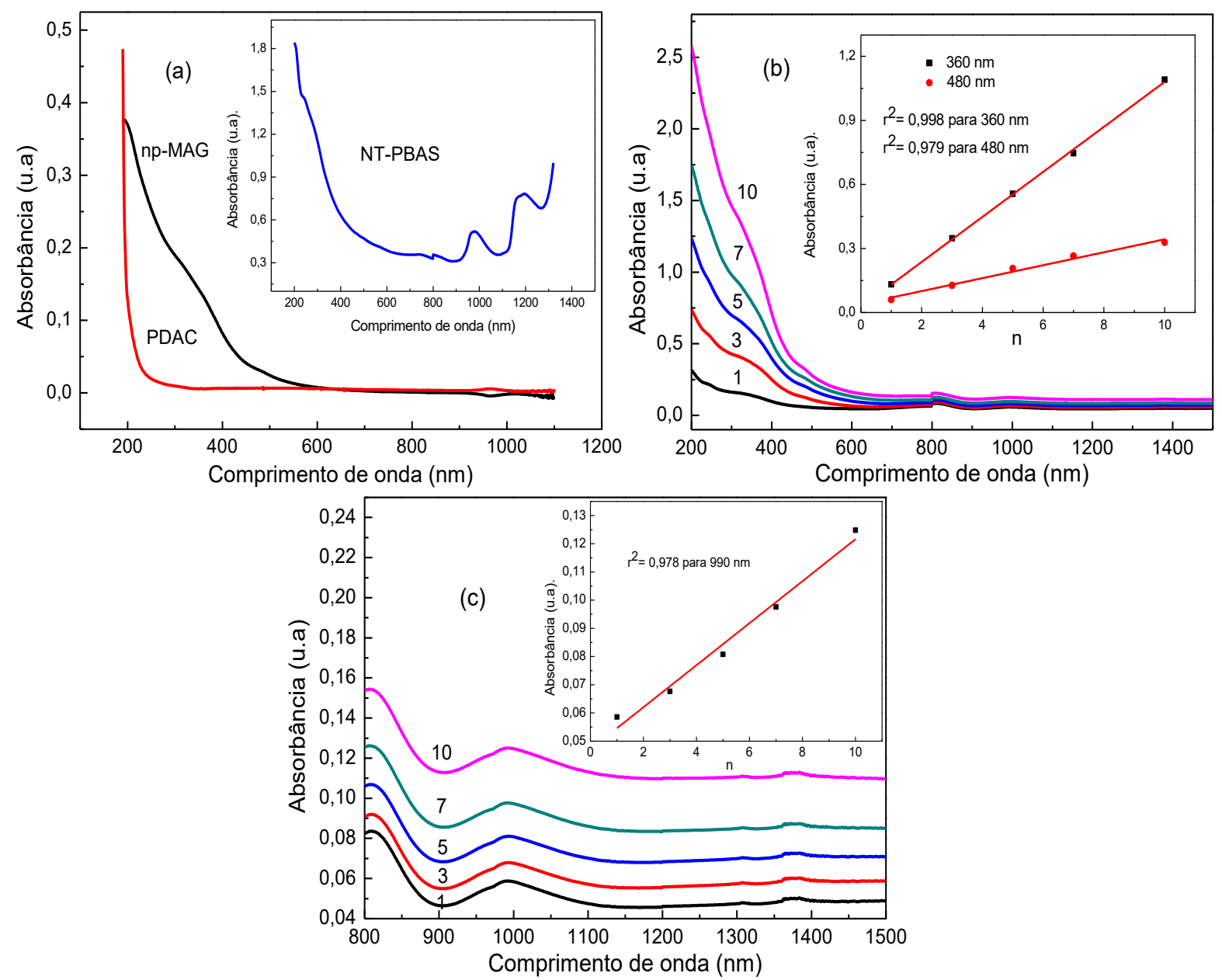

Figura 17- (a) Espectros de absorção Uv-vis das soluções de PDAC, np-MAG e NTPBAS; (b) e (c) Espectros de absorção Uv-vis dos eletrodos com 1, 3, 5, 7 e 10 tetracamadas. Os gráficos inseridos mostram a relação linear entre absorbância e número de tetracamadas depositadas.

\subsubsection{Microscopia de Força Atômica}

As imagens de AFM dos filmes com número variado de tetracamadas são apresentadas na Figura 18. De um modo geral, observa-se que a superfície dos filmes é recoberta com partículas esféricas de np-MAG. Além disso, é possível perceber um acúmulo de np-MAG à medida que o número de tetracamadas aumenta, assim como observado por espectroscopia UV-vis. 

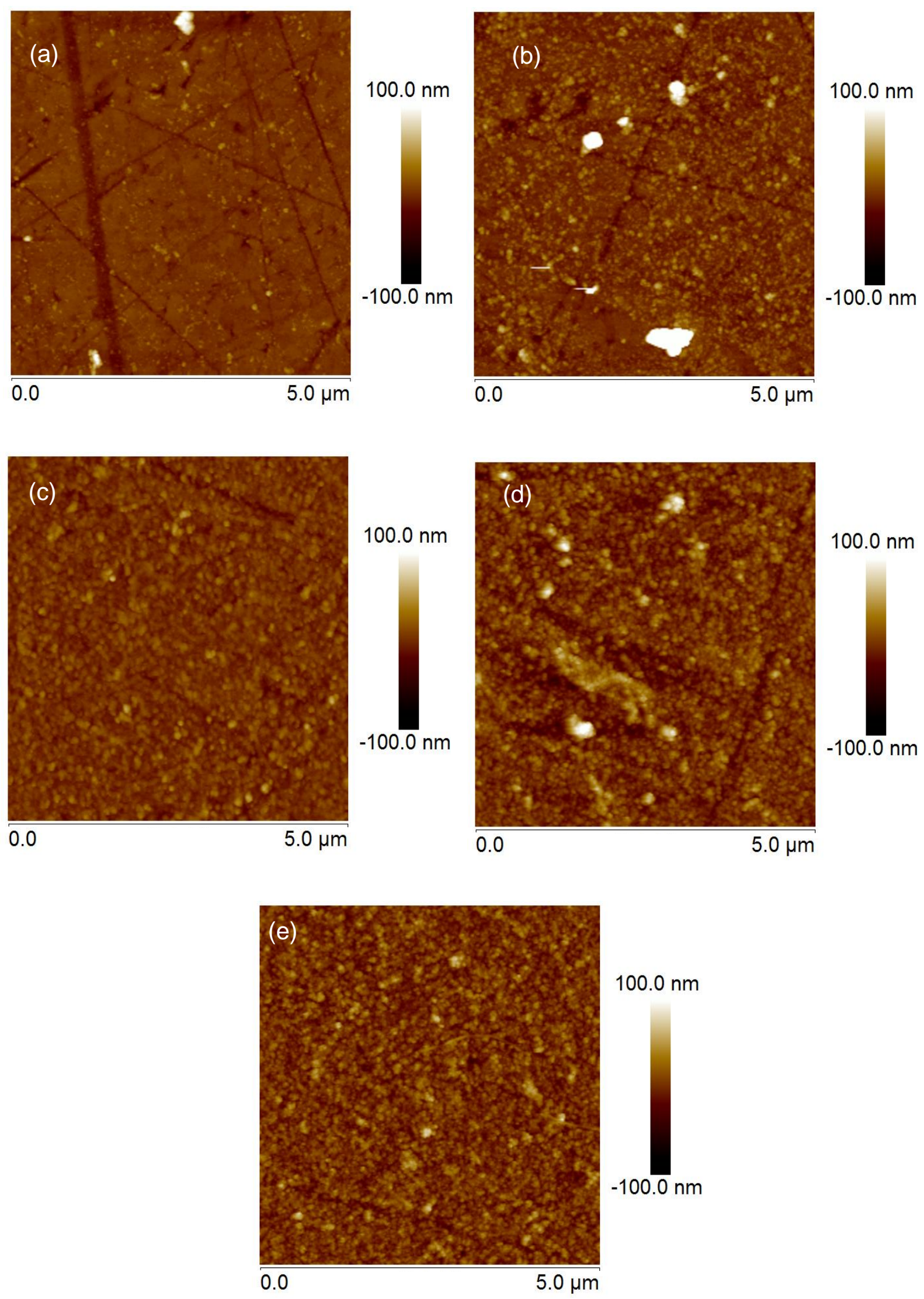

Figura 18- Imagens de AFM dos filmes com (a)1 (b) 3 (c) 5 (d) 7 (e)10 tetracamadas. 
Na Figura 19 são apresentados os parâmetros morfológicos (rugosidade e espessura) dos filmes em função do número de tetracamadas. Na Figura 19(a) notase que a rugosidade do filme aumenta gradativamente até atingir um patamar, em que não varia mais. Esse comportamento é típico de sistemas onde a adsorção é controlada por nucleação. Na deposição das primeiras tetracamadas, apenas parte da superfície do substrato é ocupado por núcleos de nanomateriais. À medida que mais tetracamadas são depositadas, os espaços vazios deixados entre os materiais de uma tetracamada são preenchidos por materiais de tetracamadas subsequentes (Santos et al., 2014; ALCANTARA et al., 2011). Num determinado momento, esse espaço é completamente preenchido e a rugosidade da superfície não varia mais quando mais tetracamadas são depositadas.
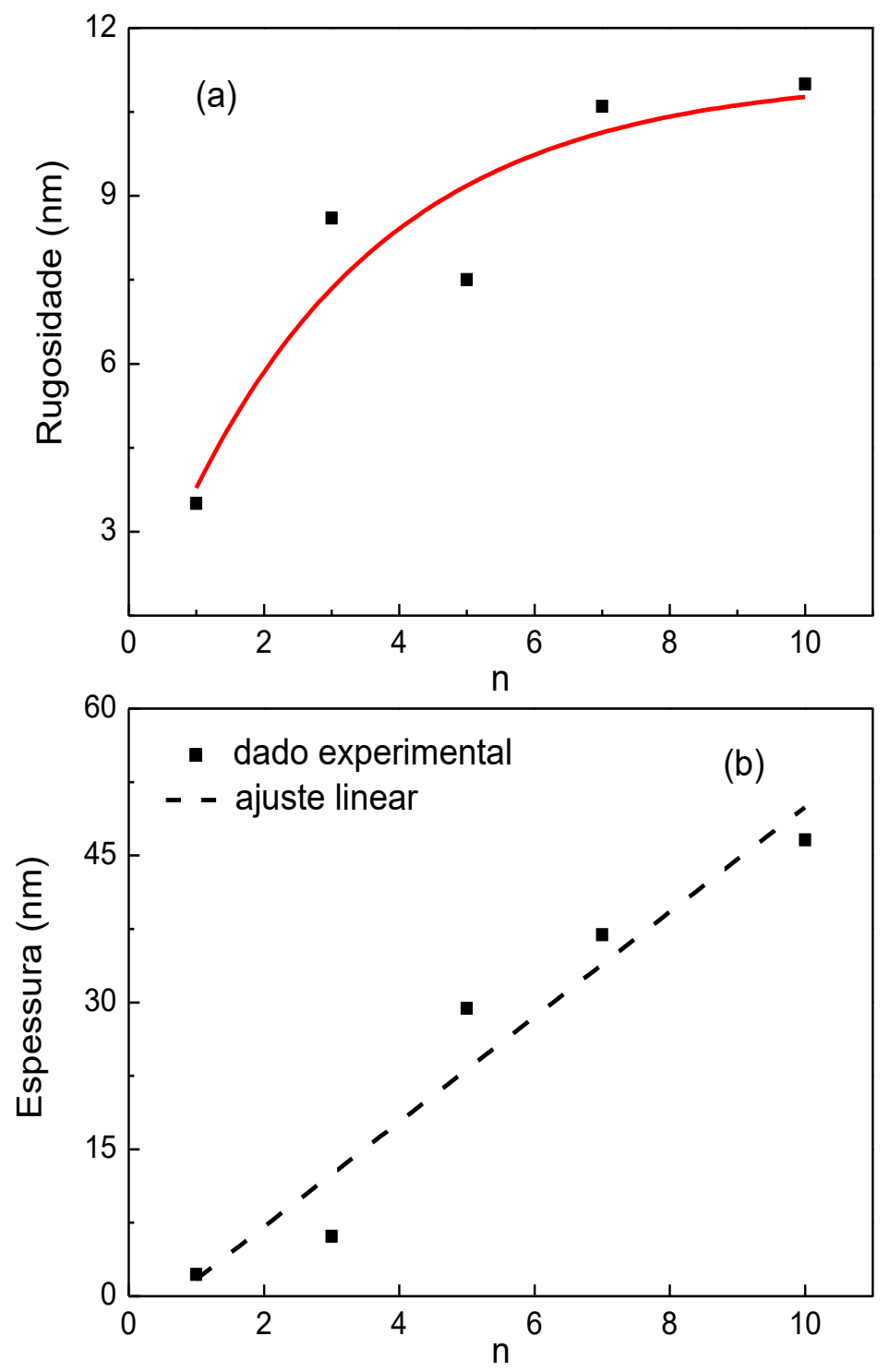

Figura 19- (a) Rugosidade e (b) espessura do filme em função do número de tetracamadas depositadas (n). 
Na Figura 19(b) observa-se que a espessura dos filmes tem uma dependência linear com o número de tetracamadas. Pelo ajuste linear, a espessura por tetracamada é aproximadamente 4,5 nm. Uma vez que apenas as np-MAG apresentam diâmetro de $8 \mathrm{~nm}$, o valor de 4,5 nm significa que as np-MAG de uma determinada tetracamada ocupam os vazios deixados pela camada inferior, de modo que com a deposição o filme fica mais denso, com partículas cada vez mais empacotadas na estrutura do filme.

\subsection{Caracterização eletroquímica}

Os experimentos para caracterização eletroquímica dos eletrodos modificados foram realizados com ferricianeto de potássio $\left(\mathrm{K}_{3} \mathrm{Fe}(\mathrm{CN})_{6}\right)$ em $\mathrm{KCl}$, que apresenta um processo redox bem definido e é frequentemente utilizado para estimar a área eletroativa, bem como parâmetros cinéticos e termodinâmicos de eletrodos quimicamente modificados (ZHANG et al., 2010).

\subsubsection{Voltametria cíclica}

Na Figura 20 são apresentados os voltamogramas obtidos para o par redox $\mathrm{K}_{3} \mathrm{Fe}(\mathrm{CN})_{6}$ com o eletrodo modificado com número variado de tetracamadas (PDAC/NT-PABS/np-MAG/NT-PABS) $n$, com $n=1,3,5,7$ e 10. Os voltamogramas obtidos com o eletrodo não modificado e com eletrodo modificado com filme (PDAC/NT-PABS)5 são também apresentados para fins de comparação. De um modo geral, picos de oxidação e redução bem definidos são observados, portanto, todos os eletrodos são capazes de conduzir a reação redox, a saber

$$
\mathrm{Fe}(\mathrm{CN}) 6^{3-}+\mathrm{e}^{-} \rightleftharpoons \mathrm{Fe}(\mathrm{CN}) 6^{4-}
$$

Os parâmetros eletroquímicos para cada eletrodo são apresentados na Figura 21. A diferença de potencial entre os picos anódico e catódico $\left(\Delta \mathrm{E}_{\mathrm{p}}\right)$ foi menor para o eletrodo modificado com uma tetracamada (Figura 21a). A partir de então, o valor de $\Delta \mathrm{E}_{\mathrm{p}}$ aumentou à medida que mais tetracamadas foram depositadas. Essa diferença foi maior ainda no eletrodo modificado com PDAC/NT-PABS, que apresentou também um deslocamento dos potenciais de pico, para valores menores, indicando que nesses eletrodos o processo redox tem tendência a irreversibilidade, ou seja, sem a presença 
das np-MAG o processo de transferência de elétrons na superfície do eletrodo tem tendência a ocorrer mais lentamente devido a diminuição da área superficial do eletrodo.

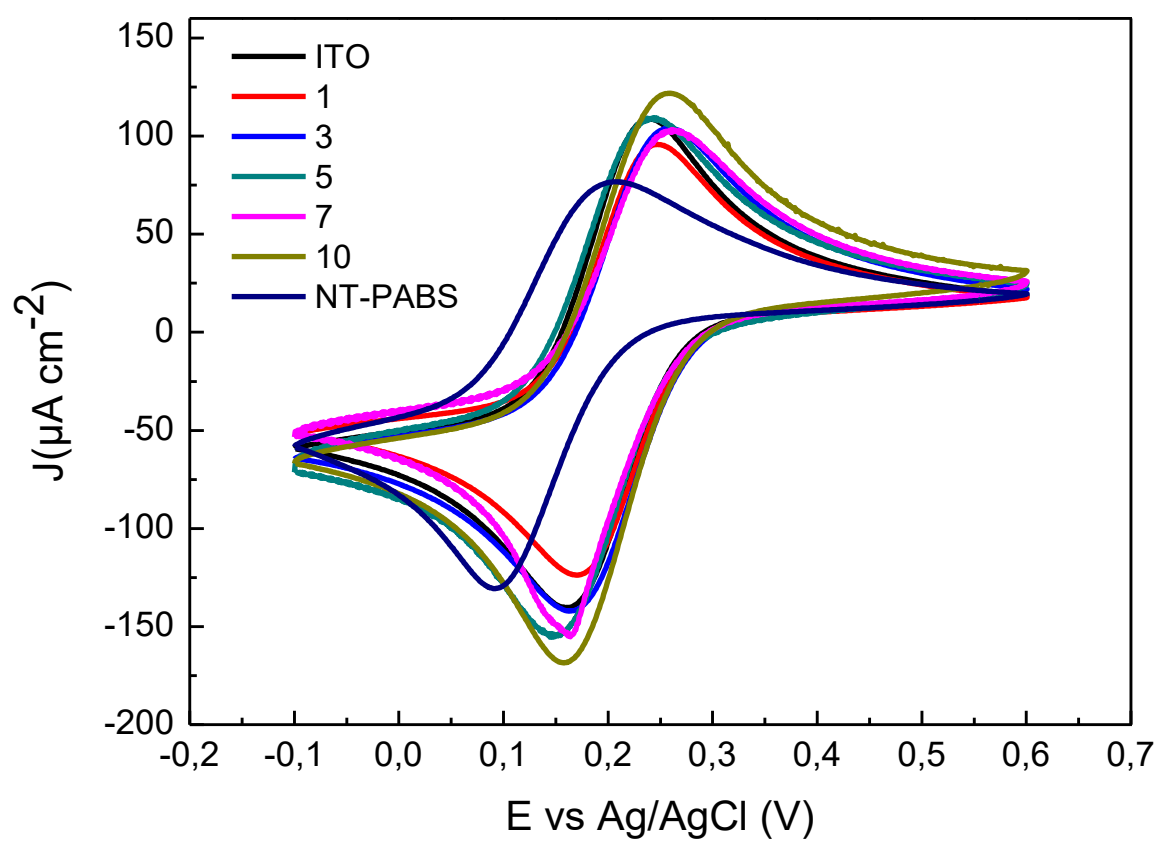

Figura 20- Voltamogramas cíclicos do ITO, eletrodos modificados com 1,3,5,7 e 10 tetracamadas (PDAC/NT-PABS/np-MAG/NT-PABS) e eletrodo com 5 bicamadas (PDAC/NT-PABS), na solução de $\mathrm{K}_{3} \mathrm{Fe}(\mathrm{CN})_{6} 1 \times 10^{-3} \mathrm{~mol} \mathrm{~L}^{-1}$ em KCl 0,1 $\mathrm{mol} \mathrm{L}^{-1}$, com velocidade de $25 \mathrm{mV} \mathrm{s}^{-1}$

O cálculo da área eletroativa dos eletrodos foi realizado com a equação 8 , de Randles-Sevick descrita a seguir (BRETT; BRETT, 1993):

$$
I_{p}=2,69 \times 10^{5} n^{3 / 2} A_{0}{ }_{0}^{1 / 2} C_{0} v^{1 / 2}
$$

Onde, $\mathrm{I}_{\mathrm{p}}, \mathrm{n}, \mathrm{D}_{\mathrm{o}}, \mathrm{C}_{\mathrm{o}} \mathrm{e} v$ são respectivamente a corrente de pico anódico, número de elétrons transferidos (1), coeficiente de difusão de oxidação $\left(7,6 \times 10^{-6} \mathrm{~cm}^{2} \mathrm{~s}^{-1}\right)$ (BARD; FAULKNER, 2001), concentração de ferricianeto $\left(1 \times 10^{-6} \mathrm{~mol} \mathrm{~cm}^{-3}\right)$ e velocidade de varredura $\left(25 \mathrm{mV} \mathrm{s}^{-1}\right)$.

O eletrodo de 10 camadas apresentou a maior área eletroativa, embora não tenha sido observado qualquer dependência da área eletroativa com o número de tetracamadas como mostra a Figura 21 (b). 

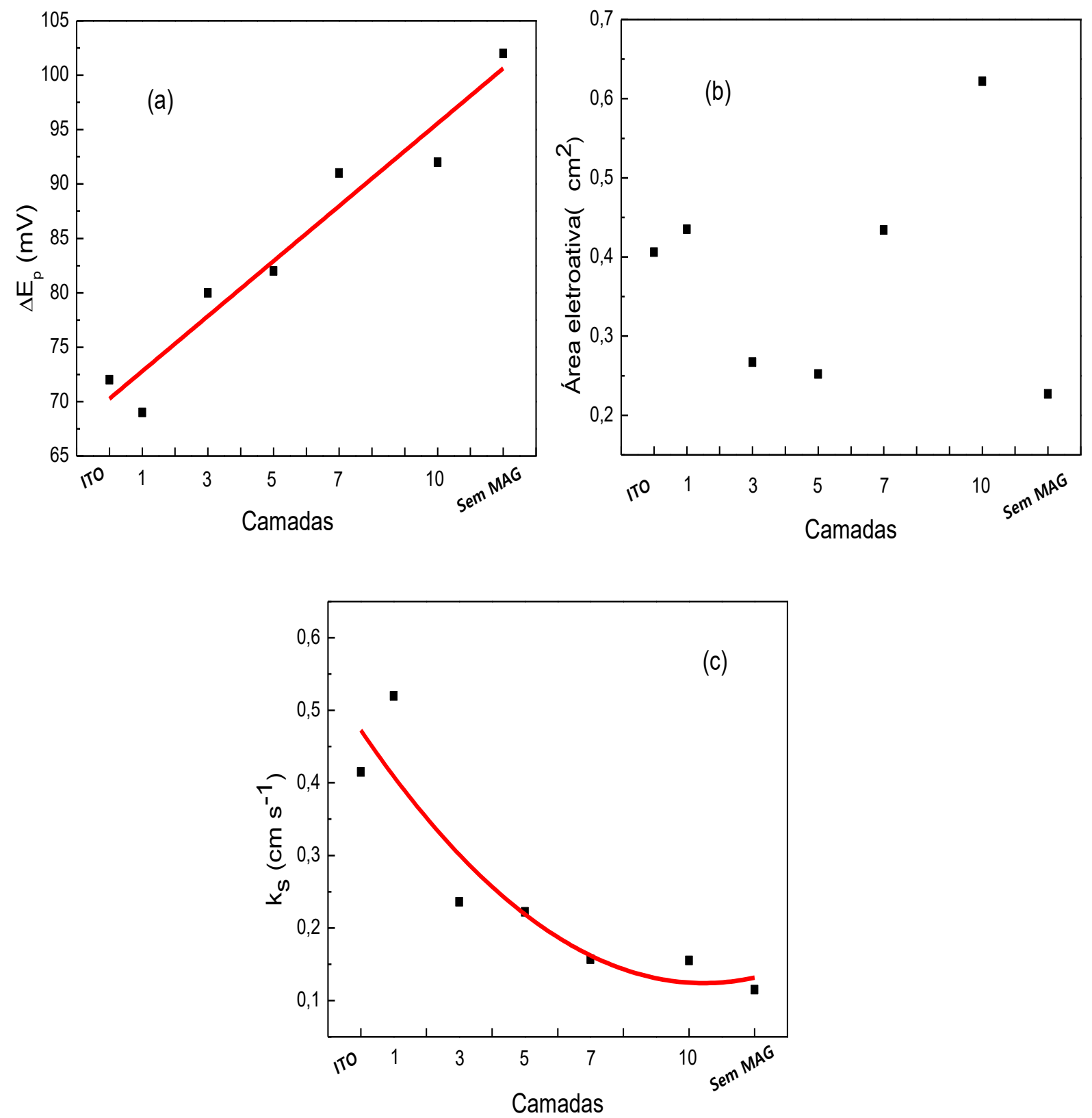

Figura 21- Parâmetros eletroquímicos obtidos na voltametria cíclica de eletrodos com diferentes camadas na solução de $\mathrm{K}_{3} \mathrm{Fe}(\mathrm{CN})_{6} 1 \times 10^{-3} \mathrm{~mol} \mathrm{~L}^{-1} \mathrm{em} \mathrm{KCl} \mathrm{0,1} \mathrm{mol} \mathrm{L}^{-1}$, com velocidade de $25 \mathrm{mV} \mathrm{s}^{-1}$ (a) $\Delta \mathrm{E}$, (b) área eletroativa e (c) ks.

A constante aparente de taxa de transferência de elétrons $\left(\mathrm{k}_{\mathrm{s}}\right)$, parâmetro importante na comparação quantitativa do processo de transferência de elétrons na superfície eletrodo, foi calculada pela equação 9 desenvolvida por Nicholson (1965): 


$$
\mathrm{k}_{\mathrm{s}}=\frac{\Psi\left[\mathrm{D}_{\mathrm{O}} \Pi v\left(\frac{\mathrm{nF}}{\mathrm{RT}}\right)\right]^{\frac{1}{2}}}{\left(\frac{\mathrm{D}_{\mathrm{O}}}{\mathrm{D}_{\mathrm{R}}}\right)^{\frac{\alpha}{2}}}
$$

Em que, $\Psi$ é um parâmetro cinético encontrado de acordo com $\Delta \mathrm{E}$ em tabela desenvolvida por Nicholson, Do e Dr são respectivamente o coeficiente de difusão de oxidação $\left(7,6 \times 10^{-6} \mathrm{~cm}^{2} \mathrm{~s}^{-1}\right)$ e o coeficiente de difusão de redução $\left(6,5 \times 10^{-6} \mathrm{~cm}^{2} \mathrm{~s}^{-1}\right)$ do $\mathrm{K}_{3} \mathrm{Fe}(\mathrm{CN})_{6} 1 \times 10^{-3} \mathrm{~mol} \mathrm{~L}^{-1}$ em KCl 0,1 $\mathrm{mol} \mathrm{L}^{-1}$ (BARD; FAULKNER, 2001), $v$ é a velocidade de varredura $\left(25 \mathrm{mV} \mathrm{s}^{-1}\right) \mathrm{n}$ é o número de elétrons transferidos, $\mathrm{F}$ é a constante de Faraday $\left(96485,3 \mathrm{C} \mathrm{mol}^{-1}\right), \mathrm{R}$ é a constante universal dos gases $(8,314$ $\left.\mathrm{J} \mathrm{K}^{-1} \mathrm{~mol}^{-1}\right)$, T é a temperatura absoluta $(298 \mathrm{~K})$ e $\propto$ é o coeficiente de transferência de elétrons $(0,5)$.

O aumento do valor de ks para o eletrodo de 1 tetracamada em relação ao ITO não modificado é demonstrado na Figura 21 (c), porém nas seguintes camadas depositadas esse valor diminui. Portanto, para o eletrodo com 1 tetracamada o aumento da área superficial e a presença dos nanotubos de carbono funcionalizados com um polímero condutor (PABS), favoreceu a transferência de elétrons mais rápida, porém a deposição de mais camadas pode ter bloqueado o caminho de fluxo dos elétrons na superfície do eletrodo, este mesmo comportamento foi relatado por Santos et al. (2014) que realizou esse mesmo estudo com eletrodo de np-MAG.

No eletrodo sem MAG com 5 bicamadas de PDAC/NT-PABS, esse valor é ainda menor, provavelmente o fato do PDAC ser um polímero isolante, deve ter contribuído para a diminuição de ks. Além disso, é confirmado que a presença das npMAG torna a transferência de elétrons mais rápida.

Os voltamogramas cíclicos variando a velocidade de 25 a $200 \mathrm{mV} \mathrm{s}^{-1}$ das leituras com os diferentes eletrodos em $\mathrm{K}_{3} \mathrm{Fe}(\mathrm{CN})_{6} 1 \times 10^{-3} \mathrm{~mol} \mathrm{~L}^{-1} \mathrm{em} \mathrm{KCl} \mathrm{0,1} \mathrm{mol} \mathrm{L}^{-1}$ são mostrados na Figura 22. 

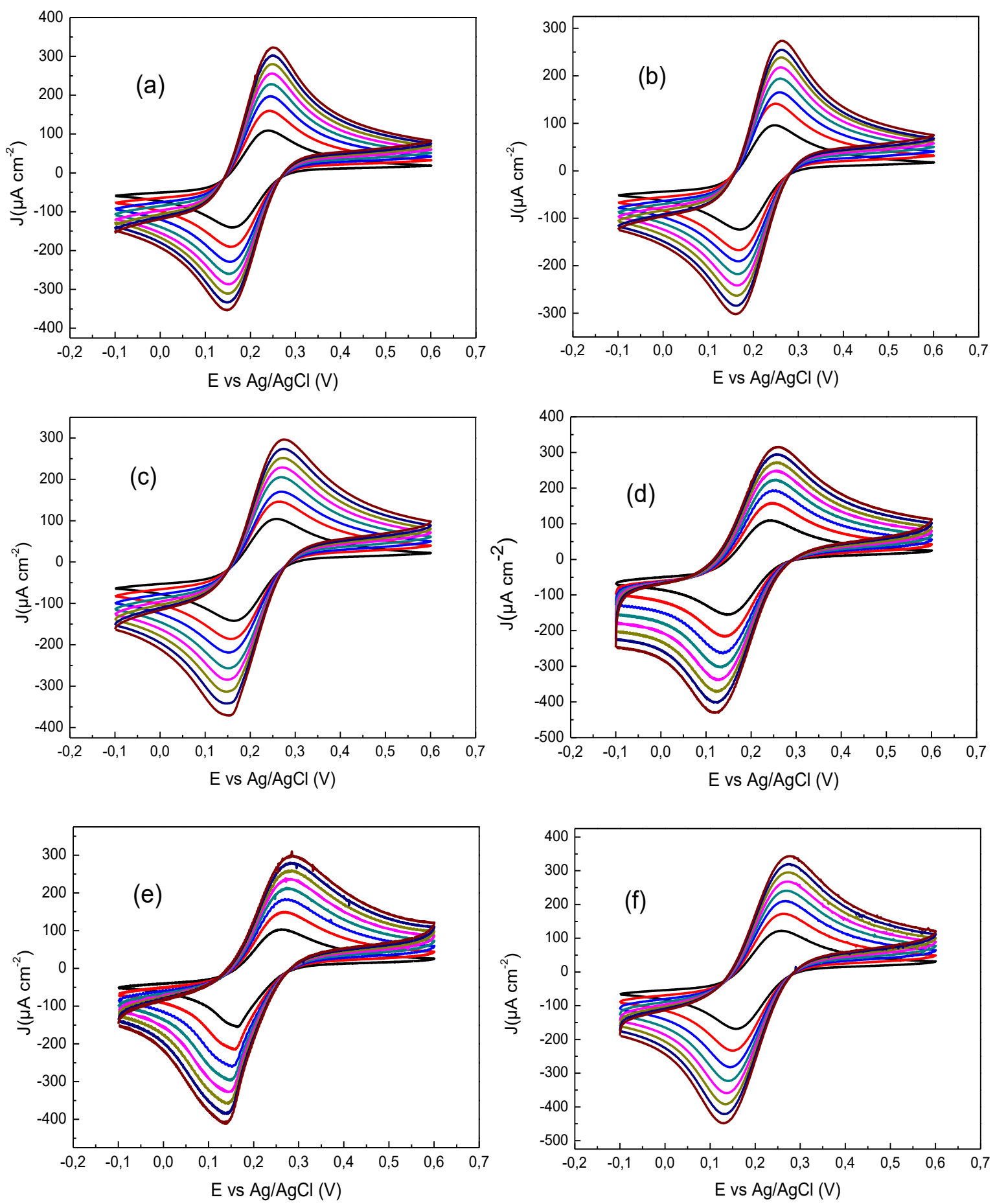

Figura 22- Voltamogramas cíclicos de $1 \times 10^{-3} \mathrm{~mol} \mathrm{~L}^{-1}$ de $\mathrm{K}_{3} \mathrm{Fe}(\mathrm{CN})_{6} \mathrm{em} 0,1 \mathrm{~mol} \mathrm{~L}^{-1}$ de $\mathrm{KCl}$, nas velocidades de 25 a $200 \mathrm{mV} \mathrm{s}^{-1}$ com eletrodo de (a) ITO (b) 1 (c) 3 (d) 5 (e) 7 (f) 10 tetracamadas.

As densidades de corrente de pico demonstraram um aumento linear em função da $v^{1 / 2}$ (Figura 23a). Esse resultado sugere que a reação nos eletrodos é controlada por difusão (BRETT; BRETT, 1993). Na Figura 23(b) é possível observar 
que a diferença de potencial de pico não varia de forma linear com o logaritmo da velocidade e a diferença de pico para todos os eletrodos foi maior que $59 \mathrm{mV} / \mathrm{n}$, considerando-se assim um processo quasi-reversível.
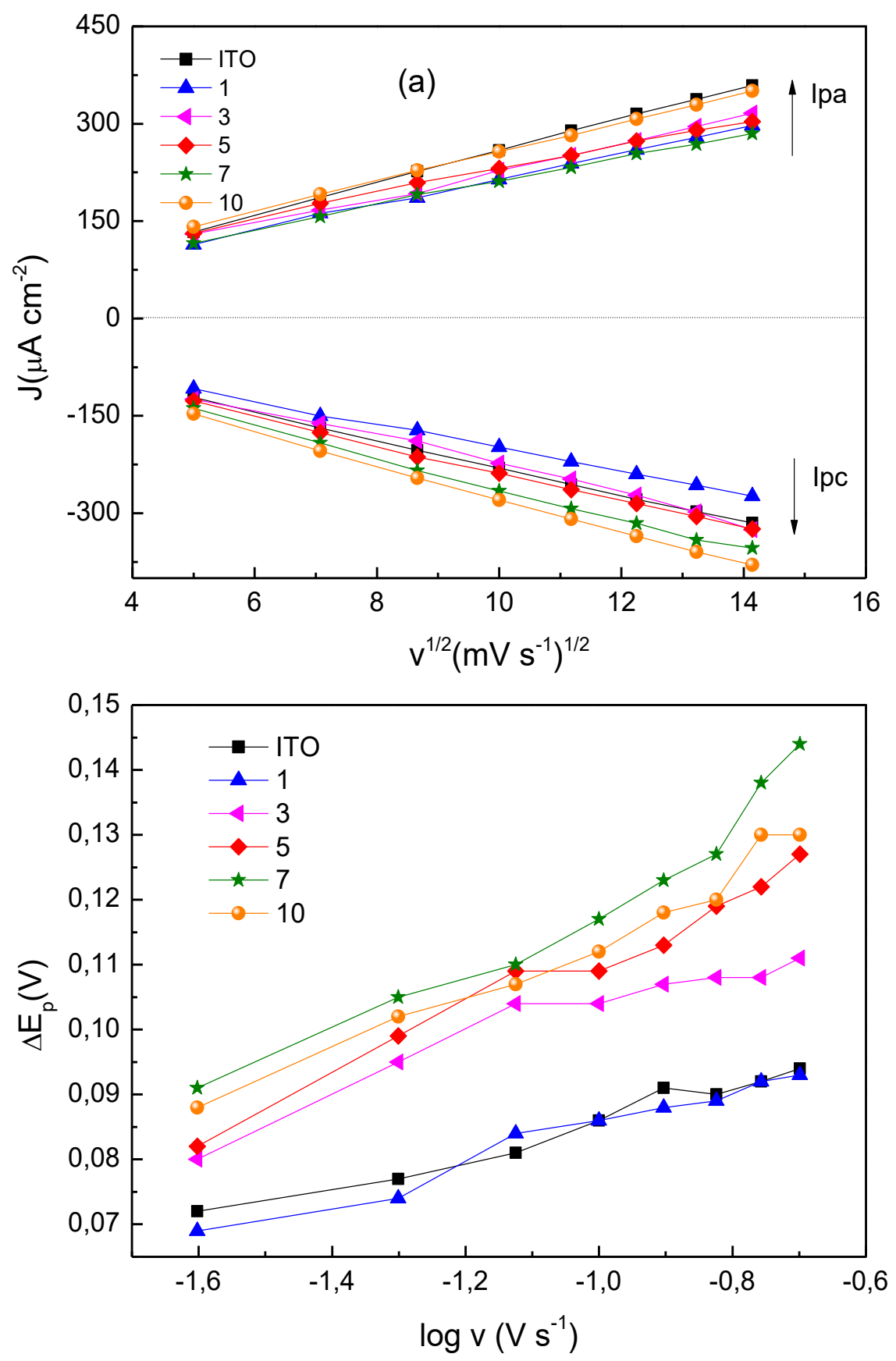

Figura 23- (a) Densidade de carga em função de $v^{1 / 2}$ (b) Diferença de potencial de picos anódicos e catódicos em função de log v. 


\subsubsection{Impedância eletroquímica}

A espectroscopia de impedância eletroquímica (EIS) é uma eficiente ferramenta para o estudo das propriedades da superfície de eletrodos modificados. Assim, a capacidade de transferência de elétrons foi investigada nos eletrodos de 5 bicamadas de PDAC/NT-PABS, de 3 tetracamadas PDAC/NT-PABS/np-MAG/NT-PABS e no ITO, em KCl 0,1 $\mathrm{mol} \mathrm{L}^{-1}$ (Figura 24a) e na solução de $\mathrm{K}_{3} \mathrm{Fe}(\mathrm{CN})_{6} 1 \times 10^{-3} \mathrm{~mol} \mathrm{~L}^{-1}$ em KCl 0,1 mol L-1 (Figura 24b).
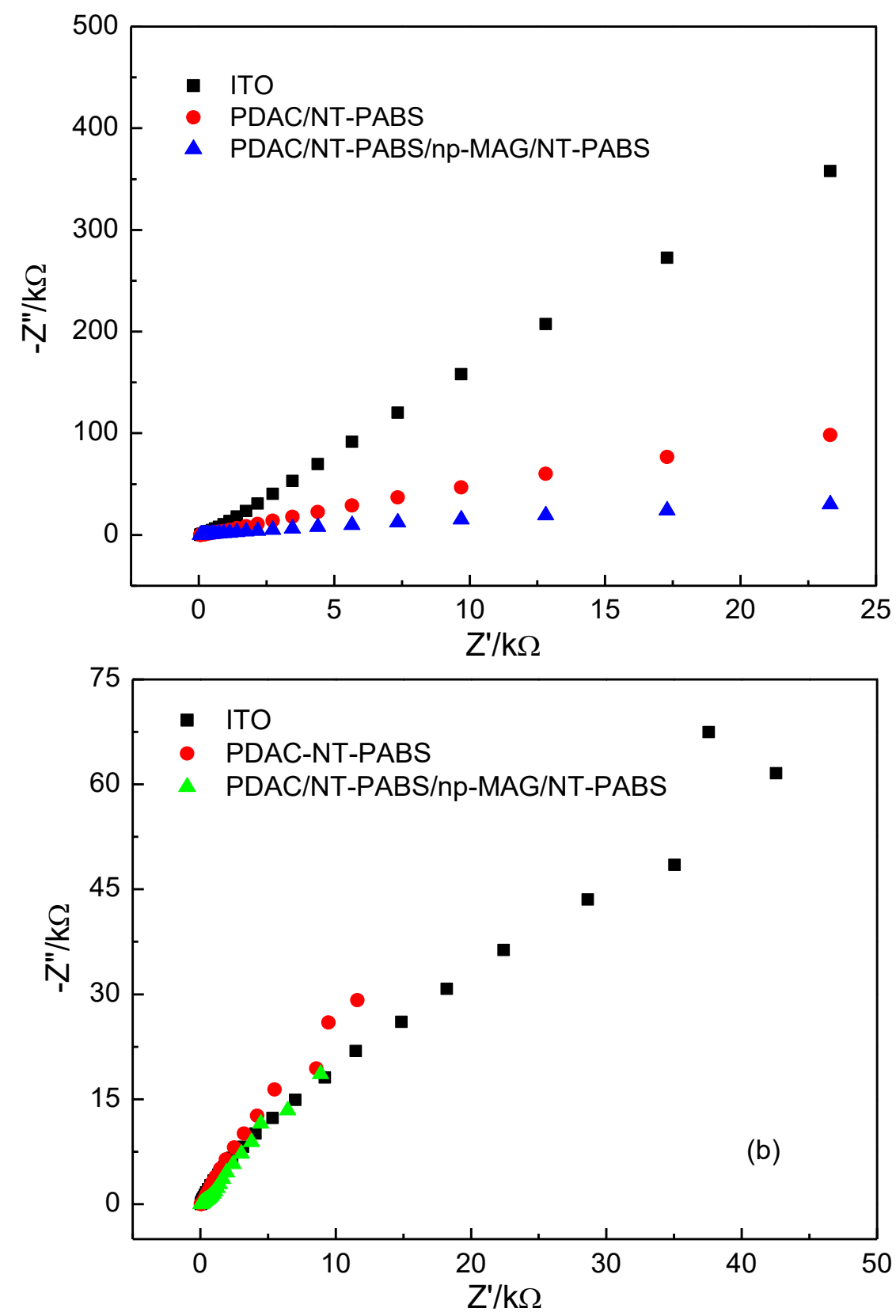

Figura 24- Espectros de impedância eletroquímica, (a) $\mathrm{KCl} 0,1 \mathrm{~mol} \mathrm{~L}^{-1}$; (b) $\mathrm{K}_{3} \mathrm{Fe}(\mathrm{CN})_{6}$ $1 \times 10^{-3} \mathrm{~mol} \mathrm{~L}^{-1} \mathrm{em} \mathrm{KCl} 0,1 \mathrm{~mol} \mathrm{~L}^{-1}$ 
Para ambos os casos, a impedância com o eletrodo modificado com as tetracamadas foi sempre menor, o que sugere que a transferência de carga é facilitada nesse eletrodo, como já observado por voltametria cíclica por meio dos dados de ks.

Os dados dos espectros de impedância foram ajustados com o circuito equivalente apresentado na Figura 25 com o software Nova 1.11. A adoção desse circuito teve como base a literatura e, também, porque com esse os parâmetros de ajuste foram os melhores. Nesse circuito, $R_{s}$ representa a resistência do eletrólito, $R_{p}$ é a resistência a transferência de carga, que determina a cinética de transporte de elétrons no eletrodo, quanto menor o valor, maior é a taxa de transferência de carga no eletrodo, $C_{p}$ é a capacitância geométrica do eletrodo e $Q$ é o elemento de fase constante (OGUNLUSI et al., 2012).

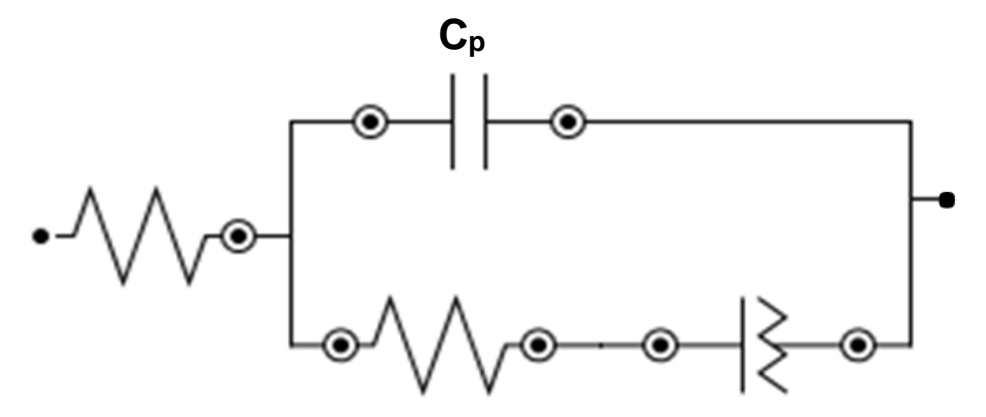

Figura 25- Circuito equivalente utilizado para ajuste dos dados de impedância.

Na Tabela 3 são apresentados os valores de cada elemento do circuito a partir dos dados obtidos em $\mathrm{KCl}$ e $\mathrm{KCl}+$ ferri/ferrocianeto. Para o experimento em $\mathrm{KCl}$, observa-se que o valor de Rs é praticamente o mesmo para todos os eletrodos, com valores de cerca de 0,06 k $\Omega$. No mesmo eletrólito, o valor de $R_{p}$ é menor para o eletrodo PDAC/NT-PABS/np-MAG/NT-PABS, enquanto o valor de $Q$ é o mesmo que o encontrado para o eletrodo de ITO sem filme. Já para o experimento realizado em $\mathrm{K}_{3} \mathrm{Fe}(\mathrm{CN})_{6}$ os valores de $\mathrm{R}_{p}$ e $\mathrm{Q}$ são bem maiores para o eletrodo desenvolvido (PDAC/NT-PABS/np-MAG/NT-PABS). Assim como observado por voltametria cíclica, a taxa de transferência eletrônica é menor nesses eletrodos, o que reflete nos valores maiores de $R_{p}$ e $Q$. Isso porque as np-MAG apresentam comportamento intermediário entre semicondutor e isolante. Além disso, as reações do par redox são dependentes da superfície do eletrodo que é muito diferente no caso dos filmes de PDAC/NT- 
PABS/np-MAG/NT-PABS. Por outro lado, a mesma superfície é mais adequada para a oxidação do ácido salicílico, como será visto mais adiante.

Tabela 3- Parâmetros de ajuste para a resposta de impedância dos eletrodos ITO, (1) PDAC/NT-PABS, (2) PDAC/NT-PABS/np-MAG/NT-PABS.

\begin{tabular}{|c|c|c|c|c|c|c|}
\hline & \multicolumn{6}{|c|}{ Eletrodo } \\
\hline & \multicolumn{3}{|c|}{$\mathrm{KCl}$} & \multicolumn{3}{|c|}{$\mathrm{K} 3 \mathrm{Fe}(\mathrm{CN})_{6}$} \\
\hline do & ITO & 1 & 2 & ITO & 1 & 2 \\
\hline$R_{s}(k \Omega)$ & 0,06 & 0,06 & 0,07 & 0,06 & 0,06 & 0,06 \\
\hline$C_{p}(\mu F)$ & 0,99 & 3,10 & 0,72 & 2,92 & 5,89 & 8,13 \\
\hline$R_{p}(\Omega)$ & 13,603 & 22,953 & 2,8679 & 103,59 & 140,68 & 308,22 \\
\hline$Q(m F)$ & 11,7 & 3,62 & 11,6 & 24,7 & 7,57 & 480 \\
\hline
\end{tabular}

\subsection{Escolha do eletrodo de trabalho}

Os eletrodos nanoestruturados em estudo foram utilizados na análise de ácido salicílico por voltametria cíclica. O pico de oxidação do ácido salicílico foi encontrado em todos os eletrodos modificados, enquanto que para o ITO não modificado o pico não ficou evidenciado como mostra a Figura 26. 


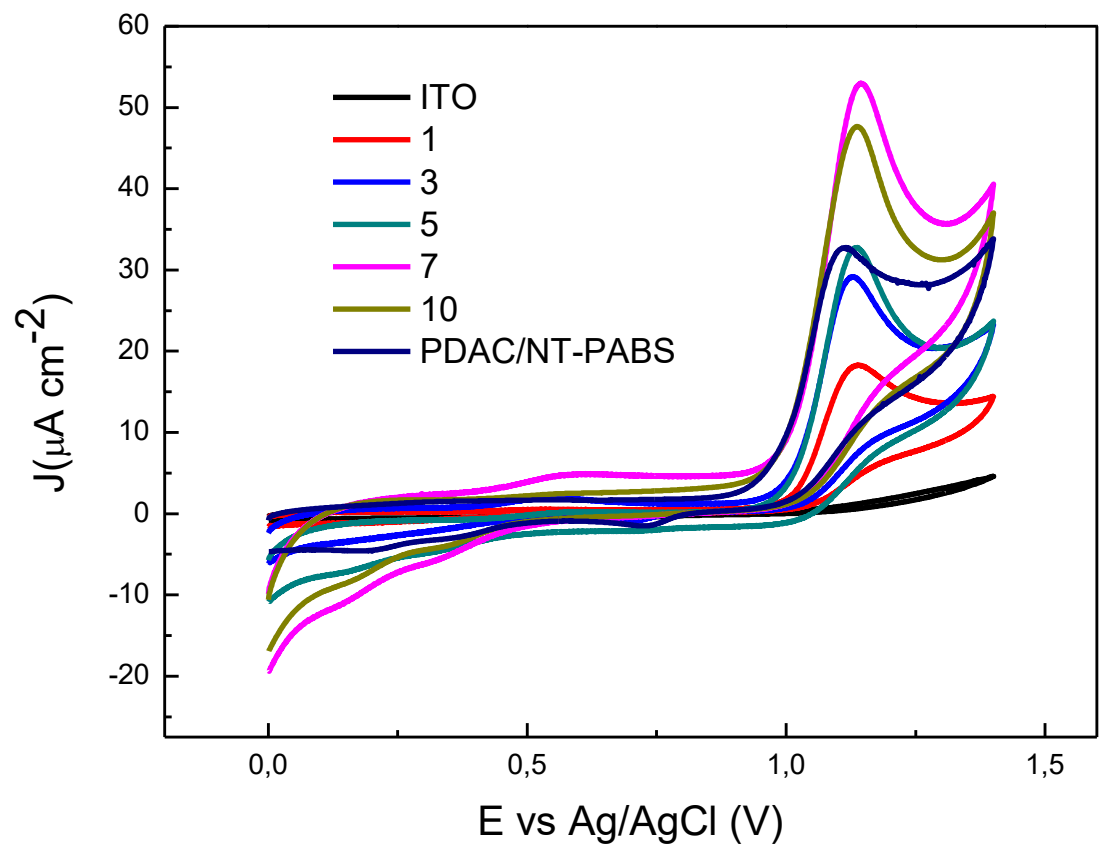

Figura 26- Voltamogramas cíclicos do ITO, eletrodos modificados com 1,3,5,7 e 10 tetracamadas (PDAC/NT-PABS/np-MAG/NT-PABS) e eletrodo com 5 bicamadas (PDAC/NT-PABS), na solução de ácido salicílico em concentração de $50 \mu \mathrm{mol} \mathrm{L}^{-1} \mathrm{em}$ ácido acético $0,1 \mathrm{~mol} \mathrm{~L}^{-1}$, com velocidade de $25 \mathrm{mV} \mathrm{s}^{-1}$

Portanto, a modificação dos eletrodos proporcionou maior eficiência no processo de oxidação do analito de interesse. Os eletrodos com np-MAG apresentaram maior eficiência do que o eletrodo de 5 bicamadas de PDAC/NT-PABS, como apresentado na Tabela 4. Diante disso, o aumento da atividade eletrocatalítica, devido ao uso de materiais com grande área superficial permitiu uma melhor sensibilidade dos eletrodos na oxidação do ácido salicílico.

A maior densidade de corrente de pico, obtida na oxidação do ácido salicílico foi no eletrodo de 7 camadas, apesar disso a escolha pelo eletrodo de 3 tetracamadas que foi utilizado nos experimentos subsequentes foi influenciada pelo tempo de preparo relativamente curto (Tabela 4 , coluna 4) quando comparado aos demais eletrodos. 
Tabela 4- Densidade de pico de oxidação do ácido salicílico e tempo de preparo dos diferentes eletrodos.

\begin{tabular}{c|c|c|c}
\hline \multirow{2}{*}{ Eletrodo } & Camadas & $\mathbf{J}\left(\mu \mathrm{A} \mathrm{cm}^{-2}\right)^{*}$ & $\begin{array}{c}\text { Tempo } \\
\text { aproximado de } \\
\text { preparo do } \\
\text { eletrodo }\end{array}$ \\
\hline \hline \multirow{2}{*}{ ITO } & - & 0 & - \\
\hline \multirow{2}{*}{$\begin{array}{c}\text { PDAC/SWCNT/np- } \\
\text { Fe/SWCNT }\end{array}$} & 1 & 12,38 & $20 \mathrm{~min}$. \\
\cline { 2 - 4 } & 3 & 19,1 & $1 \mathrm{~h}$ \\
\cline { 2 - 4 } & 7 & 22,70 & $2 \mathrm{~h} 20 \mathrm{~min}$. \\
\hline PDAC/SWCNT & 10 & 31,90 & $3 \mathrm{~h} 20 \mathrm{~min}$. \\
\hline \hline
\end{tabular}

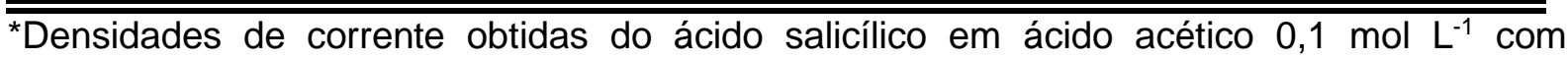
concentração de $50 \mu \mathrm{mol} \mathrm{L}{ }^{-1}$, velocidade de $25 \mathrm{mV} \mathrm{s}^{-1}$.

\subsection{Comportamento eletroquímico do ácido salicílico na superfície do eletrodo}

Estudos de voltametria cíclica foram realizados para verificar os processos oxidação e redução do ácido salicílico na superfície do eletrodo. Um possível esquema de oxidação dessa espécie e os principais produtos formados conforme relatado na literatura são apresentados na Figura 27. Na superfície do eletrodo em um potencial aplicado o ácido salicílico perde um elétron, formando um radical aromático, ao mesmo tempo que hidroxilas ativas são formadas a partir da molécula de água e que combinadas com o radical aromático geram o ácido 2,3-di-hidroxibenzoico e ácido 2,5di-hidroxibenzoico (WANG et al., 2010; Al et al., 2005). Alguns autores relatam que podem ocorrer outras transformações químicas, como a liberação de substituintes e adição de radical hidroxila no anel aromático, para formar hidroquinona e catecol na oxidação do ácido salicílico (LOUHICHI et al.,2006; RABAAOUI et al., 2012). 


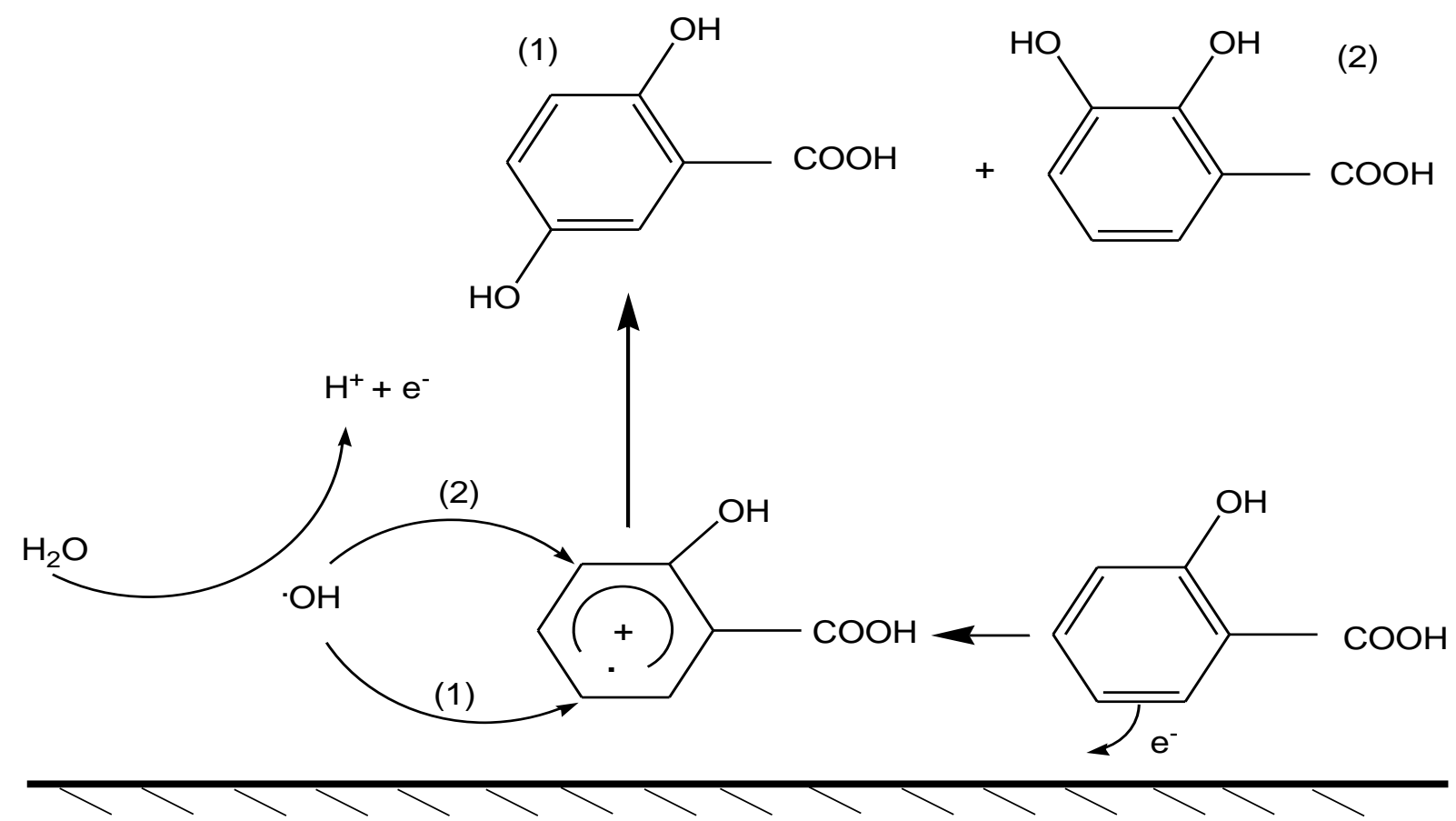

Figura 27- Esquema de oxidação do ácido salicílico na superfície do eletrodo, (1) ácido 2,5-di-hidroxibenzoico; (2) ácido 2,3-di-hidroxibenzoico.

Fonte: adaptado de Ai et al. (2005)

Os voltamogramas cíclicos do ácido salicílico (Figura 28a), apresentaram comportamento parecido com o encontrado na literatura, com diminuição do pico de oxidação a cada medição realizada (ZHANG et al., 2010; TORRIERO et al., 2004).

Frequentemente, é relatado que os compostos formados eletroquimicamente na oxidação do ácido salićlico, podem ocasionar a formação de filme polimérico isolante em diferentes eletrodos. Um mecanismo de reação que ocorre por meio de ânions fenóxidos com a formação de uma película de polioxifenileno foi proposto por pesquisadores (MENGOLI, 1980; RABAAOUI et al., 2012). Outra possibilidade é a adsorção do ácido salicílico carregado positivamente na superfície do eletrodo, que tem como última camada nanotubos de carbono que possuem sítios carregados negativamente.

Na Figura 28(b) é apresentado uma ampliação do voltamograma que mostra uma reação química reversível na superfície do eletrodo, com pico anódico (1a) em $0,57 \mathrm{~V}$ e pico catódico (1c) em $0,63 \mathrm{~V}$. Estes picos podem ser atribuídos à reação de oxidação e redução de hidroquinona a benzoquinona como é mencionado por Zhang et al. (2010). O pico 1, em torno de $1,19 \mathrm{~V}$ apresentado na Figura 28(a) é 
frequentemente utilizado na quantificação de ácido salicílico por sua maior densidade de corrente e melhor definição. Torriero et al. (2004), atribuem este pico a uma reação irreversível, decorrente da fração fenólica presente no ácido salicílico.

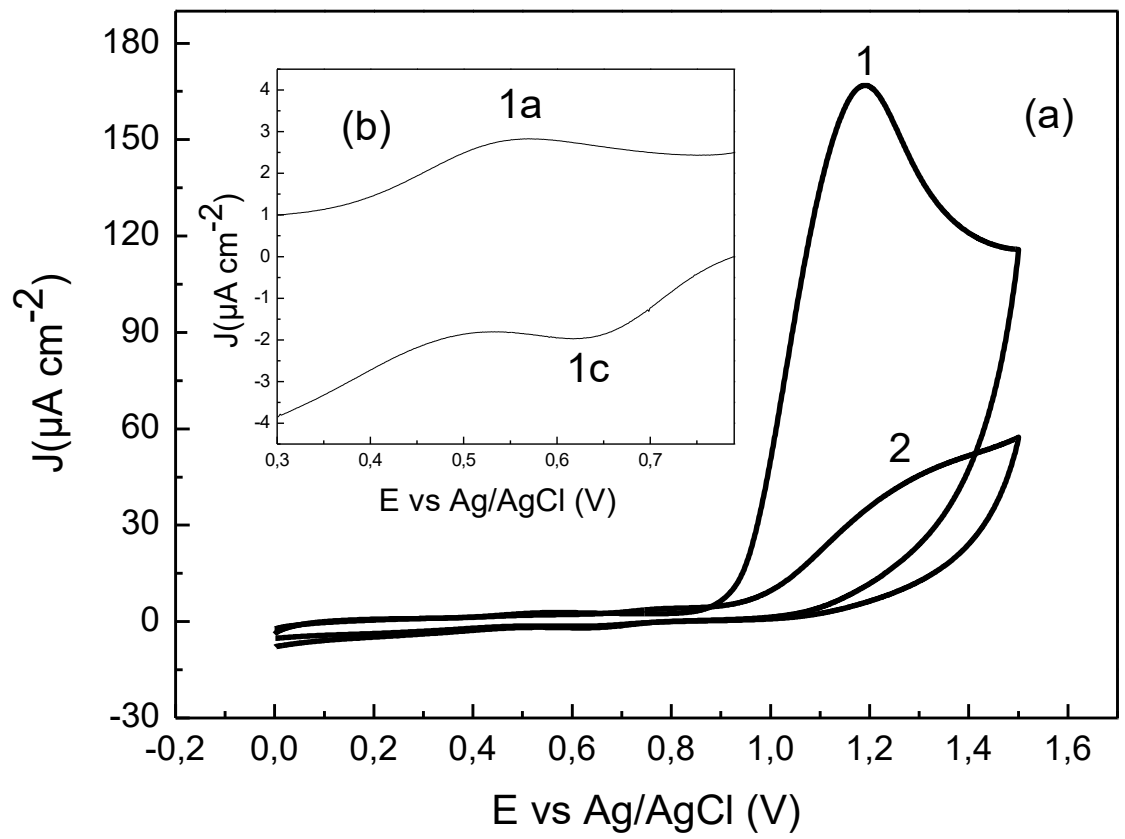

Figura 28- Voltamograma cíclico do ácido salicílico $2,5 \times 10^{-3} \mathrm{~mol} \mathrm{~L}^{-1} \mathrm{em}$ ácido acético $0,1 \mathrm{~mol} \mathrm{~L}^{-1}$ na velocidade de $25 \mathrm{mV} \mathrm{s}^{-1}$ (a) 1- primeira medida, 2- segunda medida; (b) Varredura de 0,3 a $0,8 \mathrm{~V}$ do primeiro ciclo.

O potencial de pico 1 apresentou variação conforme a mudança de concentração de ácido salicílico como mostra a Figura 29, é possível observar que o potencial diminui com o aumento da concentração. Porém, a altura de pico praticamente não variou com o aumento de $5 \times 10^{-3} \mathrm{~mol} \mathrm{~L}^{-1}$ para $10 \times 10^{-3} \mathrm{~mol} \mathrm{~L}^{-1}$ na concentração. Esse resultado demonstra que nessas concentrações já ocorreu diminuição dos sítios ativos na superfície do eletrodo e, consequentemente, sua saturação. 


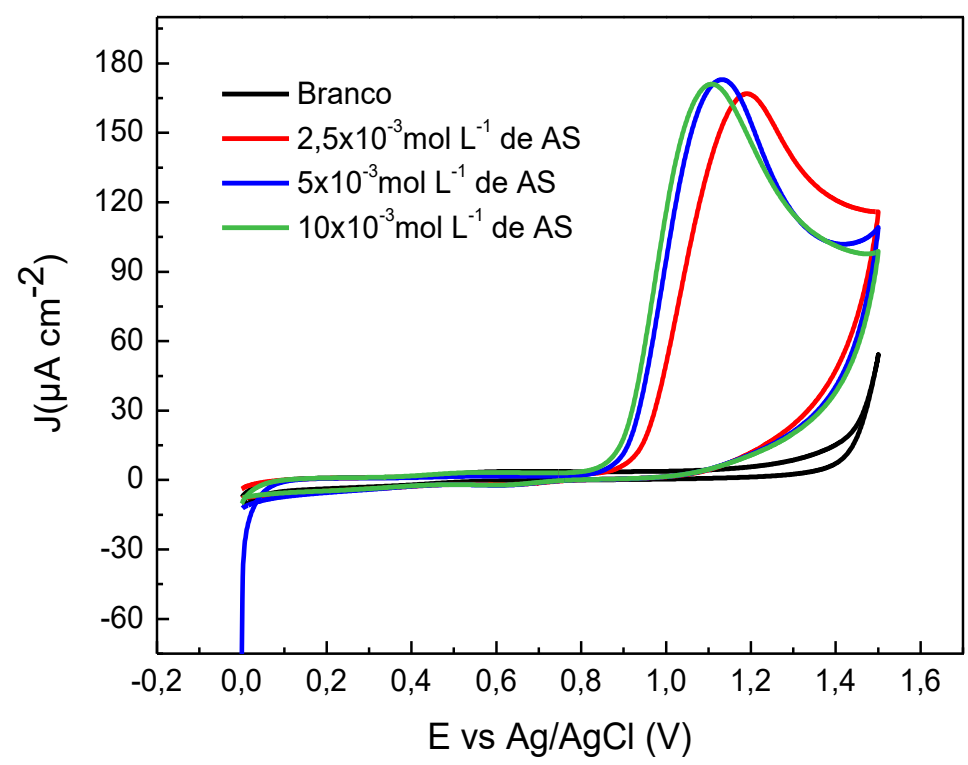

Figura 29- Voltamograma cíclico do ácido acético $0,1 \mathrm{~mol} \mathrm{~L}^{-1}$ (branco) e do AS em ácido acético $0,1 \mathrm{~mol} \mathrm{~L}^{-1}$ em diferentes concentrações, na velocidade de $25 \mathrm{mV} \mathrm{s}^{-1}$

\subsection{Otimização dos parâmetros na voltametria de pulso diferencial}

\subsubsection{Condicionamento do eletrodo}

Estudos eletroquímicos quantitativos de ácido salicílico em solução aquosa podem ser difíceis devido à formação de películas de polímero na superfície do eletrodo, como observado nos experimentos de voltametria cíclica. Mesmo em solução com concentrações mais baixas de ácido salicílico, utilizada nos experimentos de voltametria de pulso diferencial, ocorreu decaimento da altura do pico de oxidação após a segunda leitura (Figura 30a).

Portanto, para se obter a repetição do sinal, foi necessário a limpeza do eletrodo após as leituras, que foi realizada em uma solução de metanol:água (1:10) em um potencial de $-1 \mathrm{~V}$. O metanol tem afinidade com ácido salicílico e é frequentemente utilizado na sua extração em amostras, a Figura 30 (a) mostra que após o condicionamento o pico aumentou ficando próximo a primeira leitura, evidenciado a eficiência do condicionamento nessas condições apresentadas. A Figura 30 (b) demonstra o tempo de condicionamento necessário, a partir de 60 segundos a densidade de corrente do pico permanece praticamente constante, sendo adotado, portanto esse tempo no condicionamento do eletrodo para as medidas posteriores. 

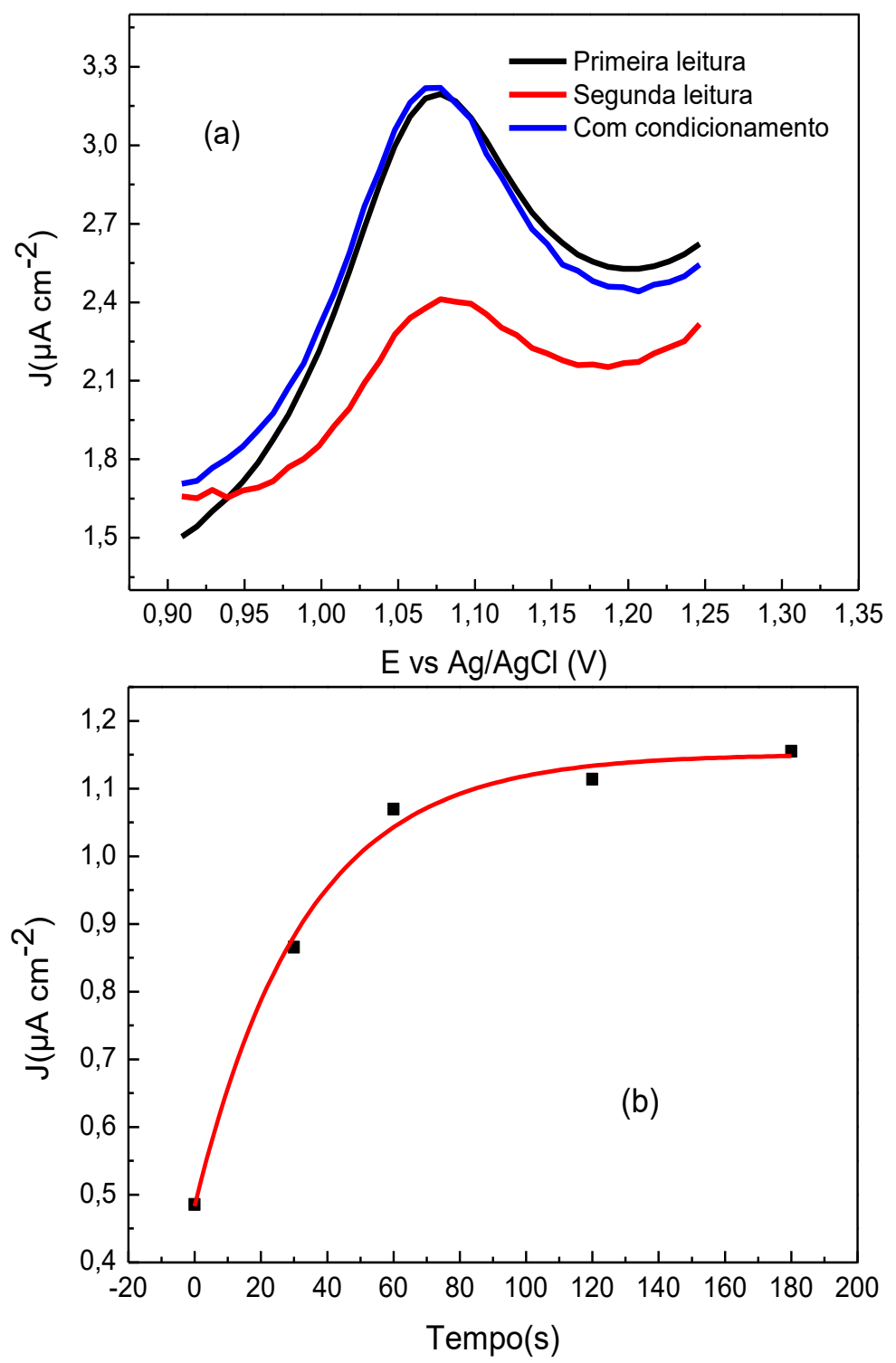

Figura 30- (a) Voltamograma de pulso diferencial na primeira leitura, segunda leitura e após realização de condicionamento por 120 segundos, (b) Densidades de corrente do pico de oxidação do ácido salicílico na concentração de $5,8 \mu \mathrm{mol} \mathrm{L}^{-1} \mathrm{em}$ tampão acetato de amônio $0,1 \mathrm{~mol} \mathrm{~L}^{-1}, \mathrm{pH} 3,5 \mathrm{com}$ amplitude de pulso de $50 \mathrm{mV}$ e velocidade de $5 \mathrm{mV} \mathrm{s}^{-1}$ em função do tempo de condicionamento.

\subsubsection{Eletrólito de suporte}

O eletrólito de suporte é um fator importante para o experimento eletroquímico uma vez que afeta a condutividade da solução e a taxa de transferência eletrônica. Portanto, foi realizado estudo do pH, composição e concentração do eletrólito de suporte mais adequado para a quantificação do ácido salicílico. 
Conforme mostrado pela Figura 31(a), o potencial de pico anódico diminui linearmente com o aumento do $\mathrm{pH}$. Além disso, a densidade de corrente do pico é maior em valores de $\mathrm{pH}$ mais baixos (Figura 31b) sendo que no $\mathrm{pH}$ de 6,5 e 7,5 não observou-se pico na faixa potencial de 0,9 a 1,25 V. Então ficou evidente que a concentração de $\mathrm{H}^{+}$tem influência significativa no processo de oxidação do ácido salicílico, o que está de acordo com o relatado na literatura (TORRIERO et al., 2004; GHOREISHI et al., 2015).
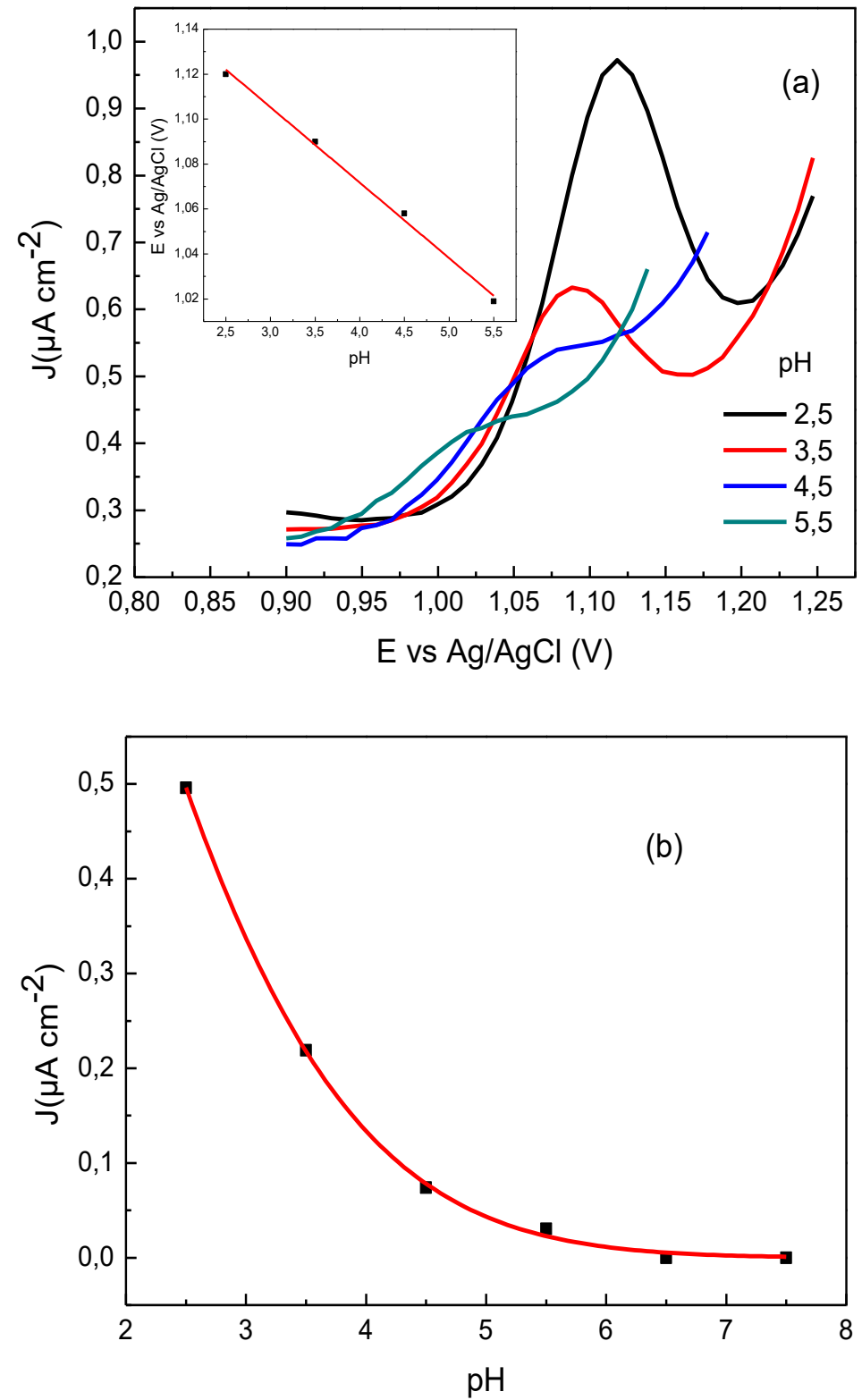

Figura 31- (a) Voltamograma de pulso diferencial do ácido salicílico $5,8 \mu \mathrm{mol} \mathrm{L}^{-1}$, em tampão RB $0,1 \mathrm{~mol} \mathrm{~L}^{-1}$ nos diferentes $\mathrm{pH}$ com amplitude de pulso de $25 \mathrm{mV}$ e velocidade de $5 \mathrm{mV} \mathrm{s}^{-1}$, (b) Densidades de corrente de pico em função do $\mathrm{pH}$. 
Diante deste estudo, foram testados diferentes eletrólitos de suporte com menores valores de $\mathrm{pH}$. Na Figura 32 são apresentados os valores de densidade de corrente na oxidação do ácido salicílico em diferentes eletrólitos. $O$ ácido acético e os tampões acetato de amônio e acetato de sódio foram os que apresentaram melhores resultados em termos de sensibilidade, sendo o ácido acético escolhido para o desenvolvimento do trabalho por ser de manipulação mais fácil e menos tóxico.

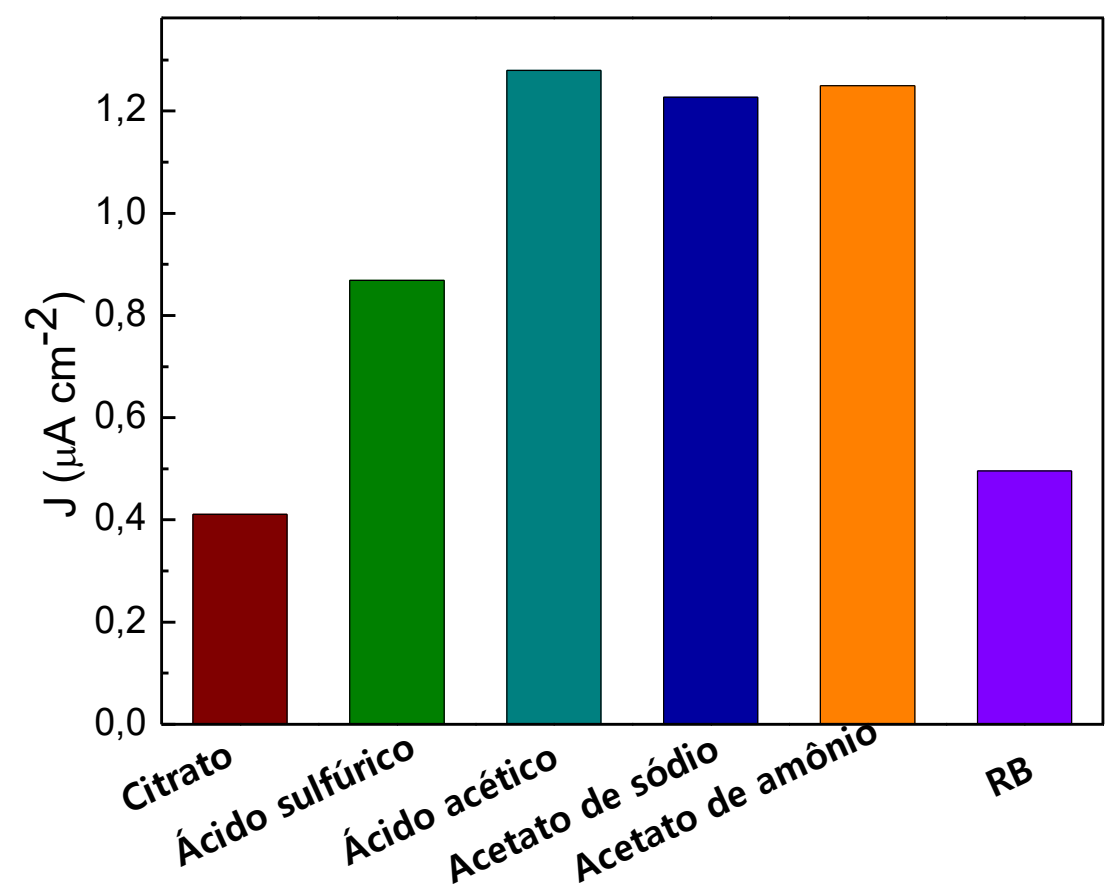

Figura 32- Densidade de corrente de pico da oxidação de ácido salicílico na concentração de 5,8 $\mu \mathrm{mol} \mathrm{L}{ }^{-1}$ nos eletrólitos: tampões citrato e RB com pH 2,5, ácido sulfúrico $\mathrm{pH}$ 1, ácido acético $\mathrm{pH}$ 2,9, tampões acetato de amônio e de sódio $\mathrm{pH} 3,5$, todos na concentração de $0,1 \mathrm{~mol} \mathrm{~L}^{-1} \mathrm{com}$ amplitude de pulso de $25 \mathrm{mV}$ e velocidade de $5 \mathrm{mV} \mathrm{s}^{-1}$.

O ácido acético 0,$01 ; 0,1$ e $0,5 \mathrm{~mol} \mathrm{~L}^{-1}$ foi testado como eletrólito de suporte para verificar a influência na variação da concentração no processo eletroquímico de interesse. A maior densidade de pico observada foi na concentração de $0,1 \mathrm{~mol} \mathrm{~L}^{-1}$, evidenciado na Figura 33. Na concentração de $0,01 \mathrm{~mol} \mathrm{~L}^{-1}$, a densidade de corrente foi menor provavelmente pelo ligeiro aumento da resistência do meio. 


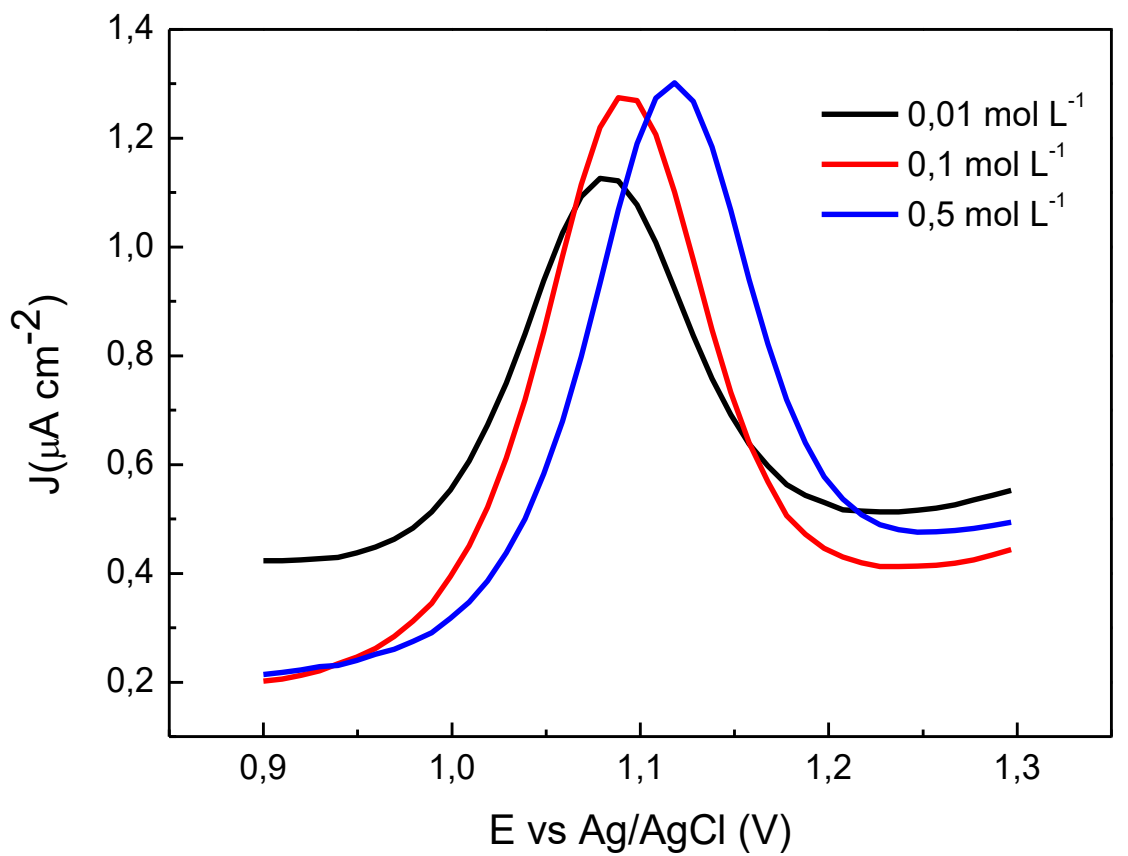

Figura 33- Voltamogramas de pulso diferencial de ácido salicílico $5,8 \mu \mathrm{mol} \mathrm{L}^{-1} \mathrm{em}$ ácido acético nas diferentes concentrações com amplitude de pulso de $25 \mathrm{mV}$ e velocidade de varredura de $5 \mathrm{mV} \mathrm{s}^{-1}$.

\subsubsection{Velocidade de varredura e amplitude de pulso}

A variação da velocidade de varredura nos experimentos de voltametria de pulso diferencial foi realizada, mostrando que para velocidade de $10 \mathrm{mV} \mathrm{s}^{-1}$ e acima deste valor os picos não ficaram bem definidos conforme apresentado na Figura 34.

Isto é verificado devido a reação de oxidação do ácido salicílico ser um processo irreversível, que tem como característica uma transferência lenta de elétrons. 

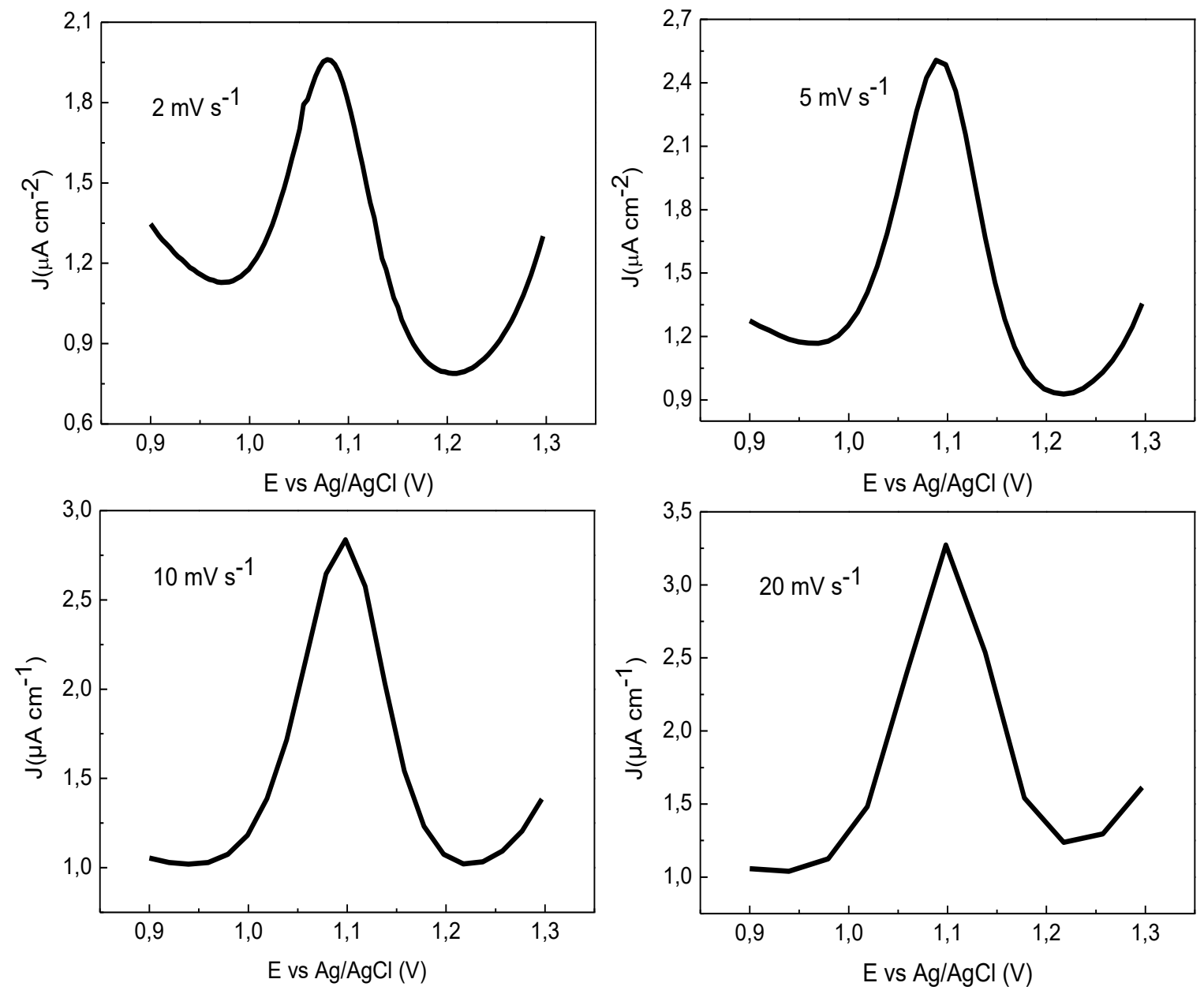

Figura 34- Voltamograma de pulso diferencial de ácido salicílico $5,8 \mu \mathrm{mol} \mathrm{L}^{-1} \mathrm{em}$ ácido acético $0,1 \mathrm{~mol} \mathrm{~L}^{-1}$ com diferentes velocidades e amplitude de pulso de $25 \mathrm{mV}$.

Considerando as velocidades de 2 e $5 \mathrm{mV} \mathrm{s}^{-1}$, que resultaram em densidade de corrente de pico de 0,996 e 1,467 $\mu \mathrm{A} \mathrm{cm}^{-2}$, respectivamente e picos bem definidos, a escolha foi pela velocidade de $5 \mathrm{mV} \mathrm{s}^{-1}$ por ter maior sensibilidade, parâmetro analítico importante na quantificação do ácido salicílico.

As amplitudes de pulso estudadas foram de 5 a $150 \mathrm{mV}$, este parâmetro influenciou na densidade de corrente dos picos que teve um aumento linear como mostra a Figura 35(a). Outra característica foi o deslocamento do pico para potenciais menores quando houve o aumento da amplitude de pulso (Figura 35b). 

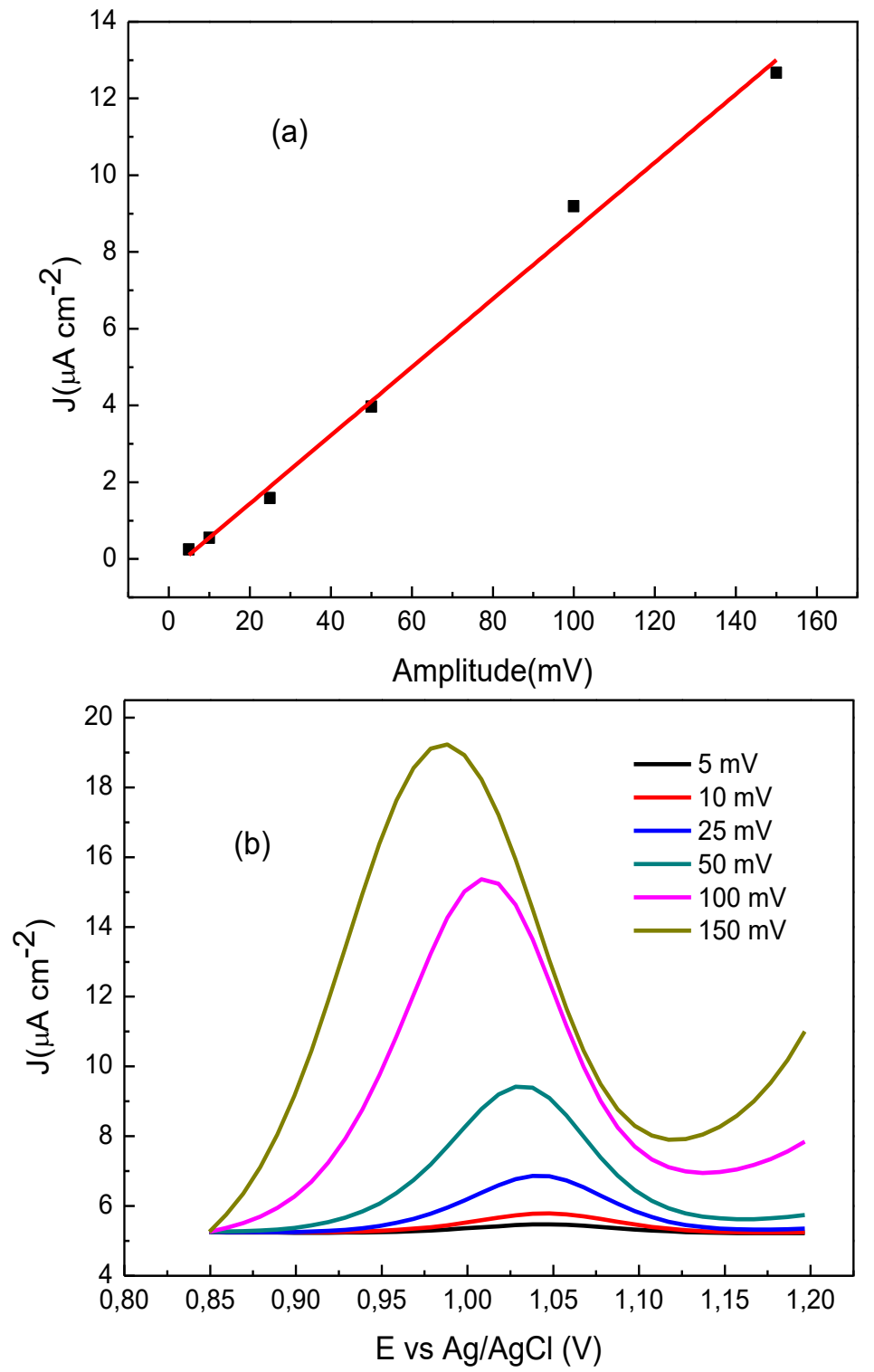

Figura 35- (a) Densidade de corrente de pico em função da amplitude de pulso, (b) Voltamograma de pulso diferencial de ácido salićlico $5,8 \mu \mathrm{mol} \mathrm{L}^{-1} \mathrm{em}$ ácido acético $0,1 \mathrm{~mol} \mathrm{~L}^{-1} \mathrm{em}$ diferentes amplitudes de pulso e velocidade de varredura de $5 \mathrm{mV} \mathrm{s}^{-1}$.

Apesar das amplitudes de pulso de 100 e $150 \mathrm{mV}$ apresentarem maior altura de pico, nessas amplitudes a largura do pico foi maior, o que pode influenciar na quantificação do ácido salićlico em amostras, por aumentar a capacidade de interferências de espécies com potencial de oxidação próximas do ácido salicílico, dificultando a separação dos picos. Diante disso, a amplitude de pulso de $50 \mathrm{mV}$ foi utilizada nos experimentos.

Portanto, a Tabela 5 mostra as condições utilizadas para os experimentos de validação de metodologia. 
Tabela 5- Parâmetros de voltametria de pulso diferencial.

\begin{tabular}{c|c}
\hline Parâmetros & Condições experimentais \\
\hline \hline Condicionamento do eletrodo & Metanol:Água(1:10), 1 V por 60 segundos \\
\hline Eletrólito de suporte & Ácido acético $0,1 \mathrm{~mol} \mathrm{~L}^{-1}$ \\
\hline Velocidade de varredura & $25 \mathrm{mV} \mathrm{s}^{-1}$ \\
\hline Amplitude de pulso & $50 \mathrm{mV}$ \\
\hline \hline
\end{tabular}

\subsection{Parâmetros de validação}

\subsubsection{Precisão}

Com as otimizações realizadas, a densidade de corrente de pico na oxidação de ácido salicílico apresentou coeficiente de variação de 3\% para 7 leituras consecutivas, os voltamogramas são mostrados na Figura 36. Esse valor de repetitividade está de acordo com o indicado no guia para validação de métodos analíticos e bioanalíticos da ANVISA (2003), que considera aceitável coeficiente de variação menor que $5 \%$.

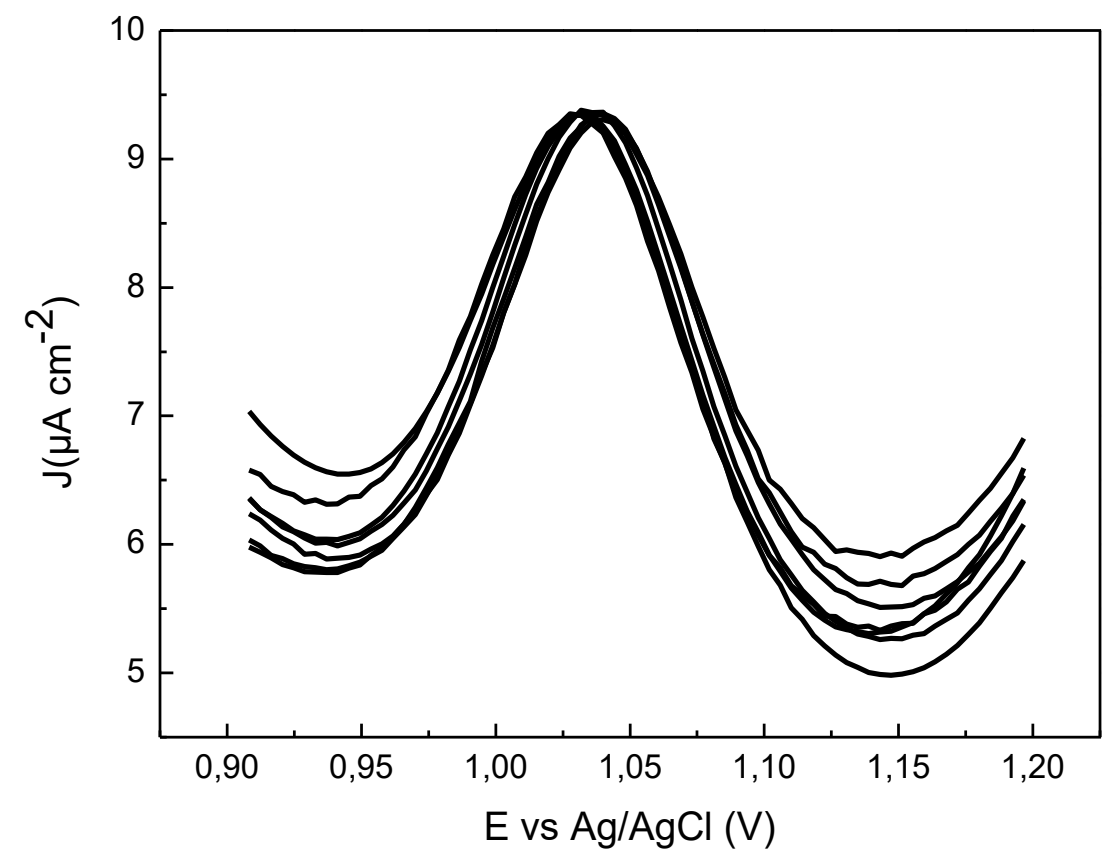

Figura 36- Voltamogramas de pulso diferencial de 7 medidas consecutivas de ácido salicílico 5,8 $\mu \mathrm{mol} \mathrm{L}-1$ em ácido acético $0,1 \mathrm{~mol} \mathrm{~L}^{-1}$ com amplitude de pulso de $50 \mathrm{mV}$ e velocidade de varredura $5 \mathrm{mV} \mathrm{s}^{-1}$ 
Esses resultados foram aceitáveis, sendo realizadas leituras com um mesmo eletrodo, porém ainda tem uma deficiência nas repetições medidas com diferentes eletrodos, que apresentou coeficiente de variação de $11 \%$ entre as médias de 5 leituras, realizadas com 3 eletrodos diferentes, preparados no mesmo dia. Apesar disso, a quantificação de ácido salicílico nas amostras não é comprometida, já que é realizada com adição de padrão e as leituras feitas com um mesmo eletrodo.

$\mathrm{Na}$ Figura 37, a precisão das medidas é avaliada em 4 eletrodos, preparados em dias diferentes e os resultados são confiáveis para no máximo 7 leituras consecutivas, a partir desse valor houve decaimento da densidade de corrente de pico no eletrodo 1, apesar do eletrodo dos demais eletrodos apresentarem sinal mais estável, a vida útil do eletrodo foi limitada em 7 leituras.

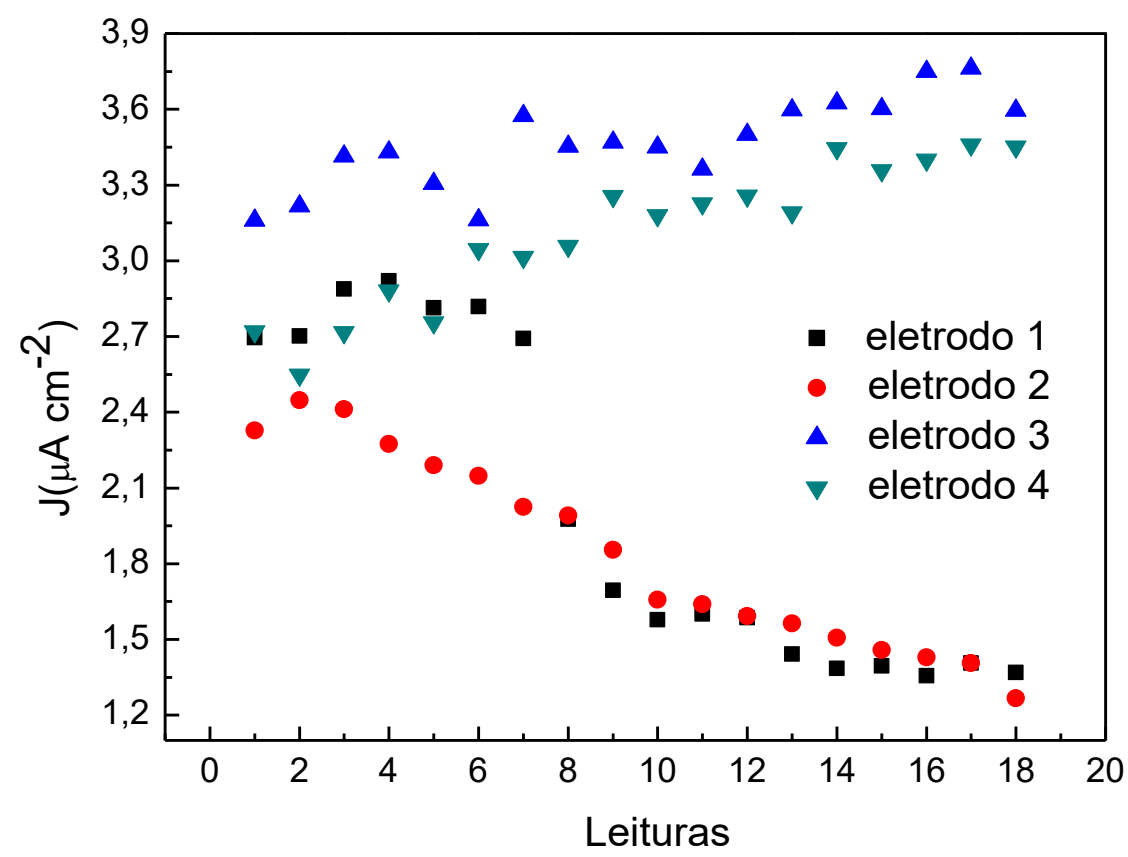

Figura 37- Densidades de corrente de pico na oxidação do ácido salicílico na concentração de $5,8 \mu \mathrm{mol} \mathrm{L}-1$ em ácido acético $0,1 \mathrm{~mol} \mathrm{~L}^{-1} \mathrm{com}$ amplitude de pulso de $50 \mathrm{mV}$ e velocidade de varredura $5 \mathrm{mV} \mathrm{s}^{-1} \mathrm{em}$ função do número de leituras consecutivas.

O coeficiente de variação para as médias das 7 leituras realizadas com os eletrodos foi de $15,5 \%$. Possivelmente essa variação é ocasionada devida o preparo dos eletrodos serem realizados de forma manual, sujeito a maiores erros. 


\subsubsection{Especificidade}

O estudo de especificidade realizado com a presença de possíveis interferentes mostrou erro relativo maior nas medidas em que o ácido cinâmico foi adicionado na solução de ácido salicílico, como mostra a Tabela 6 . 0 erro foi devido a diminuição de altura do pico para as medidas na presença de ácido benzoico e cinâmico, na presença de ácido ascórbico e p-hidroxibenzoico a altura do pico aumentou.

Tabela 6- Erro relativo entre as densidades de corrente da oxidação do ácido salicílico sem e com a presença dos interferentes nas diferentes concentrações.

\begin{tabular}{|c|c|c|c|}
\hline \multirow{2}{*}{ Interferentes } & \multicolumn{3}{|c|}{ Concentrações* } \\
\hline & $0,58 \mu \mathrm{mol} \mathrm{L-1}$ & $5,8 \mu \mathrm{mol}$ L-1 & $58 \mu \mathrm{mol} \mathrm{L}-1$ \\
\hline Ácido benzoico & $-4,2 \%$ & $-5,76 \%$ & $-14,5 \%$ \\
\hline Ácido cinâmico & $-9,46 \%$ & $-24,9 \%$ & $-34,5 \%$ \\
\hline Ácido ascórbico & $4,97 \%$ & $11,8 \%$ & $12 \%$ \\
\hline $\begin{array}{c}\text { Ácido } \\
\text { p-hidroxibenzoico }\end{array}$ & $1,6 \%$ & $18,4 \%$ & $30 \%$ \\
\hline
\end{tabular}

A interferência desses compostos pode ser minimizada através do uso do método de adição de padrão na quantificação de ácido salicílico em amostras complexas.

\subsubsection{Faixa linear de trabalho}

A faixa linear de trabalho foi realizada através da medida com dois eletrodos de trabalho diferentes, com concentração partindo de um valor próximo ao limite de quantificação. Neste estudo pode-se observar que a partir de $46,3 \mu \mathrm{mol} \mathrm{L}^{-1}$ de ácido salicílico, ocorre o decaimento do sinal e já não há linearidade na relação entre a concentração e a densidade de corrente de pico (Figura 38). A altura do pico pode ter diminuído, devido a saturação do eletrodo que perde sensibilidade, limitando assim seu uso em concentrações abaixo de 46,3 $\mu \mathrm{mol} \mathrm{L}^{-1}$. 


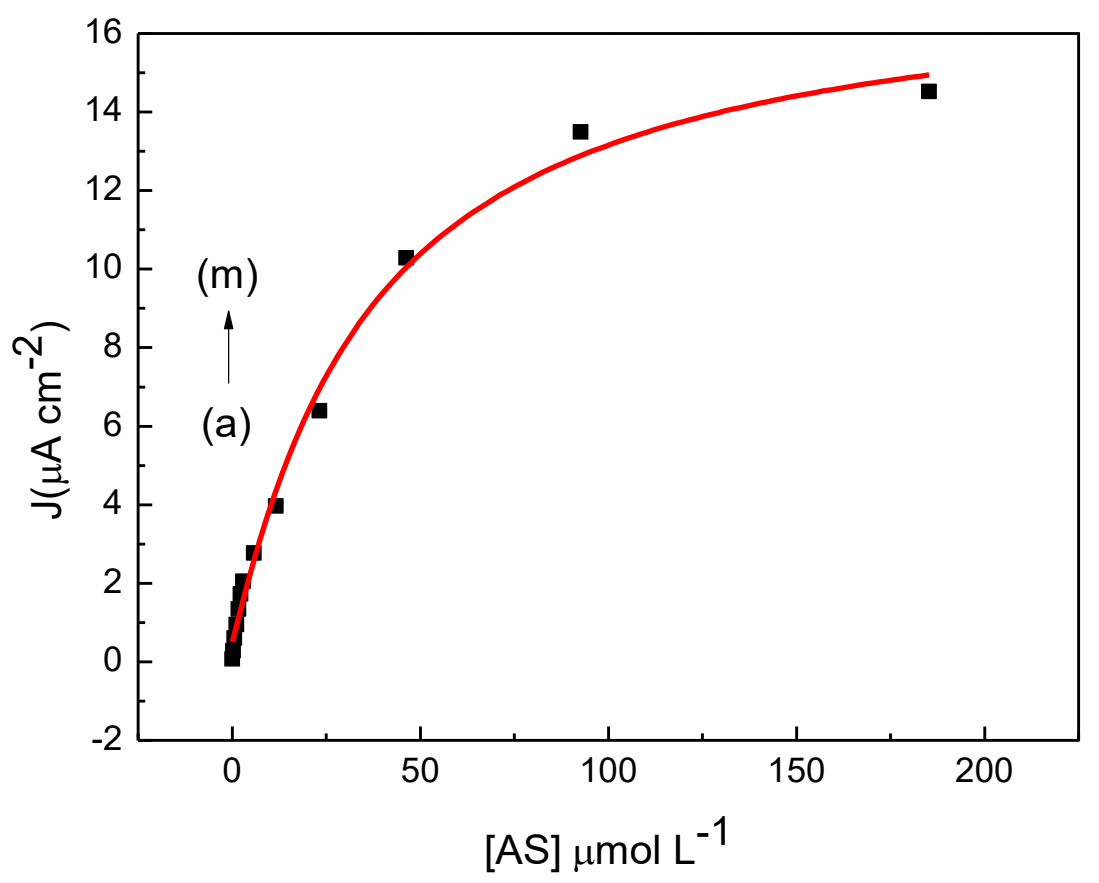

Figura 38- Densidades de corrente de pico de oxidação em função das concentrações de ácido salicílico (a) 0,1 (b) 0,3 (c) 0,6 (d) 1,2 (e) 1,7 (f) 2,3 (g) 2,9 (h) 5,8 (i) 11,6 (j) 23,2 (k) 46,3 (I) 92,7 (m)185,3 $\mu \mathrm{mol} \mathrm{L}^{-1}$ em ácido acético 0,1 $\mathrm{mol} \mathrm{L}^{-1}$ (amplitude de pulso de $50 \mathrm{mV}$ e velocidade de varredura $5 \mathrm{mV} \mathrm{s}^{-1}$ ).

Os voltamogramas de pulso diferencial e a curva analítica na região linear que foi apresentada na análise do ácido salicílico, são mostrados na Figura 39, sendo observado nessa faixa duas regiões lineares, a primeira entre as concentrações de 0,6 a $2,9 \mu \mathrm{mol} \mathrm{L-1}$ com equação de regressão linear $y=0,21+0,64 x$ e $r^{2}=0,996$ e a segunda entre as concentrações de 2,9 e 46,3 $\mu \mathrm{mol} \mathrm{L}^{-1}$, com equação de regressão linear $y=1,7+0,2 x$ e $r^{2}=0,995$.

A sensibilidade atribuída ao método foi a inclinação da reta da primeira faixa linear, portanto $0,64 \mu \mathrm{A} \mathrm{cm}^{-2} / \mu \mathrm{mol} \mathrm{L}^{-1}$. 


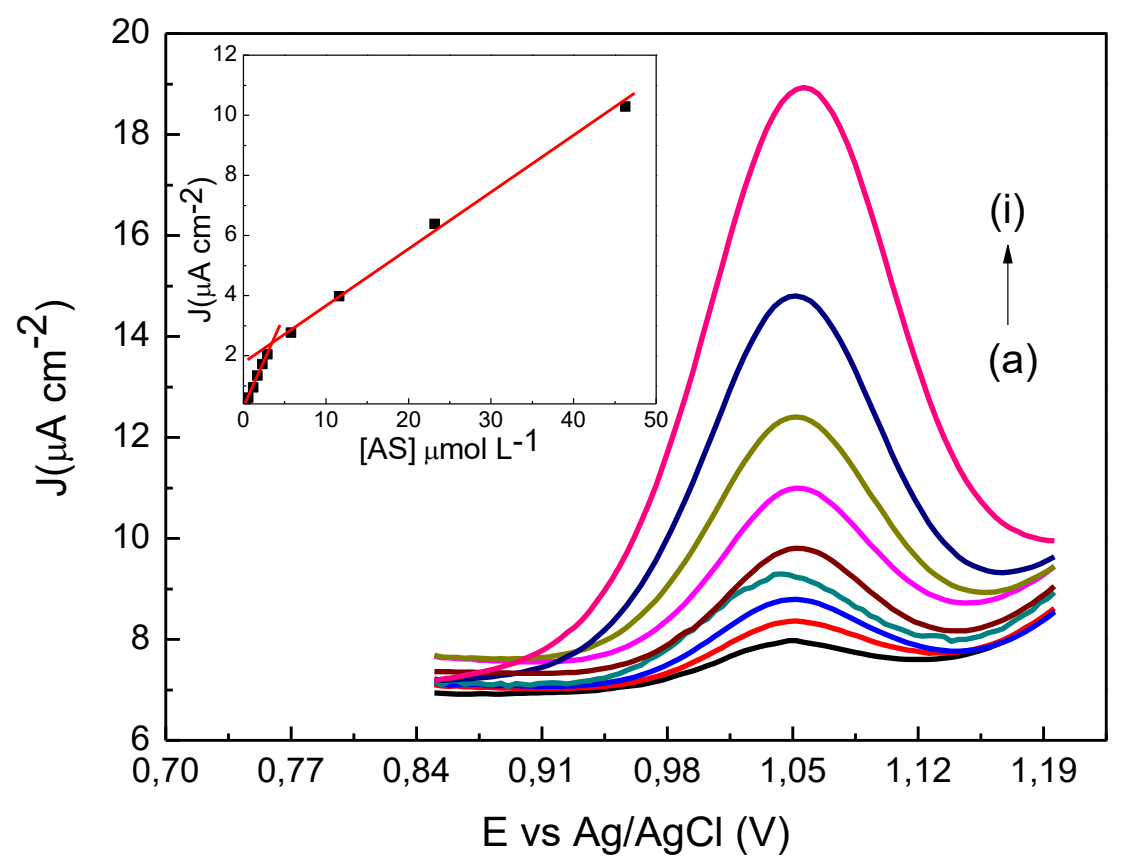

Figura 39- Voltamograma de pulso diferencial do ácido salicílico nas concentrações de (a) 0,6 (b) 1,2 (c) 1,7 (d) 2,3 (e) 2,9 (f) 5,8 (g) 11,6 (h) 23,2 (i) 46,3 $\mu \mathrm{mol} \mathrm{L}^{-1} \mathrm{em}$ ácido acético $0,1 \mathrm{~mol} \mathrm{~L}^{-1}$, com amplitude de pulso de $50 \mathrm{mV}$ e velocidade de varredura $5 \mathrm{mV} \mathrm{s}^{-1}$. Inserido a curva analítica (densidade de corrente de pico versus concentração de ácido salicílico).

\subsubsection{Limite de detecção e quantificação}

Os valores obtidos para limite de detecção e de quantificação foram respectivamente $0,02 \mu \mathrm{mol} \mathrm{L}^{-1}$ e $0,07 \mu \mathrm{mol} \mathrm{L}{ }^{-1}$. Esses valores são satisfatórios, para a quantificação de ácido salicílico no produto dermatológico utilizado neste trabalho. Essa é uma das vantagens das técnicas eletroquímicas, pois a alta sensibilidade permite quantificações em amostras com valores baixos de concentrações do analito, sem a necessidade de realização de pré-concentração.

Além disso, o limite de detecção ficou abaixo dos valores obtidos em outros métodos eletroquímicos mencionados na revisão bibliográfica, que teve o valor de $0,05 \mu \mathrm{mol} \mathrm{L}{ }^{-1}$ como menor limite de detecção dentre os métodos citados, sendo utilizado um eletrodo de MWCNT/Nafion, com isso parece que a modificação dos eletrodos com nanotubos de carbono é mais eficiente do que com outros materiais, para a detecção do ácido salicílico. 


\subsubsection{Comparação entre métodos}

A determinação do ácido salicílico em produto dermatológico, foi realizada por HPLC/UV-vis para a comparação, com os resultados obtidos no método eletroquímico proposto.

Inicialmente foi realizado testes com 3 fases móveis diferentes reportadas na literatura nomeadas da seguinte forma:

Fase móvel 1: Tampão acetato de amônio (concentração $0,01 \mathrm{~mol} \mathrm{~L}^{-1} \mathrm{e} \mathrm{pH} \mathrm{4,5):}$ Acetonitrila (80:20) (JANGBAl et al., 2012).

Fase móvel 2: água: metanol: ácido acético (54:45:1) (TORRIERO et al., 2004).

Fase móvel 3: Água: acetonitrila: ácido acético (54:45:1) (adaptada de TORRIERO et al., 2004).

Os espectros de UV-vis (Figura 40), demonstraram o melhor comprimento de onda para o ácido salicílico nas diferentes fases móveis, a maior absorbância para a fase móvel 1 foi em $230 \mathrm{~nm}$ e para as fases móveis 2 e 3 em 237 nm.

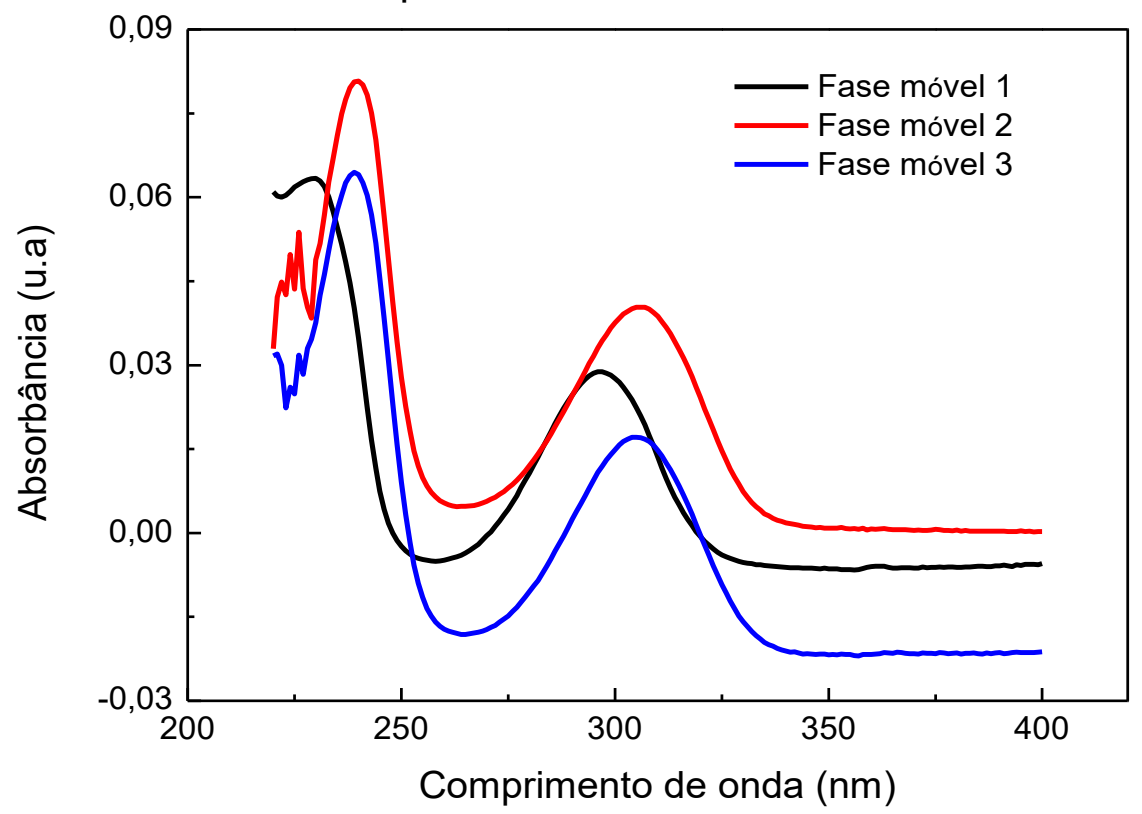

Figura 40- Espectros de UV-vis do ácido salicílico $8,7 \mu \mathrm{mol} \mathrm{L}^{-1} \mathrm{em}$ diferentes fases móveis.

Os comprimentos de onda com maior absorção foram então utilizados nos experimentos de HPLC/UV-vis. A área do pico e o tempo de retenção requerido nessa análise são apresentados na Tabela 7. A fase móvel 3 apresentou maior área de pico e tempo de retenção baixo, tornando a análise mais rápida, sendo então escolhida para as medidas seguintes. O eluente utilizado foi a própria fase móvel. 
Tabela 7- Área do pico e tempo de retenção dos cromatogramas de ácido salicílico na concentração de $87 \mu \mathrm{mol} \mathrm{L}^{-1}$

\begin{tabular}{c|c|c|c}
\hline \hline Fase móvel & $\begin{array}{c}\text { Comprimento } \\
\text { de onda }(\mathbf{n m})\end{array}$ & $\begin{array}{c}\text { Área do pico } \\
\text { (mAu.min) }\end{array}$ & $\begin{array}{c}\text { Tempo de retenção } \\
\text { (minutos) }^{\star}\end{array}$ \\
\hline \hline 1 & 230 & $3,93 \pm 0,13$ & $4,15 \pm 0,47881$ \\
\hline 2 & 237 & $2,88 \pm 0,167$ & $8,68 \pm 0,08742$ \\
\hline 3 & 237 & $4,45 \pm 0,19$ & $4,25 \pm 0,00776$ \\
\hline
\end{tabular}

*Média \pm Desvio padrão de 7 medidas

A faixa linear de trabalho desse método, foi determinada através da realização de cromatogramas nas concentrações de 0,7 a $868,8 \mu \mathrm{mol} \mathrm{L}^{-1}$. A relação ente a área do pico e a concentração de ácido salicílico perdeu a linearidade a partir da concentração de $434,4 \mu \mathrm{mol} \mathrm{L}{ }^{-1}$, com diminuição da sensibilidade nas medidas como mostra a Figura 41.

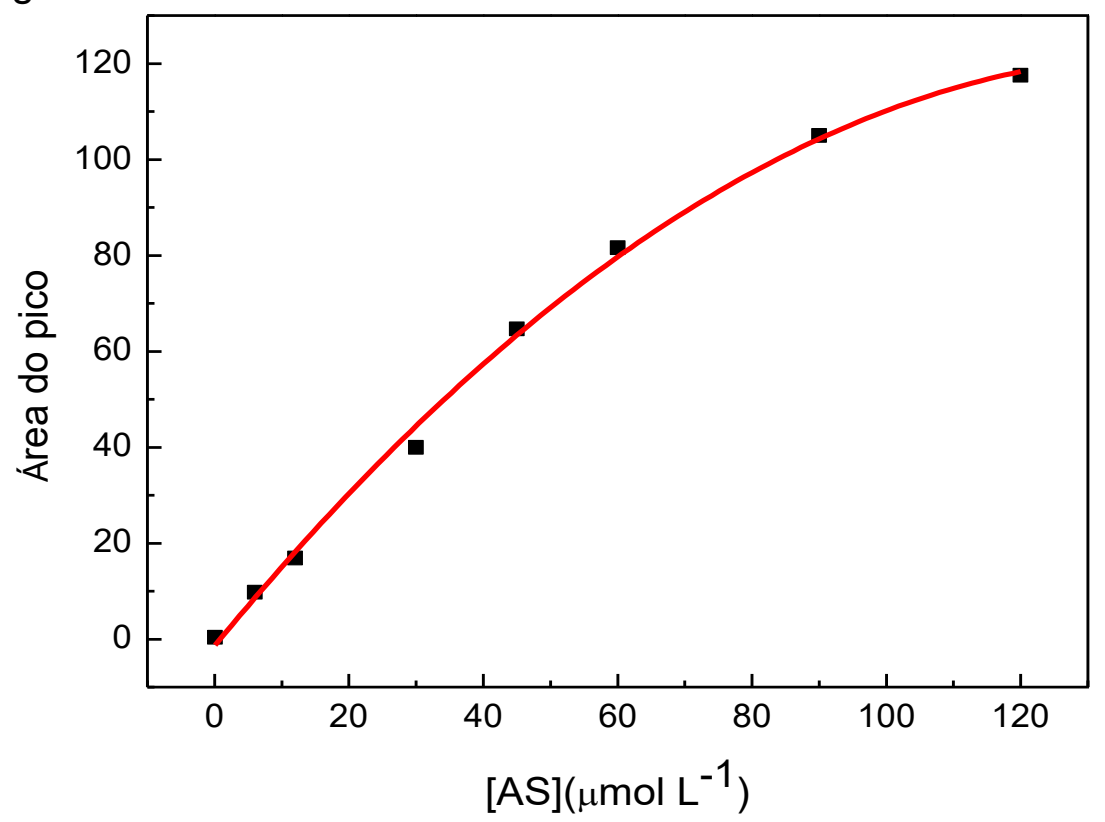

Figura 41- Área do pico em função do padrão de ácido salicílico nas concentrações 0,7 a $868,8 \mu \mathrm{mol} \mathrm{L}^{-1}$.

Diante disso, cromatogramas de ácido salicílico em concentrações mais baixas dentro dessa faixa linear de trabalho foi realizado (Figura 42a), para se obter a curva analítica utilizada na quantificação do ácido salicílico na amostra de produto dermatológico. A curva analítica teve equação de regressão linear $y=0,16+0,2 x$ e $r^{2}=$ 0,998, demonstrando linearidade na relação entre a concentração medida e a área do 
pico, possibilitando assim a aplicação do método como referência, para validar e avaliar o desempenho do método eletroquímico desenvolvido. Na Figura 42(b) é apresentado o cromatograma da amostra de produto dermatológico, diluída conforme descrito nos materiais e métodos, com o pico bem definido do ácido salicílico em tempo de retenção de aproximadamente 4,25 minutos.
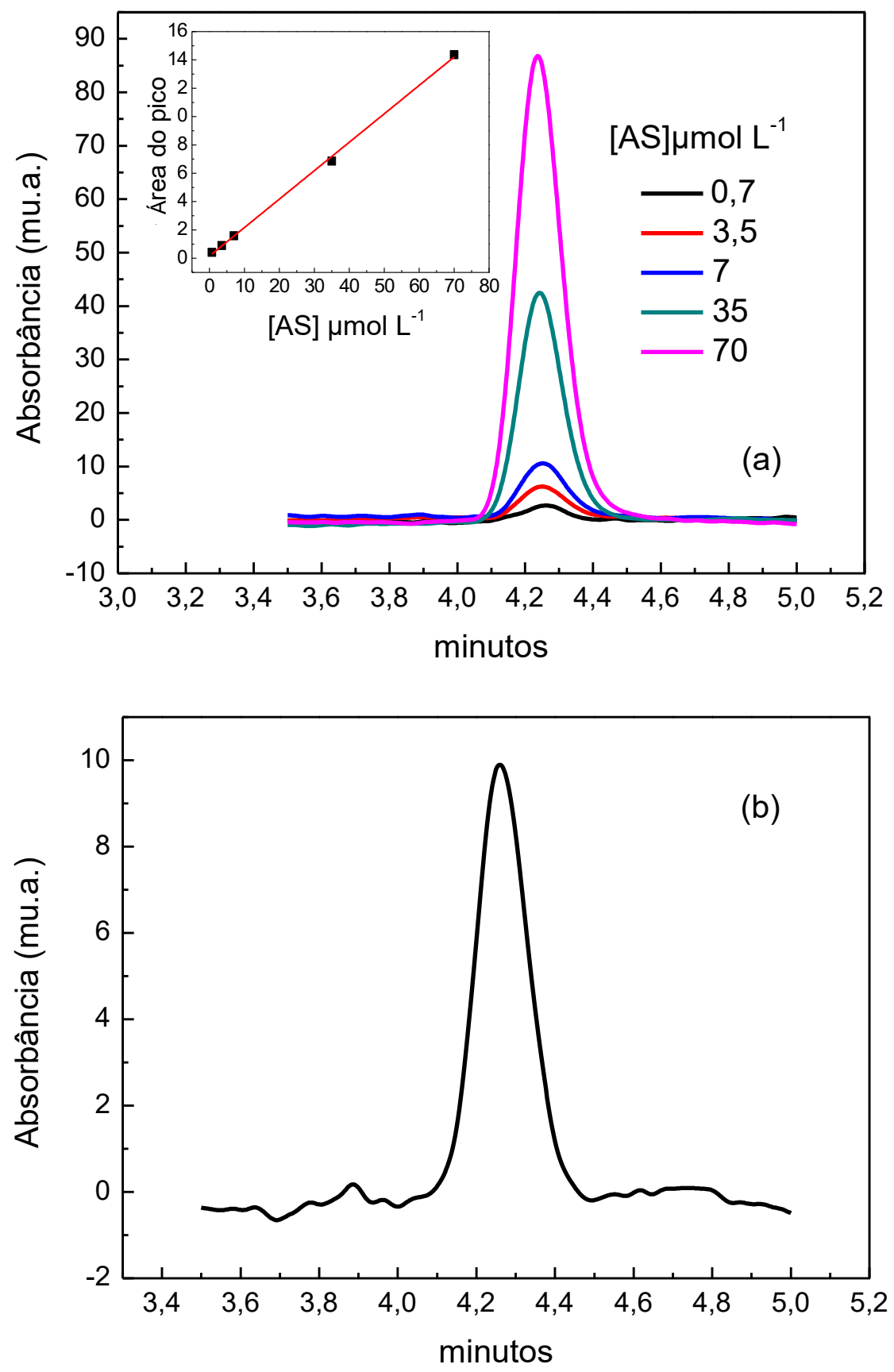

Figura 42- (a) Cromatogramas do ácido salicílico nas diferentes concentrações (inserido a curva analítica) (b) Cromatograma do ácido salicílico na amostra. 
Após a realização destes testes cromatográficos, foram realizadas as medidas na amostra de produto dermatológico com o método eletroquímico desenvolvido. Os voltamogramas de pulso diferencial, da amostra e das adições realizadas são mostrados na Figura 43(a). A quantificação do ácido salicílico foi realizada com o método de adição de padrão, onde a o valor da concentração presente na amostra é determinado pela extrapolação da curva analítica até o ponto de intersecção com eixo das concentrações (Figura 43b). Essa concentração é calculada pela equação de regressão linear dessa curva analítica.

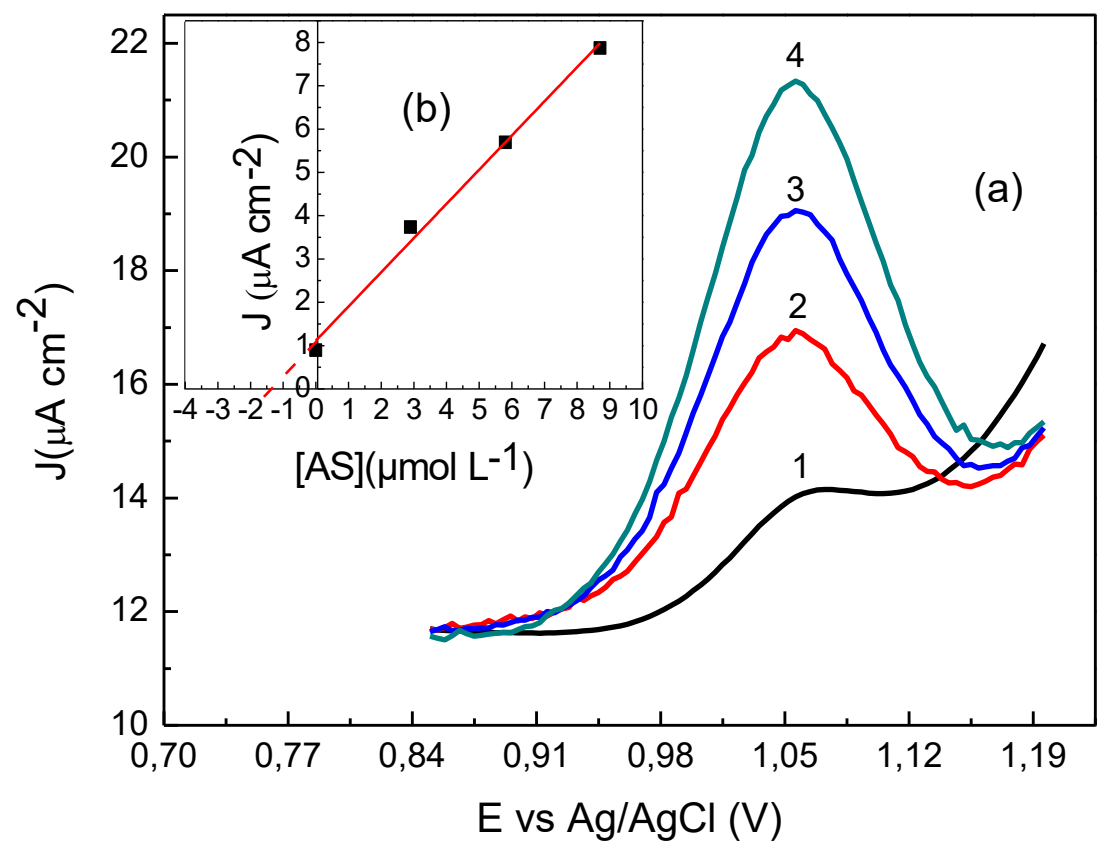

Figura 43- (a) Voltamograma de pulso diferencial (1) da amostra, (2) amostra $+2,9$ $\mu \mathrm{mol} \mathrm{L}{ }^{-1}$, (3) amostra $+5,8 \mu \mathrm{mol} \mathrm{L}^{-1}$, (4) amostra $+8,7 \mu \mathrm{mol} \mathrm{L}^{-1}$ de ácido salicílico em ácido acético $0,1 \mathrm{~mol} \mathrm{~L}^{-1}$, com amplitude de pulso de $50 \mathrm{mV}$ e velocidade de varredura $5 \mathrm{mV} \mathrm{s}^{-1}$.

Esses testes com amostra foram realizados em triplicata e os valores encontrados foram próximos do valor de concentração do ácido salicílico rotulado no produto dermatológico (Tabela 8). Os testes estatísticos realizados, para verificar se existe concordância entre os valores obtidos pelo método de referência e o método proposto, teve $F_{\text {calculado }}(1,79)$ menor que $\circ F_{\text {tabelado }}(19)$. Portanto as variâncias dos valores encontrados nos dois métodos foram consideradas iguais. No teste $t$ (Student) o valor de tcalculado $(0,0183)$ foi menor que o tabelado $(2,78)$, então os resultados obtidos 
na determinação de ácido salicílico em produto dermatológico por HPLC/UV-vis e DPV não apresentaram diferenças significativas, a um nível de confiança de $95 \%$.

Tabela 8- Valores da concentração de ácido salicílico encontrado no produto dermatológico por HPLC/UV-vis e DPV.

\begin{tabular}{c|c|c|c}
\hline \hline \multirow{2}{*}{$\begin{array}{c}\text { Média } \pm \text { desvio } \\
\text { padrão }\end{array}$} & 144,8 & $146,61 \pm 7,98$ & $146,85 \pm 10,65$ \\
\cline { 2 - 4 } & & & \\
\hline \hline
\end{tabular}




\section{CONCLUSÕES}

A deposição de nanotubos de carbono e nanopartículas de óxido de ferro no substrato ITO foi assegurada pelo monitoramento com espectroscopia de UV-vis e microscopia de força atômica, onde observou-se que a quantidade adsorvida de nanomateriais aumentou linearmente com o número de tetracamadas, permitindo assim um grande controle do processo de fabricação do eletrodo.

A presença de np-MAG nos eletrodos aumentou a transferência de elétrons e a densidade de corrente de pico na oxidação do ácido salicílico, isto mostra que esse nanomaterial proporcionou maior eficácia ao método proposto. O eletrodo apresentou melhor resposta voltamétrica nas medidas de ácido salicílico após a realização de condicionamento entre as leituras, devido o processo de oxidação do ácido salicílico formar produtos que podem ter contaminado o eletrodo.

Os parâmetros de voltametria mais adequado e sensível para a quantificação de ácido salićlico foram ácido acético $0,1 \mathrm{~mol} \mathrm{~L}^{-1}$ como eletrólito de suporte, velocidade de varredura de $5 \mathrm{mV} \mathrm{s}^{-1}$ e amplitude de pulso de $50 \mathrm{mV}$. O coeficiente de variação para 7 medidas consecutivas foi de $3 \%$, apesar desse coeficiente aumentar 5 vezes quando utilizado eletrodos preparados em dias diferentes, o método não é comprometido devido as leituras serem realizadas com um mesmo eletrodo para cada alíquota e a quantificação ser feita com adição de padrão.

A faixa linear de trabalho, limite de detecção e quantificação teve valores apropriados para a quantificação de ácido salicílico em produto dermatológico, sem a necessidade de realização de pré-concentração.

Os resultados obtidos na quantificação de ácido salicílico com DPV tiveram concordância com o método de referência (Cromatografia). Portanto, o método desenvolvido apresentou resultados satisfatórios sendo adequado para a determinação de ácido salicílico em produto dermatológico, com vantagens como rapidez, baixo custo e fácil utilização. 


\section{REFERÊNCIAS BIBLIOGRÁFICAS}

Al, S.; WANG, Q.; LI, H.; JIN, L. Study on production of free hydroxyl radical and its reaction with salicylic acid at lead dioxide electrode. Journal of Electroanalytical Chemistry, v. 578, p. 223-229, 2005.

AGOSTINHO, S. M. L.; VILLAMIL, R. F. V.; NETO, A. A.; ARANHA, H. O eletrólito suporte e suas múltiplas funções em processos de eletrodo. Quím. Nova, v. 27, n. 5, p. 813-817, 2004.

AJAYAN, P. M. Nanotubes from Carbon. Chem. Rev., v. 99, p. 1787-1799, 1999.

ALCANTARA, G. B.; PATERNO, L. G.; FONSECA, F.J.; MORAIS, P.C.; SOLER, M.A.G. Morphology of cobalt ferrite nanoparticle-polyelectrolyte multilayered nanocomposites. J. Magn. Magn. Mater., v. 323, p. 1372-1377, 2011.

ANVISA, Agência Nacional de Vigilância Sanitária. Resolução RDC no 79, de 28 de agosto de 2000.

ANVISA, Agência Nacional de Vigilância Sanitária. Guia para validação de métodos analíticos e bioanalíticos. Resolução RE no 899, de 29/05/2003.

BARD, J. A.; FAULKNER, L. R. Electrochemical methods: fundamentals and application, John Wiley: New York, $2^{\mathrm{a}}$ edition, 2001.

BIANCO, A.; KOSTARELOS, K.; PRATO, M. Making carbon nanotubes biocompatible and biodegradable. Chem. Commun., v. 47, p. 10182-10188, 2011.

BRITISH PHARMACOPOEIA. Commission on Human Medicines, v. 1, p. 603, 2009.

BRETT, A. M. O.; BRETT, C. M. A.; Electrochemistry: Principles, Methods, and Applications. Oxford University Press, 1993. 
CAZALS, Yves. Auditory sensori-neural alterations induced by salicylate. Progress in Neurobiology, v. 62, p.583-631, 2000.

CORNELL, R. M. The Iron Oxides: Structure, Properties, Reactions, Occurences and Uses, Wiley-VCH, Second Edition, 2014.

CORREA-DUARTE, M. A.; GIERSIG, M.; KOTOV, N. A.; LIZ-MARZA, L. M. Control of Packing Order of Self-Assembled Monolayers of Magnetite Nanoparticles with and without $\mathrm{SiO}_{2}$ Coating by Microwave Irradiation. Langmuir, v. 14, p. 6430-6435, 1998.

DEVADAS, B.; MADHU, R.; CHEN, S.; YEH, H. Controlled electrochemical synthesis of new rare earth metal lutetium hexacyanoferrate on reduced graphene oxide and its application as a salicylic acid sensor. J. Mater. Chem. B, v. 2, p. 7515, 2014.

DOULACHE, M.; BENCHETTARA, A.; TRARI, M. Detection of Salicylic Acid by Electrocatalytic Oxidation at a NickelModified Glassy Carbon Electrode. Journal of Analytical Chemistry, vol. 69, n. 1, p. 51-56, 2014.

DUTHIE, G. G.; WOOD, A. D. Natural salicylates: foods, functions and disease prevention. Food Funct., v. 2, p. 515, 2011.

FARMACOPÉIA BRASILEIRA. Agência Nacional de Vigilância Sanitária e Fundação Oswaldo Cruz/Editora, v. 2, p. 569, 2010.

FERNANDES, D. M.; COSTA, M.; PEREIRA, C.; BACHILLER-BAEZA, B.; RODRÍGUEZ-RAMOS, I.; GUERRERO-RUIZ, A.; FREIRE, C. Novel electrochemical sensor based on $\mathrm{N}$-doped carbon nanotubes and $\mathrm{Fe}_{3} \mathrm{O}_{4}$ nanoparticles: Simultaneous voltammetric determination of ascorbic acid, dopamine and uric acid. Journal of Colloid and Interface Science, v. 432, p. 207-213, 2014. 
GAO, C.; GUO, Z.; LIU, J.; HUANG, X. The new age of carbon nanotubes: An updated review of functionalized carbono nanotubes in electrochemical sensors. Nanoscale, v. 4, p. 1948-1963, 2012.

GAWANDE, M. B.; BRANCO, P. S.; RAJENDER, S. V. Nano-magnetite $\left(\mathrm{Fe}_{3} \mathrm{O}_{4}\right)$ as a support for recyclable catalysts in the development of sustainable methodologies. Chem. Soc. Rev., v. 42, p. 3371-3393, 2013.

GU, H. Paper-based electroanalytical devices for in situ determination of salicylic acid in living tomato leaves. Biosensors and Bioelectronics, v. 60, p. 154160, 2014.

GHOREISHI, S. M.; KASHANI, F. Z.; KHOOBI, A.; ENHESSARI, M. Fabrication of a nickel titanate nanoceramic modified electrode for electrochemical studies and detection of salicylic acid. Journal of Molecular Liquids, v. 211 p. 970-980, 2015.

HUANG, Z. H.; WANG, Z. L.; SHI, B. L.; WEI, D.; CHEN, J. X.; WANG, S.; GAO, B.Simultaneous Determination of Salicylic Acid, Jasmonic Acid, Methyl Salicylate, and Methyl Jasmonate from Ulmus pumila Leaves by GC-MS. International Journal of Analytical Chemistry, v. 2015, p. 1-7, 2015.

$\mathrm{ICH}$, International Conference on Harmonisation. Validation of Analytical Procedures: Methodology. Q2B (CPMP/ICH/281/95), 1995.

INMETRO, Instituto Nacional de Metrologia. Orientação Sobre Validação de Métodos Analíticos. DOQ-CGCRE-008 - Revisão 04, Rio de Janeiro, 2011.

JANGBAI, W.; WONGWILAI, W.; GRUDPAN, K.; LAPANANTNOPPAKHUN S. Sequential Injection Chromatography as Alternative Procedure for the Determination of Some Food Preservatives. Food Anal. Methods, n.5, p. 631-636, 2012. 
KAISER, J. Will an Aspirin a Day Keep Cancer Away? Science, v. 337, p. 1471, 2012.

KANG, Y. S.; RISBUD, S.; RABOLT, J. F.; STROEVE, P. Synthesis and Characterization of Nanometer-Size $\mathrm{Fe}_{3} \mathrm{O}_{4}$ and $\mathrm{Y}-\mathrm{Fe}_{2} \mathrm{O}_{3}$ Particles. Chem. Mater., v. 8, p. 2209-2211, 1996.

KISSINGER, P. T.; HEINEMAN, W. R. Cyclic Voltammetry. Journal of Chemical Education, v. 60, n. 9, 1983.

LOUHICHI, B.; BENSALASH, N.; GADRI, A. Electrochemical Oxidation of Benzoic Acid Derivatives on Boron Doped Diamond: Voltammetric Study and Galvanostatic Electrolyses. Chem. Eng. Technol., v. 29,p. 944-950, 2006.

LU, L.; ZHU, X.; QUI, X.; HE, H.; XU, J.; WANG, X. Graphene Oxide/Multiwalled Carbon Nanotubes Composites as na Enhanced Sensing Platform for Voltammetric Determination of Salicylic Acid. Int. J. Electrochem. Sci., v. 9, p. 8057-8066, 2014.

LU, S.; BAI, L.; WEN, Y.; LI, M.; YAN, D.; ZHANG, R.; CHEN, K. Water-dispersed carboxymethyl cellulose-montmorillonite-single walled carbon nanotube composite with enhanced sensing performance for simultaneous voltammetric determination of two trace phytohormones. J Solid State Electrochem, v. 19, p. 2023-2037, 2015.

MACHADO, I. R. L.; MENDES, H. M. F.; ALVES, G. E. S. FALEIROS, R. R. Nanotubos de carbono: potencial de uso em medicina veterinária. Ciência Rural, Santa Maria, v.44, n.10, p.1823-1829, 2014.

MADAN, R. K.; LEVITT, J. A review of toxicity from topical salicylic acid preparations. J. Am. Acad. Dermatol, v. 70, n. 4, p. 788-792, 2014. 
MEDINA, A. R.; CORDOVA, M. L. F.; BARRALES, P. O.; DÍAZ, A. M. Flow-through UV spectrophotometric sensor for determination of (acetyl)salicylic acid in pharmaceutical preparations. International Journal of Pharmaceutics, v. 216, p. 95$104,2001$.

MENGOLI,G.; MUSANI, M. M.The influence of amines on the anodic coupling of phenols to polyoxyphenylene films. Journal of applied eletrochemistry, v. 10, p. 459-471, 1980.

MORAES, F.C.; CABRAL, M.F.; MASCARO, L.H.; MACHADO, S.A.S. The electrochemical effect of acid functionalisation of carbon nanotubes to be used in sensors development. Surface Science, v. 605, p. 435-440, 2011.

MUÑOZ, E. O.Grafeno: el material más fuerte del mundo. Cienciacierta, n. 24, 2011.

NICHOLSON,R. S. Theory and application of cyclic voltammetry for measurement of electrode reaction kinetics. Analytical Chemistry, v. 37, n.11, p.1351-1355, 1965.

NIGAM, S.; BARICK, K. C.; BAHADUR, D. Development of citrate-stabilized $\mathrm{Fe}_{3} \mathrm{O}_{4}$ nanoparticles: Conjugation and release of doxorubicin for therapeutic applications. Journal of Magnetism and Magnetic Materials, v. 323, p. 237-243, 2011.

OGUNLUSI, G. O.; ADEKUNLE, A. S.; MAXAKATO, N. W.; MAMBA, B.B. Characterization of a Nano-synthesised Cobalt Complex and its Electrocatalytic Properties towards Nitrite Oxidation. Int. J. Electrochem. Sci., v. 7, p. $2904-2917$, 2012.

PATERNO, L. G.; MATTOSO, L. H. C.; OLIVEIRA JR., O. N. Filmes poliméricos ultrafinos produzidos pela técnica de automontagem: preparação, propriedades e aplicações. Quim. Nova, v. 24, n. 2, p. 228-235, 2001. 
PATERNO, L. G.; SOLER, M. A. G. Layer-by-Layer Enabled Nanomaterials for Chemical Sensing and Energy Conversion. JOM, v. 65, n. 6, p. 709, 2013.

POPOV,V. N. Carbon nanotubes: properties and application. Materials Science and Engineering. R 43, p. 61-102, 2004.

PULGARÍN, J.A. M.; MOLINA, A. A.; ROBLES, I. S. F. Simultaneous determination of salicylic acid and salicylamide in biological fluids. Spectrochimica Acta Part A, v. 79, p. 909-914, 2011.

RABAAOUI, N.; ALLAGUIB, M. S. Anodic oxidation of salicylic acid on BDD electrode: Variable effects and mechanisms of degradation. Journal of Hazardous Materials, v. 243, p. 187- 192, 2012.

RAJU, N.; TEAGUE, M. S.; HIRSH, J.; O'DONNELL, M.; EIKELBOOM, J. Effect of Aspirin on Mortality in the Primary Prevention of Cardiovascular Disease. The American Journal of Medicine, v. 124, p. 621-629, 2011.

SAJID, M.; NAZAL, M. K.; MANSHA, M.; ALSHARAA, A.; JILLANI, S. M. S.; BASHEER, C. Chemically modified electrodes for electrochemical detection of dopamine in presence of uric acid and ascorbic acid: a review. Trends in Analytical Chemistry, 2015.

SANTOS, J. G. M.; SOUZA, J. R.; LETTI, C. J.; SOLER, M. A. G.; MORAIS, P. C.; PEREIRA-DA-SILVA, M. A.; PATERNO, L. G. Iron Oxide Nanostructured Electrodes for Detection of Copper(II) Ions. J. Nanosci. Nanotechnol., v. 14, p. 6614-6623, 2014.

SHARMA, A.; BARAL, D.; RAWAT, K.; SOLANKI, P. R.; BOHIDAR, H. B. Biocompatible capped iron oxide nanoparticles for Vibrio cholerae detection. Nanotechnology, v. 26, n. 17, p. 175302, 2015. 
SHEIKH, S.; ASGHAR, S.; PATNI, S. A. Liquid Chromatographic Technique for Stability Indicating Analytical Method Development and Validation of Salicylic Acid and Tolnaftate in Pharmaceutical Ointment by High Performance. International Journal of Scientific and Research Publications, v. 2, p. 1-6, 2012.

SIGMA ALDRICH. Disponível em: http://www.sigmaaldrich.com/catalog/product/aldric h/639230?lang=pt\&region=BR. Acesso em: 14 de Novembro de 2015.

SKOOG, D. A.; WEST, D. M.; HOLLER, F. J.; CROUCH, S. R. Fundamentos de Química. Analítica. Editora Thomson, tradução da 8ª edição, 2006.

SOLER, M. A. G.; PATERNO, L. G.; SINNECKER, J. P.; WEN, J. G.; SINNECKER, E. H. C. P.; NEUMANN, R. F.; BAHIANA, M.; NOVAK, M. A.; MORAIS, P. C. Assembly of $\mathrm{y}-\mathrm{Fe}_{2} \mathrm{O}_{3} /$ polyaniline nanofilms with tuned dipolar interaction. $\mathrm{J}$ Nanopart Res, v. 14, p.653, 2012.

SUN, L.; PAN, Z.; XIE, J.; LIU, X.; SUN, F.; SONG, F.; BAO, N.; GU, H. Electrocatalytic activity of salicylic acid on Au@Fe304 nanocomposites modified electrode and its detection in tomato leaves infected with Botrytis cinerea. Journal of Electroanalytical Chemistry, v. 706, p. 127-132, 2013.

SCHWERTMANN, U.; CORNELL, R. M. Iron Oxides in the Laboratory: Preparation and Characterization, VCH Publishers, New York, 1991.

TORRIERO, A. A. J.; LUCO, J. M.; SERENO, L.; RABA, J. Voltammetric determination of salicylic acid in pharmaceuticals formulations of acetylsalicylic acid. Talanta, v. 62, p.247-254, 2004.

TSIERKEZOS, N. G.; RITTER, U.; THAHA, Y. N.; DOWNING, C. Application of multi-walled carbon nanotubes modified with boron oxide nanoparticles in electrochemistry. Ionics, v. 21, p. 3087-3095, 2015.

WANG, J.; Analytical Electrochemistry, Wiley-VCH, 3ª edition , 2006 
WANG, Z.; AI, F.; XU, Q.; YANG, Q.; YU, J. H.; HUANG, W. H.; ZHAO, Y. D. Electrocatalytic activity of salicylic acid on the platinum nanoparticles modified electrode by electrochemical deposition. Colloids and Surfaces B: Biointerfaces, v. 76, p. 370-374, 2010.

YOUSSEF, R. M.; KORANYA, M. A.; AFIFY, M. A. Development of a stability indicating HPLC-DAD method for the simultaneous determination of mometsone furoate and salicylic acid in na ointment matrix. Anal. Methods, v. 6, p. 3410, 2014.

YU, L.; YANG, X.; YEB, Y.; WANG, D. Efficient removal of atrazine in water with a $\mathrm{Fe}_{3} \mathrm{O}_{4} / \mathrm{MWCNTs}$ nanocomposite as a heterogeneous Fenton-like catalyst. RSC Adv., v. 5, p. 46059, 2015.

ZHANG, W.; XU, B.; HONG, Y.; YU, Y.; YE, J.; ZHANG, J. Electrochemical oxidation of salicylic acid at well-aligned multiwalled carbon nanotube electrode and its detection. J Solid State Electrochem, v. 14, p. 1713-1718, 2010.

ZHAO, B.; HU, H.; YU, A.; PEREA, D.; HADDON, R. C. Synthesis and Characterization of Water Soluble Single-Walled Carbon Nanotube Graft Copolymers. J. Am. Chem. Soc., v. 127, p. 8197-8203, 2005.

ZOSKI, C. G. Handbook of Electrochemistry. Elsevier, 2007. 